\title{
EXTRACORPOREAL LIFE SUPPORT FOR CARDIOPULMONARY FAILURE
}

Exlracorporeal circulation refers to the circulation of blood outside the body, substituting artificial organs for biologic organs. Using venoarterial access and high blood flow, extracorporeal circulation can substitute for all or part of cardiac or pulmonary function. Total cardiopulmonary bypass is the use of extracorporeal circulation to replace heart and lung function to permit cardiac surgery. Vascular access is gained directly at the time of thoracotomy and the artificial organs are combined in the "heart/lung machine."

With variations in vascular access and artificial organs this technique has been adopted to support the patient with failing heart or lungs, with the hope that those organs will recover or (more recently) can be replaced with a transplanted organ. In these applications the techniques of extracorporeal circulation are modified to achieve major vascular access without thoracotomy, to control bleeding, and to allow servoregulation over a wide range of use. The artificial organs of the heart/lung machine are modified to minimize blood damage and maximize efficiency and reliability. With these modifications extracorporeal circulation can be greatly prolonged (from hours to weeks). The scope of this monograph is to review prolonged extracorporeal circulation without thoracotomy for cardiac or pulmonary support.

The clinical applications of prolonged extracorporeal circulation fall into four natural groupings: pediatric patients, adult patients, cardiac failure, or pulmonary failure. Most of the clinical research has focused on patients with respiratory failure, and on the artificial lung or membrane oxygenator. For these reasons the acronym ECMO (extracorporeal membrane oxygenation) has been used for this technique. Since the technique involves not just oxygenation but all functions of the heart and lungs, this is a misnomer, but it has become common usage. In general we will use the terms "extracorporeal circulation" for the overall procedure, and "extracorporeal life support" (ECLS) for prolonged extracorporeal circulation. Many of the aspects of extracorporeal circulation are covered in other reviews. ${ }^{1-4}$ This article updates the monograph published in current 
Problems in Surgery in $1978 .^{5}$ We will discuss the history of ECLS, the artificial organs, the physiology, the clinical techniques, and clinical results of ECLS.

\section{HISTORY}

Between 1935 and 1954 John Gibbon Jr., Clarence Dennis, and others pursued the development of a mechanical device to take over the functions of the heart and lungs to permit surgical operations on the heart and great vessels. ${ }^{6,7}$ The entire project was stimulated by a patient with a lethal pulmonary embolism. Obviously a machine that could be used to permit cardiopulmonary bypass for this problem could be used for cardiac surgery and a variety of other applications. To substitute for the heart Gibbon used a roller pump that remains in general practice today. To substitute for the lung, he devised a system in which anticoagulated blood was directly exposed to oxygen, dripping along the wires of a vertically-mounted metal screen. The approach of direct exposure of blood to oxygen was successful, and subsequently modified by Dennis, ${ }^{8}$ Morrow, ${ }^{9}$ Cross, ${ }^{10}$ DeWall,${ }^{11}$ Rygg, ${ }^{12}$ and many others, leading to the single-use, disposable, direct gas interface oxygenators that are widely used today. Lillehei ${ }^{13}$ was the first to use extracorporeal circulation for cardiac surgery, establishing cross circulation between a parent and a child with congenital heart disease, using the parent as the heart/lung machine. Gibbon ${ }^{14}$ was the first to use the prosthetic heart/lung machine for a cardiac operation, opening the door to the routine application and success of extracorporeal circulation for cardiac surgery.

As experience with extracorporeal circulation developed during the 1950s, it was obvious that the life-supporting technique itself became lethal when used for more than a few hours. Thrombocytopenia, coagulopathy, hemolysis, generalized edema, and deterioration of organ function all occurred in proportion to the amount of time on cardiopulmonary bypass. The experiments of Lee, ${ }^{15}$ Dobell, ${ }^{16}$ and others indicated that the direct exposure of blood to oxygen gas was responsible for this apparent toxicity. These observations prompted the development of an artificial lung in which a gas permeable membrane was interposed between the blood and the gas phase. Observation of blood in the Kolff artificial kidney, in which the blood was separated from the environment by a cellophane membrane, indicated that venous blood could become oxygenated if a suitable gas permeable membrane were developed. ${ }^{17}$ The first successful membrane oxygenator was built by Clowes et al. ${ }^{18}$ They used sheets of polyethylene membranc that had a low but definite permeability to oxygen and carbon dioxide. By using a very large surface area, a device was built that allowed gas exchange without a direct gas inter- 
face, and this handmade device was used for cardiac surgery in patients in $1956{ }^{19}$ The development of dimethylpolysiloxane membranes by Kammermeyer in $1957^{20}$ was a major advance. This unique material allows for the transfer of carbon dioxide and oxygen at rates that were more than ten times faster than those through other plastics. Using this new plastic (called "silicone rubber") Kolobow, ${ }^{21}$ Landé $^{22}$ Pierce, ${ }^{23}$ and others ${ }^{24,25}$ constructed blood oxygenators that were quite efficient and successful. The development of these early membrane oxygenators demonstrated (1) that it would be possible to conduct prolonged extracorporeal circulation free of gas interfaces; (2) that diffusion of oxygen through blood would be the limiting factor in oxygenator design rather than the materials; and (3) that blood flow patterns, headers, and manifolds, and stagnant areas leading to thrombogenesis would be important considerations in the design of membrane lungs. In the mid 1960s laboratory research began on prolonged extracorporeal circulation by those who were studying function and improvement of membrane lungs, particularly Kolobow, ${ }^{26}$ Pierce, $^{23}$ Galletti, ${ }^{27}$ Bramson and Hill, ${ }^{28}$ Landé and Lillehei ${ }^{29}$ and Bartlett and Drinker. ${ }^{30}$

The diffusion limitation of oxygen through the blood film, and the use of secondary flows to address this problem were studied by Weissman and Mockros, ${ }^{31}$ Bartlett and Drinker, ${ }^{32}$ and others. ${ }^{33}$ With the collaboration of medical industry a series of membrane lungs became available for clinical trials and general usage. Kolobow and ' $\mathrm{Ka}$ pol, ${ }^{34}$ Bartlett and Drinker ${ }^{35}$ and others ${ }^{36-38}$ demonstrated that extracorporeal circulation of the blood could be carried out for days or weeks without toxicity or hemolysis as long as the direct blood gas contact was avoided. Beginning with Gibbon, all the studies on extracorporeal circulation have been conducted with the use of heparin anticoagulation, using a dose sufficient to produce an infinitely long clotting time. Bartlett and Drinker ${ }^{32}$ demonstrated that much lower doses of heparin could be used, producing prolonged but measurable clotting time that minimized bleeding complications. Several groups studied the management and physiology of prolonged extracorporeal circulation in a variety of animal models. ${ }^{39,40}$

With these modifications in the equipment and technology of cardiopulmonary bypass, it was possible to characterize physiologic ${ }^{41}$ and hematologic ${ }^{42}$ responses of the normal animal during prolonged extracorporeal circulation. Several investigators demonstrated that extracorporeal circulation for days was possible without causing significant injury to normal animals. Hemodynamics were easy to regulate. Acidosis, capillary permeability, and organ deterioration, which often plagued cardiopulmonary bypass in the operating room, did not occur. Bleeding was minimal with adequate control of heparin. Hemolysis was negligible. Thrombocytopenia inevitably occurred but was manageable. All of these studies in the animal 
laboratory showed that the technique was feasible, and provided the background for early clinical trials.

The first attempts at respiratory support in infants were reported by Rashkind ${ }^{43}$ Dorson, ${ }^{44}$ and White. ${ }^{45,46}$ The first successful human case was reported by Hill in $1972 .{ }^{47}$ The patient was a young man who sustained a ruptured aorta and other injuries in a motorcycle accident in Santa Barbara, California. Hill and his team from San Francisco brought the equipment to Santa Barbara, and managed the patient on venoarterial extracorporeal support for 3 days. It was hoped that a temporary period of life support with extracorporeal circulation would allow the damaged lung to recover. The timing of Hill's report was important, because it was in the early 1970s that the full concept of intensive care units was developed, acute renal failure was being treated with hemodialysis, and acute respiratory failure (adult respiratory distress syndrome [ARDS]) was the major problem in critically ill patients. Hill's success gave great impetus to both laboratory and clinical research on prolonged extracorporeal circulation. Reports of several other successful cases soon followed. ${ }^{48-56}$

In 1974 the Lung Division of the National Heart and Lung Institute proposed a multicenter prospective randomized study of ECMO in adult respiratory failure. This study began in 1975, which was a pivotal year for extracorporeal support. In that year a meeting was held outside of Copenhagen that included most of the investigators studying prolonged extracorporeal support. This meeting was hosted by Zapol and Qvist, and the proceedings were reported in a benchmark publication. ${ }^{57}$ The plans for the National Institutes of Health (NIH) ECMO study were reported and reviewed at that meeting. ${ }^{58}$ Four different membrane oxygenators were manufactured and used in 1975: the Kolobow Sci-Med, the Landé-Edwards, the PierceGE, and the Bramson. The Food and Drug Administration did not become involved with devices until 1976. The first successful treatment with ECMO of a newborn infant was accomplished in May 1975, and was reported at the Copenhagen meeting.

\section{ADULT RESPIRATORY FAILURE}

The NIH-sponsored study of ECMO in adult patients was completed in 1979 and reported in $1980{ }^{59}$ Other related studies of pathology findings ${ }^{60}$ and epidemiology of respiratory failure ${ }^{61}$ in the study centers were reported. This was the first attempt at a prospective randomized study of a life support technique in which the end point was death. There were many problems with the study. Nine centers were involved, some of which had no prior experience with ECMO before their first study patient. The logistics of consent to the study tended to exclude the best risk and worst risk patients. A nationwide epidemic of influenza pneumonia occurred in 1976, and 
these patients dominated the trial. Bleeding complications were major, with average bloud loss exceeding $2 \mathrm{~L} / \mathrm{day} .{ }^{62}$ Although the purpose of ECMO is lung rest, many of the patients remained on high ventilator settings. ${ }^{62}$ The study was planned for 300 patients, but it was terminated after 92 patients were entered because the survival in both control and ECMO groups was less than $10 \%$ and it seemed unlikely that the results would be any different after 300 patients. The cause of death was related to technical complications in a significant number of patients, but extensive and apparently irreversible fibrosis was uniformly found at autopsy, indicating that the major problem was not the technology but the underlying parenchymal lung disease ${ }^{60}$ As a result of this study clinical research on ECMO in adult patients essentially stopped in 1979. Since that time only occasional cases have been reported in the United states and the study of extracorporeal support in adults was developed primarily in Europe.

\section{EVOLUTION OF THE CONCEPT OF EXTRACORPOREAL CARBON DIOXIDE REMOVAL}

Luciano Gattinoni, in association with Theodore Kolobow at the NIH, learned the techniques of extracorporeal support in sheep. He returned to Milan with the following hypotheses:

1. The purpose of ventilation is to excrete carbon dioxide; oxygenation can be achieved by inflation and airway oxygenation alone.

2. Progressive lung injury in ARDS is caused in part by ventilatorinduced high pressure or overdistension injury of the most normal alveoli. When functional residual capacity is severely decreased, the remaining alveoli can be overinflated if high tidal volumes are used, leading quickly to alveolar injury and fibrosis. An extracorporeal support system should eliminate the need for high airway pressure and high $\mathrm{Fio}_{2}$, although this was not always done in the NIH-sponsored ECMO study.

3. If the emphasis should be on carbon dioxide removal to eliminate the need for high pressure ventilation, this could be accomplished with venovenous access, using relatively low blood flow and large membrane lung surface area.

4. This system would allow for normal pulmonary blood flow. even if the lung is severely injured with large amounts of transpulmonary shunting. The venoarterial bypass used in the NIH ECMO study caused decreased pulmonary blood flow, which might have contributed to microthrombosis or inhibition of lung healing. 
Gattinoni and his colleagues used these principles in venovenous extracorporeal gas exchange in a variety of adult patients selected by the same criteria used for the NIH ECMO study. In 1986 they reported 21 survivors in 43 patients $(49 \%){ }^{63}$ These results were corroborated by Lennartz et al. in Marburg, Germany, ${ }^{64}$ Falke in Dusseldorf, ${ }^{65}$ Bindslev ${ }^{66}$ in Stockholm, and Todd in Toronto. ${ }^{67}$ Similar results were reported by Morioka of Kumamoto, Japan. ${ }^{68}$ All of these investigators reported their results at a European communities conference held at Marburg in $1988 .^{69}$

\section{NEONATAL RESPIRATORY FAILURE}

Bartlett, Gazzaniga, and their colleagues at the University of California, Irvine, treated the first successful neonatal ECMO patient ${ }^{70}$ in 1975 (named Esperanza by the nurses, meaning hope). ${ }^{71}$ This was soon followed by other successful neonatal cases. ${ }^{72}$ By 1981 their group had treated 45 newborn cases with 25 survivors. ${ }^{73}$ The technique for newborn infants was fairly standardized, and included venoarterial access via the right internal jugular vein and right carotid artery, heparin titration based on whole blood activated clotting times, "lung rest" at low ventilator settings, and recognition of persistent pulmonary hypertension as the primary underlying pathophysiology. In 1979 the first neonatal ECMO seminar was held at the University of California, Irvine, demonstrating the circuit, technology, and concept of the ECMO team and specialists. This led to the development of ECMO research teams at Richmond, Pittsburgh, and Detroit. In 1980 the neonatal ECMO project moved from the University of California, Irvine, to the University of Michigan and experience gradually increased from a few cases each year to a few cases each month. Representatives of other centers attended the annual seminar, and some established ECMO teams, all with a standardized system and protocol. By the end of 1986715 newborn cases had been treated in 18 centers $^{74}$ with excellent survival results reported from each center. ${ }^{75 \cdots 81}$

With the technique standardized and an experienced team trained, the Michigan group carried out a prospective randomized study in newborn infants between 1982 and $1984 .{ }^{82}$ They used a statistical technique called randomized play-the-winner, in which assignment to one treatment or the other is randomized, but influenced by all the previous patients in the study. ${ }^{83,84}$ Statistical significance is reached when there is a significantly larger group of patients in one arm of the study compared to the other. This resulted in the unusual groupings of 1 control patient (who died) and 11 ECMO patients (all of whom survived). This proved that the results with ECMO were better than conventional therapy, but the study was treated with skepticism. ${ }^{8.5}$ The most articulate of the critics, 
Ware and Epstein, ${ }^{85}$ undertook to design a prospective randomized study of ECMO in neonatal respiratory failure, but soon encountered the same problems of ethics and logistics. They solved this problem by using a similar adaptive statistical design, and reported their prospective randomized study (with similar results) in $1989 .{ }^{86}$

\section{CARIIAC FAILLIRE}

Extracorporeal life support has been used for cardiac support for three decades, following the initial studies of Dennis, ${ }^{87}$ who placed a transseptal catheter into the left atrium via the internal jugular vein and right atrium, and perfused the obtained oxygenated blood into the femoral artery, providing systemic perfusion and unloading the failing left ventricular at the same time. Although successful, this technique was never widely applied, primarily because counterpulsation with an intra-aortic balloon was simpler, and provided adequate support for most patients with a failing but recoverable left ventricle. Extra corporeal life support has been reserved for right ventricular failure or biventricular failure. For these reasons, the technique has been used most extensively in pediatric patients following operations to repair congenital defects. When low cardiac output occurs in these children, it is usually due to right or biventricular failure, and often improves during a few days of ECLS, as the heart adjusts to new hydrodynamics. In recent years the success of cardiac transplantation has renewed interest in extracorporeal circulation as a means of cardiac support, both for supporting the failing transplanted heart temporarily, or for serving as a bridge to cardiac transplantation. ${ }^{70}$

\section{CURRENT STATUS}

In 1990 there are 65 centers using extracorporeal support as routine treatment for severe respiratory failure in newborn infants, and an additional dozen centers using extracorporeal support for adult respiratory failure. With more than 3,500 newborn cases reported, the overall survival rate is $83 \% .{ }^{88}$ The most experienced centers report survival consistently greater than $90 \% .{ }^{1,2,89,90}$ Survival in centers treating adult respiratory failure is remarkably constant at $\mathbf{5 0} \% .^{91}$ Similar results are reported for support of older children ${ }^{92,93}$ and support of patients with primary cardiac disease ${ }^{94-96}$ In 1989 the active ECMO centers joined together to form a study group called the Extracorporeal Life Support Organization. The purpose of this group is to maintain the data registry, conduct clinical studies on extracorporeal support and serve as the communication center for research and clinical practice of extracorporeal life support. 


\section{PHYSIOLOGY AND PATHOPHYSIOLOGY OF EXTRACORPOREAL LIFE SUPPORT}

Extracorporeal life support is achieved by draining venous blood, removing carbon dioxide and adding oxygen through an artificial lung, and returning the blood to the circulation via a vein (venovenous) or artery (venoarterial). When used in the venoarterial mode, most of the venous blood is diverted from the central circulation, hence the term cardiopulmonary bypass (Fig 1 . In venoarterial bypass (see Fig 1,A) the functions of both the heart and lungs are replaced by artificial organs, either totally or partially. During partial venoarterial bypass, perfusate blood mixes in the aorta with left ventricular blood that has traversed the lungs. Hence, the content of oxygen and carbon dioxide in the patient's arterial blood represents a combination of blood from these two sources, and the total systemic blood flow is the sum of the extracorporeal flow plus the amount of blood passing through the heart and lungs. Much has been written about the physiology and pathophysiology of total venoarterial bypass for cardiac surgery. ${ }^{3,4}$ While the principles of gas exchange and blood flow are the same, there are scveral important differences between the conduct of ECLS and operating room bypass. These differences are discussed in detail elsewhere ${ }^{4,5}$ This discussion will focus on the physiology of prolonged partial bypass for life support.

In venovenous bypass (see Fig 1,B) the perfusate blood is returned to the venous circulation and mixes with venous blood coming from the systemic organs, raising the oxygen content and lowering the carbon dioxide content in the right atrial blood. Some of this mixed blood is returned to the extracorporeal circuit ("recirculation"' and some of it passes into the right ventricle, the lungs, and the systemic circulation. Since the volumes of blood removed and reinfused are exactly equal there is no net effect on central venous pressure, right or left ventricle filling, or hemodynamics. The content of oxygen and carbon dioxide in the patient's arterial blood represents that of right ventricular blood modified by any pulmonary function that might exist. The systemic blood flow is the native cardiac output, and is unrelated to the extracorporeal flow.

Arteriovenous extracorporeal circulation (see Fig 1,C) is commonly used for hemodialysis or hemofiltration but not for cardiac or pulmonary support. The arteriovenous route could be used for gas exchange, provided the arterial blood was desaturated, and the cardio-

\section{FIG 1.}

Three modes of extracorporeal circulation. A, venoarterial access provides both cardiac and pulmonary support: $\mathbf{B}$, venovenous access is used where only respiratory support is required; $\mathbf{C}$, arterial venous access is used for low flow devices such as hemodialysis. 

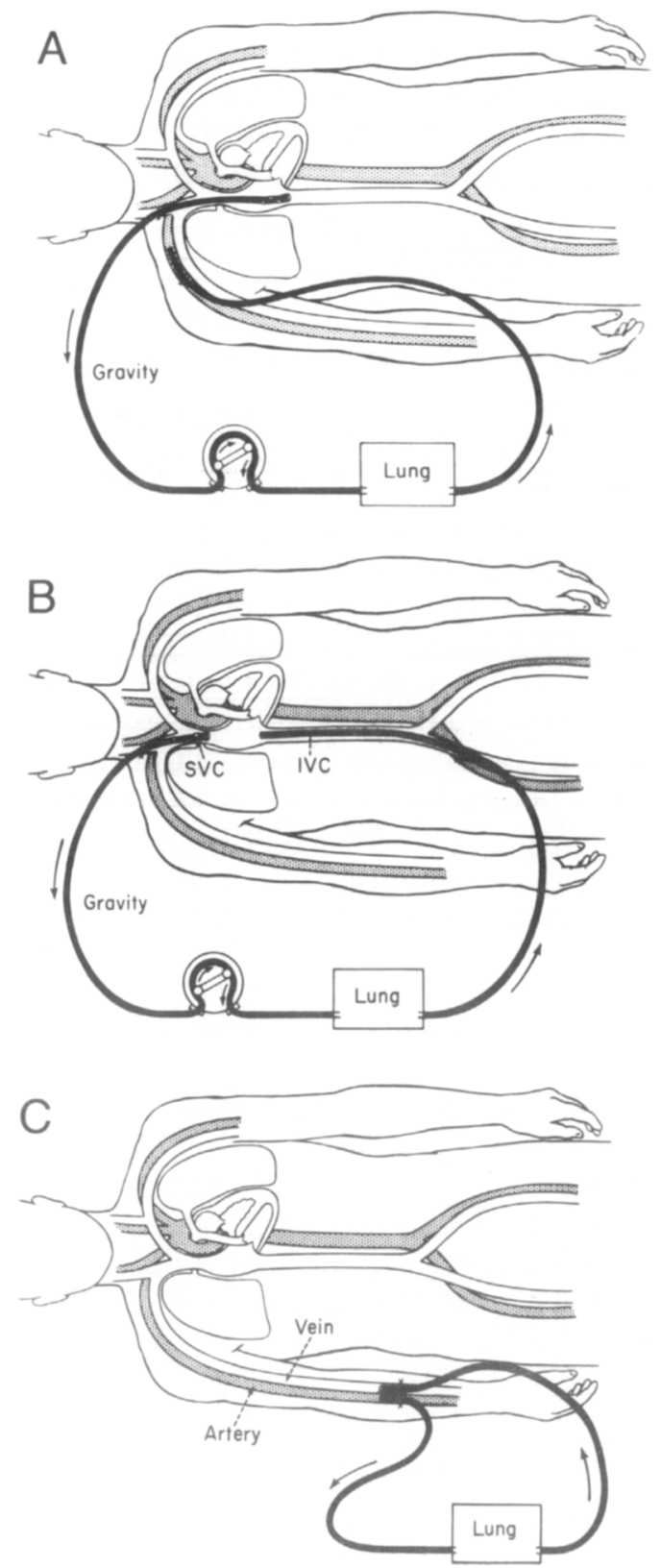
vascular system could tolerate the arteriovenous fistula with a large enough flow to achieve adequate gas exchange. This is, after all, the mechanism of gas exchange in the placenta and fetus. Because of the blood flow requirements for gas exchange support, the arteriovenous route is not a reasonable approach to total ECLS, except perhaps for the premature infant. ${ }^{97}$ Arteriovenous access could provide enough flow for partial carbon dioxide removal, either by direct diffusion or by removing bicarbonate. ${ }^{98,99}$

\section{OXYGEN KINETICS AND TISSUE RESPIRATION}

Management of ECLS requires a thorough understanding of normal and abnormal physiology, particularly those aspects of physiology related to respiration at the tissue level. Oxygen consumption $\left(\mathrm{VO}_{2}\right)$ is controlled by tissue metabolism, and hence is decreased by rest, paralysis, and hypothermia, and is increased during muscular activity, infection, hyperthermia, and increased levels of catecholamines and thyroid hormones. The metabolic rate is defined as the $\mathrm{Vo}_{2}$, or calculations based on the $\mathrm{Vo}_{2}$ (volume of oxygen consumed $x$ $5 \mathrm{Kcal} / \mathrm{L}$ estimates the energy expenditure expressed in calories). The value for oxygen consumption in normal resting humans is 5 to $10 \mathrm{cc} / \mathrm{kg} / \mathrm{min}$ in newborn infants, 4 to $6 \mathrm{cc} / \mathrm{kg} / \mathrm{min}$ in children, and 3 to $5 \mathrm{cc} / \mathrm{kg} / \mathrm{min}$ in adults. ${ }^{100,101}$ Although $V_{\mathrm{O}_{2}}$ may increase up to ten times with exercise, sepsis and catecholamines increase $\mathrm{Vo}_{2}$ by about $50 \%{ }^{100}$ The amount of oxygen absorbed across the lung in the process of pulmonary gas exchange is exactly equal to the amount of oxygen consumed by peripheral tissues during metabolism (the Fick principle ${ }^{102}$ regardless of the status of pulmonary function. Hence, $\mathrm{VO}_{2}$ can be measured at the airway or calculated as the product of the arteriovenous oxygen content difference times the cardiac output (the Fick equation).

Systemic oxygen delivery $\left(\mathrm{Do}_{2}\right)$ is the amount of oxygen delivered to peripheral tissues each minute, and hence is the product of the arterial oxygen content times the cardiac output. Oxygen delivery is controlled by cardiac output, hemoglobin concentration, hemoglobin saturation, and dissolved oxygen, in that order. The normal value for $\mathrm{Do}_{2}$ is 4 to 5 times $\mathrm{Vo}_{2}$ regardless of size, since the oxygen content of normal arterial blood is the same for all ages and sizes of patients $\left(20 \mathrm{cc} \mathrm{O}_{2} / \mathrm{dL}\right)$. Variations in oxygen delivery for patients of different size and metabolic activity are caused by variations in cardiac output. The oxygen content is rarely measured directly for clinical applications, and we are accustomed to describing blood oxygenation in terms of $\mathrm{PaO}_{2}$ or hemoglobin saturation. However, oxygen content is the most important measurement in the physiologic management of critically ill patients. The relationship of $\mathrm{PaO}_{2}$, satu- 


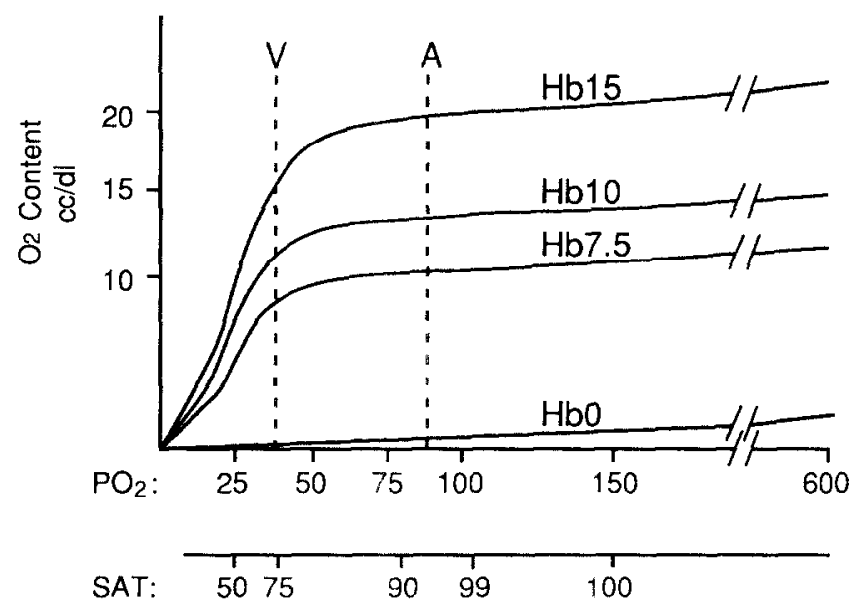

FIG 2.

Measuring oxygen in blood. The total amount of oxygen $\left(\mathrm{O}_{2}\right.$ content) is more dependent on hemoglobin $(\mathrm{Hb})$ level than dissolved oxygen $\left(\mathrm{P}_{2}\right)$ or hemoglobin saturation $(\mathrm{SAT})$. The dotted lines indicate typical values for venous and arterial blood

ration, and oxygen content is described in Figure 2. Typical values for venous and arterial blood at different levels of hemoglobin are identified. Notice that there is more oxygen in normal blood with a $\mathrm{PO}_{2}$ of 40 than there is in anemic blood with a $\mathrm{PO}_{2}$ of 100 . A unique aspect of cardiorespiratory homeostasis is the tendency to maintain systemic oxygen delivery at the normal level. In anemia, the cardiac output will increase until $\mathrm{Do}_{2}$ is normalized. In hypoxia the cardiac output increases, and in chronic hypoxia red cell mass increases under the influence of erythropoietin until systemic oxygen delivery is again normalized. We should recognize and assist these compensatory mechanisms in the critically ill patient. For example, the best treatment for a ventilated patient who is hypoxic, anemic, tachycardic, hypotensive, and hypermetabolic is usually red cell transfusion (rather than using inotropic drugs or increasing $\mathrm{F}_{\mathrm{ro}}$ ). Under most circumstances neither $\mathrm{VO}_{2}$ nor $\mathrm{Do}_{2}$ is affected by ventilation or $\mathrm{FIO}_{2}$.

The normal relationship between $\mathrm{DO}_{2}$ and $\mathrm{V}_{2}$ is shown in Figure 3. The normal ratio is $5: 1$, and when $V_{O_{2}}$ changes secondary to variations in metabolism, $\mathrm{Do}_{2}$ readjusts by increasing or decreasing cardiac output to maintain the normal ratio. If systemic oxygen delivery is moderately decreased, there is no change in oxygen consumption; hence the amount of oxygen extracted from each deciliter of arterial blood is greater. One could imagine a situation in which the rate of tissue metabolism exceeded the rate of oxygen delivery, which 


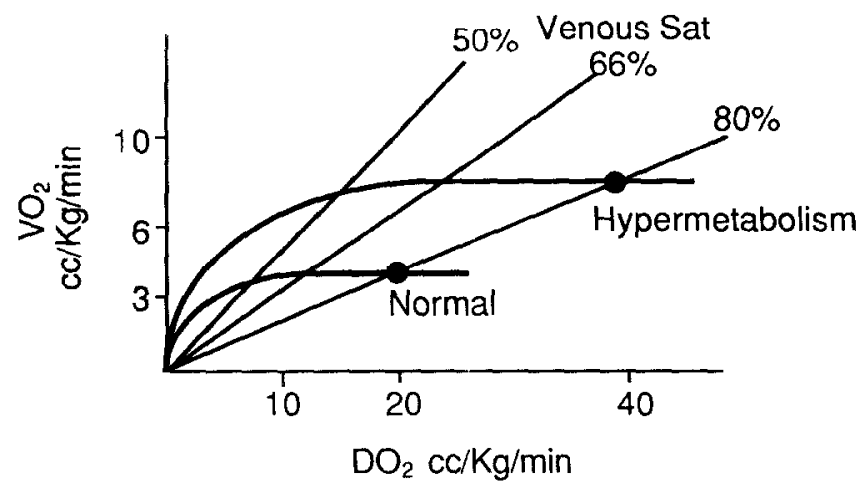

\section{FIG 3.}

Relationships between oxygen consumption $\left(\mathrm{VO}_{2}\right)$ and oxygen delivery $\left(\mathrm{DO}_{2}\right)$. Normally, oxygen delivery is five times consumption and the venous saturation (Sat) is $80 \%$. If delivery is less than twice consumption the venous saturation is less than $50 \%$ and consumption becomes dependent on delivery.

would result in anaerobic metabolism, limitation of $\mathrm{Vo}_{2}$ based on decreased oxygen supply, and oxygen "debt." In theory this would occur whenever the ratio of delivery to consumption is less than 1:1. In practice this situation occurs when the ratio is less than $2: 1 .^{103}$ (The difference is explained by the fact that some of the systemic oxygen delivery goes to tissues that consume very little oxygen, like skin, fat, and tendons.) Between this critical point at a $\mathrm{Do}_{2} \mathrm{No}_{2}$ ratio of $2: 1$ and the normal ratio of $5: 1$, decreased delivery is compensated by increased extraction, maintaining normal hemodynamic and respiratory stability. Since mixed venous blood oxyhemoglobin saturation reflects this ratio exactly, it is the most important monitor for managing critically ill patients. If the arterial blood is fully saturated, the venous saturation decreases proportionate to the amount of oxygen extracted from arterial blood. Thus, if the oxygen extraction ratio is $20 \%$ the venous saturation will be $80 \%$; if the oxygen extraction ratio is $33 \%$ the venous saturation will be $67 \%$, etc. These levels of venous saturation corresponding to various $\mathrm{Do}_{2} \mathrm{No}_{2}$ ratios are identified in Figure 3.

\section{CARBON DIOXIDE PRODUCTION}

The amount of carbon dioxide produced during systemic metabolism each minute $\left(\mathrm{VCO}_{2}\right)$ is approximately equal to the amount of oxygen consumed. The ratio of carbon dioxide production to oxygen consumption is known as the respiratory quotient, and varies depending on the energy substrate from 0.7 for fat to 0.8 for protein to 
1.0 for carbohydrate. Under normal conditions the rate and depth of breathing is controlled to maintain the arterial $\mathrm{PCO}_{2}$ at $40 \mathrm{~mm} \mathrm{Hg}$. Even a slight increase in metabolically produced carbon dioxide will result in a proportionate increase in alveolar ventilation, just enough to increase carbon dioxide excretion so that the arterial $\mathrm{PCO}_{2}$ will iemain at 40 . Unlike systemic oxygen delivery, carbon dioxide excretion is not affected by hemoglobin or blood flow, but is very sensitive to changes in ventilation. Because of this, and because carbon dioxide excretion is much more efficient than oxygenation in the lung carbon dioxide removal can be maintained at normal levels even during severe lung dysfunction.

\section{GAS EXCHANGE IN EXTRACORPOREAL LIFE SUPPORT}

\section{Oxygen Delivery}

During FCIS, oxygen delivery is controlled hy the combination of blood oxygenation in the membrane lung, flow through the extracorporeal circuit, oxygen uptake through the native lung, and cardiac output through the native heart

Blood oxygenation in the membrane lung is a function of the geometry, the thickness of the blood film, the membrane material and thickness, the $\mathrm{FIO}_{2}$, the residence time of red cells in the gas exchange area, the hemoglobin concentration, and the inlet saturation (the latter two defining the oxygen uptake capacity of each deciliter of blood). ${ }^{104}$ All of these factors are included in a single descriptor of membrane lung function called "rated flow." ${ }^{105}$ Rated flow is the amount of normal venous blood that can be raised from $75 \%$ to $95 \%$ oxyhemoglobin saturation in a given period of time. As long as the extracorporeal blood flow is less than the rated flow of the membrane lung, the blood leaving the lung will be fully saturated and the amount of systemic oxygen delivery via the extracorporeal circuit is controlled by blood flow and the oxygen uptake capacity. The amount of oxygen that can be taken up by each deciliter equals the grams of hemoglobin per deciliter times the unsaturated fraction times $1.36 \mathrm{cc} / \mathrm{g}$ (plus a small amount of dissolved oxygen). When the outlet blood is $100 \%$ saturated, the uptake capacity is the same as the arteriovenous oxygen content difference $\left(A-V_{D_{2}}\right)$. If the hemoglobin concentration is low or the venous blood saturation is high, then the amount of oxygen that can be taken up in the membrane lung is decreased. We can compensate for decreased oxygen binding capacity by increasing blood flow. Conversely we can achieve oxygen delivery at low blood flow by increasing oxygen binding capacity. 'These phenomena are demonstrated in Figure 4. Oxygen delivery for venoarterial and venovenous bypass in a typical newborn infant are demonstrated. The oxygen requirement for this infant is $20 \mathrm{cc} / \mathrm{min}$. 


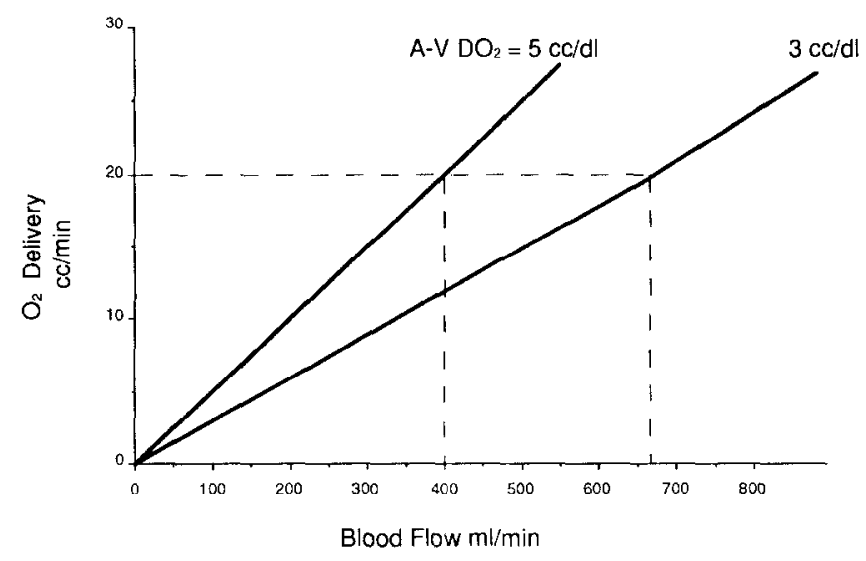

FIG 4.

Oxygen delivery is a product of oxygen carrying capacity and cardiac output. The oxygen carrying capacity is dependent on the saturation of venous blood presented to the membrane lung. Shown is the blood flow rate required to deliver $20 \mathrm{cc} / \mathrm{O}_{2} / \mathrm{min}$ at $\mathrm{A}-\mathrm{V} \mathrm{O}_{2}$ difference of 5 and $3 \mathrm{cc} / \mathrm{dL}$.

All of the oxygen required can be supplied by venoarterial bypass at a flow of 500 or venovenous bypass at a flow of 660 .

The resulting systemic $\mathrm{P}_{\mathrm{O}_{2}}$ and systemic oxygen delivery are a function of oxygen delivery through the extracorporeal circuit and oxygen delivery through the native heart and lung. In planning the size of the circuit and extracorporeal flow rate it is assumed that there will be no gas exchange across the native lung. With this assumption, in venovenous bypass the arterial $\mathrm{Po}_{2}$ and saturation will be identical to the values in the mixed right atrial blood. Because of the nature of venovenous bypass this saturation will never be higher than $95 \%$, and typically will be closer to $80 \%$ saturation with a $\mathrm{P}_{2}$ of approximately $40 \mathrm{~mm} \mathrm{Hg}$. Consequently it is common for a patient on venovenous ECLS to be cyanotic and hypoxic. Systemic oxygen delivery is perfectly adequate as long as hemoglobin is normal and there is a small compensatory increase in cardiac output. Improvement in native lung function results in increasing arterial oxygenation, and the amount of native lung function during venovenous bypass can be identified as a step up from venous to arterial saturation.

In venoarterial bypass the interpretation of arterial blood gases is more complicated. The perfusate blood is typically $100 \%$ saturated with a $\mathrm{PO}_{2}$ of $500 \mathrm{~mm} \mathrm{Hg}$. When the lung is not functioning the left ventricular ejectate blood is identical to right atrial blood, typically with a saturation of $75 \%$ and $\mathrm{P}_{2}$ of 35 . Suppose the hemoglobin is 
$15 \mathrm{~g} / \mathrm{dL}$, the perfusate oxygen content is $22 \mathrm{cc} / \mathrm{dL}$, and the right atrial and left ventricular oxygen contents are both $15 \mathrm{cc} / \mathrm{dL}$. The resultant arterial blood gases reflect the relative amounts of perfusate and native lung flow. If $\mathbf{5 0 \%}$ of the venous return is routed through the extracorporeal circuit, the oxygen content of systemic arterial blood will be $18.5 \mathrm{cc} / \mathrm{dL}$, corresponding to a saturation of $90 \%$ and a $\mathrm{Po}_{2}$ of 55 . The systemic oxygen content is determined by the formula:

$$
\text { Perfusate content } \times \frac{\text { ECC flow }}{\text { total flow }}+\text { LV blood content } \times \frac{\text { lung flow }}{\text { total flow }}
$$

Thus, during venoarterial bypass an increase in systemic $\mathrm{Po}_{2}$ may signify improving lung function at constant flows, decreasing native cardiac output at constant extracorporeal flow, or increasing extracorporeal flow at constant native cardiac output. These phenomena are described in Figure 5.

\section{Carbon Dioxide Removal}

The amount of carbon dioxide eliminated in extracorporeal circulation is a function of the membrane lung geometry, material, surface area, blood $\mathrm{PCO}_{2}$, and, to a lesser extent, blood flow and membrane lung ventilating gas flow (commonly called "sweep" flow). ${ }^{106}$

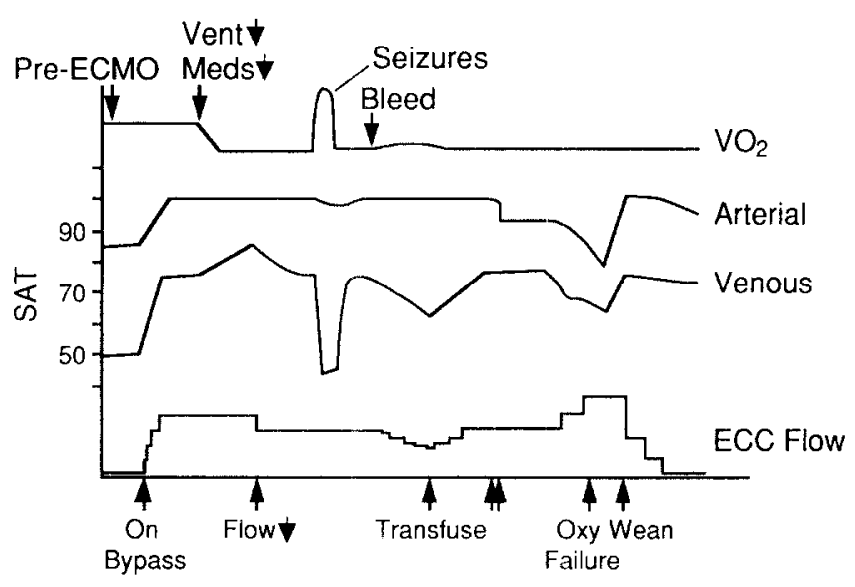

\section{FIG 5.}

The interrelationships between oxygen consumption $\left(\mathrm{VO}_{2}\right)$ and arterial and venous saturation (SAT) are shown during typical conditions on venoarterial bypass. Venous saturation decreases during increased metabolic activity or decreased systemic delivery. Systemic oxygenation decreases during transfusion when relatively more blood is diverted through the pulmonary circulation. $E C C=$ extracorporeal circulation; Vent $=$ ventilation; $M e d s=$ medication. 
Usually the ventilating gas contains no carbon dioxide, so that the gradient for $\mathrm{Co}_{2}$ transfer is the difference between the blood $\mathrm{PCO}_{2}$ and zero (when the gas flow rate is high). As the $\mathrm{PCO}_{2}$ drops during the passage of blood through the membrane lung, the gradient decreases, so that carbon dioxide excretion is less at the blood outlet end of the device than at the inlet end. Consequently, the amount of carbon dioxide transfer is relatively independent of blood flow, and only moderately dependent on inlet $\mathrm{PCO}_{2}$, with the major detcrminant of carbon dioxide elimination being total surface area and flow rate of the sweep gas (Fig 6). Carbon dioxide removal characteristics for $1.4 \mathrm{~m}^{2}$ Sci-Med membrane lung at different levels of $\mathrm{PCO}_{2}$ are shown in Figure 6 over a range of blood flows. The capacity for carbon dioxide removal is considerably greater than the capacity for oxygen uptake at the rated flow. For any silicone rubber or microporous membrane oxygenator, carbon dioxide clearance will always be more efficient than oxygenation when the oxygenator is well ventilated and functioning properly.

The extracorporeal circuit is generally planned to be capable of supplying total oxygen requirements. For this reason, the membrane lung will be capable of removing excess carbon dioxide. We can selectively increase carbon dioxide transfer (but not oxygen delivery) by increasing sweep flow and increasing the total surface area of the membrane lung in the extracorporeal circuit.

Following the above rationale with regard to oxygen delivery, as-

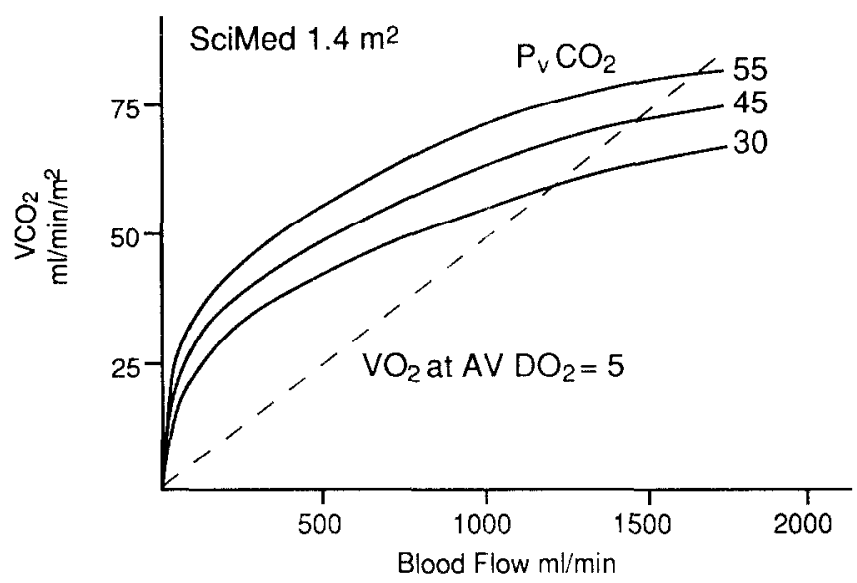

\section{FIG 6.}

Membranc lung carbon dioxide removal is dependent on membranc lung surface arca and carbon dioxide gradient, rather than blood flow. Oxygenation is dependent on blood flow (dotted line). At the rated flow of any membrane lung the carbon dioxide transfer will be higher than the oxygen transfer. $\mathrm{P}_{v} \mathrm{CO}_{2}=$ Partial pressure of $\mathrm{CO}_{2}$ in venous blood. 
suming that there is no gas exchange across the native lung, the at terial $\mathrm{PCO}_{2}$ will be the same as venous $\mathrm{PCO}_{2}$ in venovenous bypass; it will be a function of mixing perfusate and cardiac output blood in venoarterial bypass. However, because of the efficiency of extracor" poreal carbon dioxide removal, the systemic $\mathrm{PCO}_{2}$ can be "set" at any level by matching the membrane lung surface area and gas flow to the systemic carbon dioxide production. In practice the system is overdesigned for carbon dioxide removal, and if bypass is run to supply total oxygen requirements, carbon dioxide removal will be excessive, resulting in major respiratory alkalosis. 'This situation is controlled by adding carbon dioxide to the sweep gas, thus decreas ing the gradient and decreasing the amount of carbon dioxide excretion.

If the native lung can supply some oxygen absorption and the intent of extracorporeal circulation is primarily carbon dioxide removal, this can be accomplished with venovenous access and relatively low blood flow- a technique referred to as extracorporeal $\mathrm{CO}_{2}$ removal $\left(\mathrm{ECCO}_{2} \mathrm{R}\right)^{\text {(3.3. }}$

\section{HEMODYNAMICS}

Blood flow through the extracorporeal circuit is limited by the size of the venous drainage catheter. Resistance to blood flow varies directly with the length of the catheter and inversely with the fourth power of the radius of the catheter. Consequently, the shortest and largest internal diameter catheter that can be placed in the right atrium will allow the highest rate of extracorporeal blood flow. The superior vena cava allows the most direct access to the right atrium, and the right internal jugular vein usually has a large diameter. A catheter placed in the right internal jugular vein will usually permit venous drainage equivalent to the normal resting cardiac output of patients of all ages and sizes. Blood drains through the venous tubing to a pump that provides the pressure to direct the blood through the membrane lung and back into the patient. There is significant resistance to flow through the membrane lung and across the reinfusion catheter, so the pressure on the arterial side of the circuit increases with increasing blood flow. In practice the pump is set to deliver the desired flow and the postpump pressure is simply monitored. Pressures as high as $300 \mathrm{~mm} \mathrm{Hg}$ are safe, although the higher the pressure the higher the likelihood of blood leaks or circuit disruption.

The effect of venoarterial bypass on systemic perfusion is reflected in the pulse contour and pulse pressure (Fig 7). The extracorporeal pump creates a flow that is essentially nonpulsatile. Consequently, as more blood is routed through the extracorporeal circuit, the sys- 


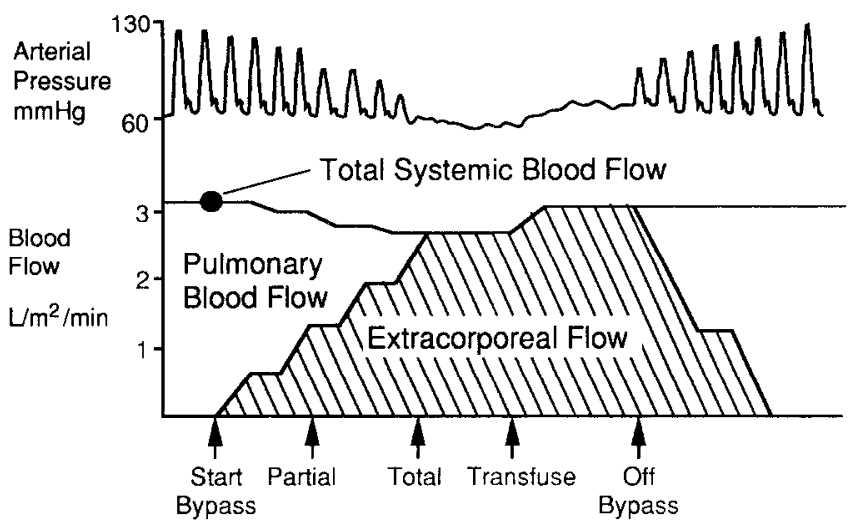

FIG 7.

Arterial pulse pressure and total blood flow during variability levels of venoarterial cardiopulmonary bypass. During total bypass systemic flow is normal but the pulse contour is flat. Usually extracorporeal blood flow during venoarterial ECLS is maintained approximately $80 \%$ of total blood flow and the pulse pressure is 10 to $15 \mathrm{mmHg}$

temic arterial pulse contour becomes dampened, then intermittent, then flat when total bypass is reached. At total bypass the left ventricle gradually distends with bronchial and thebesian flow, and ejects when it is full, leading to an occasional pulsatile beat. In practice it is unusual to reach total bypass for any sustained period of time with extrathoracic cannulation as long as there is cardiac function. Typically, venoarterial ECLS is run at about $80 \%$ of resting normal cardiac output, which allows $20 \%$ or more of the blood to pass through the lungs and left heart, resulting in a diminished but discernable pulse contour. As long as total blood flow is adequate, the presence of a pulse contour is not physiologically important. ${ }^{107}$

The importance of pulse contour and amplitude during perfusion has been controversial. There is universal agreement that the kidney "interprets" nonpulsatile flow as inadequate flow, resulting in renin production and antidiuresis. This phenomenon has been confirmed by several investigators. ${ }^{108-111}$ Several groups could find no other effects of nonpulsatile total body perfusion. ${ }^{112-115}$ However, equally competent researchers have reported a syndrome of high vascular resistance, high blood catecholamine levels, and poor tissue perfusion, resulting in cerebral changes, renal failure, and severe lactic acidosis. ${ }^{116.117}$ Trinkle defined this syndrome in animals only during nonpulsatile perfusion; however, he found an equal incidence of the poor perfusion syndrome with both pulsatile and nonpulsatile flow during cardiac surgery in man. These apparent contradictions can 
be resolved by careful examination of the experimental methods correlated with the classic studies of Harrison et al. ${ }^{118,119}$

Normally blood flow is approximately $110 \mathrm{~mL} / \mathrm{kg}$ with a pulse amplitude of 20 to $40 \mathrm{~mm} \mathrm{Hg}$ (with some species variations). The studies that demonstrated acidosis and organ failure during nonpulsatile flow were all conducted at flow rates from 60 to $100 \mathrm{~mL} / \mathrm{kg}^{115-117,120,121}$ Investigators who found no difference between pulsatile and nonpulsatile flow used perfusion rates of 130 to $200 \mathrm{~mL} / \mathrm{kg}^{112-11.5}$ This relationship could have been predicted from the studies of Harrison and others who showed that adrenal catecholamine secretion is regulated in part by carotid sinus baroreceptors. Decreased pulse amplitude caused maximal catecholamine output when total flow was less than normal, but minimal catecholamine output during normal and supernormal flow rates. From Harrison's findings, one might expect no difference between normal flow and either pulsatile perfusion or nonpulsatile perfusion at flow rates over $110 \mathrm{~mL} / \mathrm{kg}$. The high-resistance acidosis syndrome occurs during nonpulsatile perfusion at flow rates of 80 to $100 \mathrm{~mL} / \mathrm{kg}$, and during both pulsatile and nonpulsatile perfusion at flow rates less than $70 \mathrm{~mL} / \mathrm{kg}$. These findings correspond almost exactly to the reports of various investigators cited above. Harrison's studies and most of the comparative studies listed above were carried out at $37^{\circ} \mathrm{C}$. The effects of hypothermia and its relationship on the normal blood flow requirement have not been thoroughly studied. This probably accounts for some of the variations seen clinically.

The implication of these studies for total cardiopulmonary bypass in cardiac surgery is that total perfusion is usually carried out at an abnormally low blood flow rate. At normothermia this may result in catecholamine secretion and the effects could be ameliorated by pulsatile flow or alpha-blockade. During ECLS, total blood flow should be maintained at normal levels, and it is not important whether the flow is pulsatile or nonpulsatile. In practice, pulse amplitude is normal during venovenous bypass and diminished during venoarterial bypass. Developing the technology for pulsatile flow during ECLS is only important during venoarterial bypass for cardiac support. In this setting the left ventricle may not develop sufficient pressure to open the aortic valve against the resistance of continuous perfusion into the arterial system. To facilitate left ventricular ejection, pulsatile flow can be induced in the counter pulsation mode (high pressure during ventricular diastole and low pressure during ventricular systole!.

Venovenous bypass has no effect on hemodynamics. Blood is drained from and returned to the venous circulation at the same rate because the extracorporeal circuit is noncompliant. This is true whether venovenous bypass is achieved from two separate catheters or with a single double-lumen catheter. An interesting variation on 


\section{TABLE 1.}

Major Differences Between Venoarterial and Venovenous ECLS

\begin{tabular}{|c|c|c|}
\hline & Venoarterial & Venovenous \\
\hline \multicolumn{3}{|l|}{ Hemodynamics } \\
\hline Systemic perfusion & $\begin{array}{l}\text { Circuit flow and cardiac } \\
\text { output }\end{array}$ & Cardiac output only \\
\hline Arterial BP & Pulse contour damped & Pulse contour full \\
\hline CVP & Not too helpful & $\begin{array}{l}\text { Accurate guide to volume } \\
\text { status }\end{array}$ \\
\hline PA pressure & $\begin{array}{l}\text { Decreased in proportion } \\
\text { to FC.C. flow }\end{array}$ & Not affected by flow \\
\hline Effect of $\mathbf{R}-\mathbf{L}$ shunt & $\begin{array}{l}\text { Mixed venous into } \\
\text { perfusate blood }\end{array}$ & None \\
\hline $\begin{array}{l}\text { Effect of L-R (PDA) } \\
\text { shunt }\end{array}$ & $\begin{array}{l}\text { Pulmonary } \\
\text { hyperperfusion may } \\
\text { require increased flow }\end{array}$ & $\begin{array}{l}\text { No effect on ECC flow; } \\
\text { usual PDA physiology }\end{array}$ \\
\hline $\begin{array}{l}\text { Selective } \mathbf{R} \text { arm, brain } \\
\text { perfusion }\end{array}$ & Occurs & Does not occur \\
\hline \multicolumn{3}{|l|}{ Gas exchange } \\
\hline $\begin{array}{l}\text { Typical blood flow for } \\
\text { full gas exchange }\end{array}$ & $80-100 \mathrm{cc} / \mathrm{kg} / \mathrm{min}$ & $100-120 \mathrm{cc} / \mathrm{kg} / \mathrm{min}$ \\
\hline Arterial oxygenation & $\begin{array}{l}\text { Sat controlled by ECC } \\
\text { flow }\end{array}$ & $\begin{array}{l}80 \%-95 \% \text { sat. common at } \\
\text { maximum flow }\end{array}$ \\
\hline Carbon dioxide removal & $\begin{array}{l}\text { Depends on sweep gas } \\
\text { and membrane lung } \\
\text { size }\end{array}$ & Same as venoarterial \\
\hline Oxygenator (infant) & 4 or $h$ & 6 or 8 \\
\hline $\begin{array}{l}\text { Decrease initial vent } \\
\text { settings }\end{array}$ & Rapidly & Slowly \\
\hline
\end{tabular}

venuvenous bypass proposed by Kolobow ${ }^{122.123}$ and used by Durandy and Chevalier ${ }^{124}$ is the tidal flow system. In tidal flow venovenous extracorporeal circulation a single venous catheter in the right atrium is used. Venous blood is drained for about 1 second, a valve changes the access, and oxygenator blood is reinfused through the same catheter in a shorter time, typically one-half second. This system does result in some significant fluctuation in right atrial pressure, but not enough to interfere with right ventricular or leftsided hemodynamics. Venovenous bypass and venoarterial bypass are further compared in 'Table 1.

\section{BLOOD ACTIVATION AND COAGLLATION CONTROL}

Whenever blood contacts a prosthetic surface several changes occur. Enzymatic cascades are activated that lead to the production of 
fibrin, kinin, complement, and plasmin. There is increased platelet adherence and activation in white blood cell (WBC) membranes. The physiologic mechanism of thrombosis predominates. Blood protein: adhere instantly to the prosthetic surface, creating a molecular protein layer that forms the blood surface interface for the rest of the period of exposure. The proteins in this layer affect subsequent events. Some proteins like albumin "pacify," or "passivate" the surface, minimizing subsequent cellular or protein interactions. Other proteins like fibrinogen activate factor 12 , complement, and platelets The thrombogenecity of prosthetic surfaces is related to the anount of fibrinogen that adheres during blood exposure ${ }^{125,1263}$ platelets adhere to fibrinogen on the artificial surface and are stimulated to release platelet granule material that attracts other platelets and stimulates the formation of fibrin. If there is no anticoagulant present and the blood flow is slow or absent, a platelet-fibrin mesh develops in seconds, trapping red cells and white cells in the process and leading to a blood clot. If there is no anticoagulant present but the blood flow is very fast, there is not sufficient time for the development of a clot before the aggregated platelets are washed awav, so gross clotting does not occur.

When fibrin formation is inhibited by heparin the growth of the clot is impeded, even in areas of slow flow, so that aggregates of platelets and white cells grow in stagnant zones without the fibrin glue that ordinarily leads to solid thrombosis. After days or weeks of extracorporeal circulation these white thrombi can be found in virtually every microscopic low flow zone, downstream from connectors, etc. The size of the right angle step off related to the flow rate of blood going past that point probably determines whether or not red cells are trapped in the midst of the growing aggregate. When the platelet/white cell aggregate extends into the stream of rapidly flowing blood it extends until it breaks off in the bloodstream. This platelet/white cell aggregate embolizes and disaggregates in the first capillary bed, and the effete platelets recirculate until they are removed by the reticuloendothelial system. ${ }^{12 \pi} \cdot 128$ Aggregates of platelet and white cells range in size from 20 to $200 \mu$. Aggregates trapped by a $25-\mu$ filter in the arterial line of an ECMO circuit are demonstrated in Figure 8. Arterial line filtration is generally not used in ECLS, allowing these microaggregates to reach the patient's capillary bed and disaggregate. Factors that minimize platelet aggregation are smooth prosthetic surfaces, heparinized surfaces that cannol bind fibrinogen, and minimal mechanical damage. Platelet aggregation is probably enhanced by the action of the blood pump, since platelet loss is decreased when the pump is eliminated from the circuit. ${ }^{139} 130$

Extracorporeal circulation can be conducted for long periods without systemic anticoagulation as long as high flow is maintained and there are no stagnant areas. ${ }^{131-133}$ In clinical practice, however 

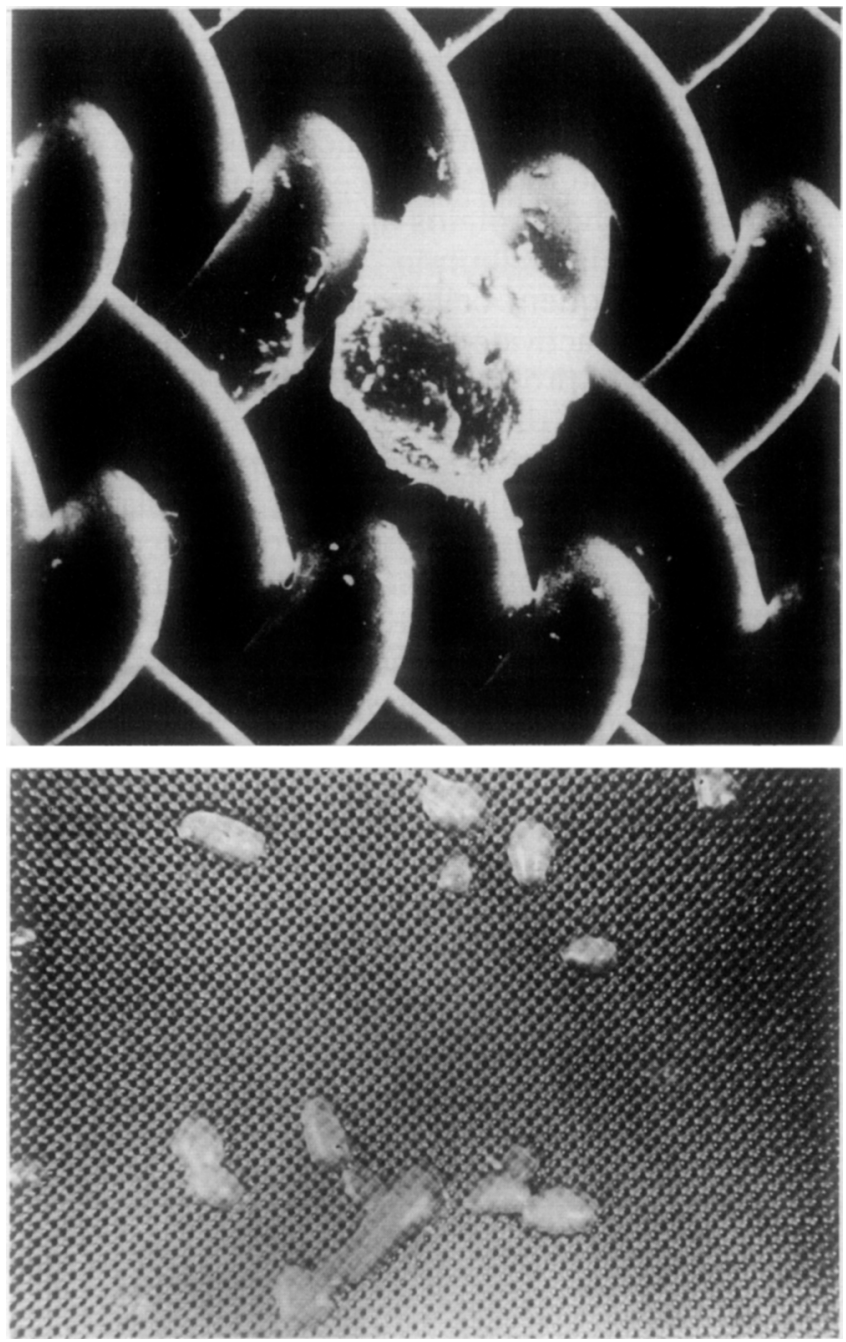

FIG 8.

Platelet aggregates picked up by a $25-\mu$ filter during extracorporeal circulation. During ECLS these aggregates embolize into the patient, disaggregate, recirculate, and are eventually removed by the reticuloendothelial system. (From Dutton RC et al: Platelet agregate emboli in patients during cardiopulmonary bypass with membrane and bubble oxygenators and blood filters. J Thorac Cardiovasc Surg 1973; 67:258. Used by permission.)

accepted practice is to use systemic heparin continuously in a dose required to maintain the whole blood activated clotting time around 200 seconds (approximately 11/2 times normal). This generally requires 30 to 60 units of heparin $/ \mathrm{kg} / \mathrm{hr}$. Heparin is bound to platelets and excreted in the urine, so higher heparin doses are required dur- 
ing diuresis and platelet transfusion, and lower heparin doses are required in patients with renal failure and thrombocytopenia. Obvi ously the heparin effect, rather than the exact heparin level, is the important parameter. Heparin effect must be measured in whole blood (whole blood activated clotting time $[A C T]$ rather than plasma (such as partial thromboplastin time or thrombin timel.

For the reasons mentioned above, platelets will be consumed during extracorporeal circulation at a steady and continuous rate. ${ }^{1 ; k-1}$ If new platelets can be made by megakaryocytes rapidly enough to balance this platelet loss then the platelet count will remain stable. In most children and newbon infants the rate of platelet generation does not match the rate of platelet loss, and platelet transfusions are necessary to maintain normal hemostasis. When the platelet count is maintained greater than $75,000 / \mathrm{mm}^{3}$ and the activated clotting time is less than 200 seconds, the risk of bleeding is relatively small, and the risk of major clotting in the circuit is negligible as long as blood flow continues.

There have been few studies of the effect of prolonged extracorporeal circulation on white cell numbers and function. ${ }^{135}$ In general, the white blood count and differential count are normal during extracorporeal circulation. Since preexisting bacterial infections usually resolve during ECLS it is reasonable to think that neutrophil phagocytosis is adequate; however, this has not been studied in detail. Complement is activated during exposure of blood to almost any surface, including the ECLS circuit. Although during ECLS this effect is minimal and subsides within a few hours, there are immediate changes characterized by complement activation and white cell aggregation. This usually results in a minimal increase in capillary permeability, a transient increase in pulmonary vascular resistance, and a transient decrease in systemic vascular resistance that is compensated by an increase in catecholamine secretion unless the blood volume is appropriately expanded.

The effect of prolonged extracorporeal circulation on red cells is negligible as long as there is no direct exposure of the blood to gas, or a negative pressure does not develop. The roller pump is adjusted so that it is almost completely occlusive, with a servoregulation mechanism to avoid negative pressure surges. With these precautions the plasma free hemoglobin level should be routinely less than $40 \mathrm{mg} / \mathrm{dL}$. and the urine should be clear. If plasma hemoglobin levels exceed 40 $\mathrm{mg} / \mathrm{dL}$ possible causes of hemolysis should be searched for.

\section{PHYSIOLOGY OF OTHER ORGANS DURING EXTRACORPOREAL LIFE SUPPORT}

Fluids and electrolytes are managed as they would be in any patient. The generalized edema seen following cardiac surgery 
is usually related to hemodilution, and should not occur during ECLS. The capillary permeability is normal during ECLS, so that if capillary leakage occurs, it is indicative of patient disease rather than extracorporeal circulation. If extensive edema occurs the patient should be treated with diuresis, since many organs including the lung) malfunction when edematous. Renal function is normal during ECLS and the volume and composition of urine is a good index of adequate systemic perfusion. The kidney responds to osmotic and loop diuretics, which are often necessary to treat fluid overload.

Protein metabolism is normal during ECLS. When properly managed the level of catecholamine secretion is normal (unlike during cardiac surgery in which catechol secretion is stimulated by hypothermia, hemodilution, and marginal systemic oxygen delivery). ${ }^{136}$ As in any critically ill patient, it is general practice to give enteral or parenteral feeding to match caloric and protein requirements. Temperature is regulated by a heat exchanger in the circuit.

Liver function is normal during the early phases of ECLS. After a period of several days a pattern of cholestatic jaundice and hepatomegaly without liver cnzyme elevation may be seen. ${ }^{137}$ This is apparently due to the accumulation of platelets and other debris in the reticuloendothelial system of the liver with concomitant limitation of conjugated bile excretion. ${ }^{138}$

Cardiac physiology is affected differently by venovenous or venoarterial extracorporeal circulation. As left atrial pressure drops during venoarterial bypass, left ventricular filling also drops, leading eventually to a decrease in pulse contour and then intermittent left ventricular ejection when the ventricle becomes full (see Fig 7). If the heart stops beating during venoarterial bypass the left atrium will gradually fill from bronchial and thebesian flow, leading to high left atrial pressure, high pulmonary hydrostatic pressure, and cardiogenic pulmonary edema. This situation may be exacerbated by increased afterload due to systemic vasospasm, volume overload, or perfusate flow directed toward the aortic valve. Consequently, if extracorporeal support is used for cardiac failure, and the ventricle does not empty, the left side of the circulation must be decompressed to avoid pulmonary edema. This can be accomplished by the creation of an atrial septal defect via a blade or balloon septostomy. Kolobow has devised an experimental system for cannulating the pulmonary artery to decompress the left side of the heart during venoarterial bypass. ${ }^{139}$ The patient's nervous and musculoskeletal systems should be normal during extracorporeal circulation. Usually patients are alert and awake and managed with minimal to moderate sedation.

Microembolization occurs constantly during extracorporeal circulation. Emboli of white blood cell and platelet aggregates referred to 
earlier can regularly be found in the perfusate. ${ }^{128}$ In addition, small aggregates of fibrin and red blood cells form in stopcocks, bridges, and other stagnant zones and subsequently embolize. Since organ function generally remains normal during a month or more of extracorporeal circulation, and since tissue infarcts are not found at autopsy, we assume that this microembolization has no functional significance. However, it is worth noting that any systemic effects of microembolization will be less with venovenous access than with venoarterial access, adding a theoretical advantage to venovenous bypass for long-term perfusion.

\section{TECHNIQUES OF CLINICAL EXTRACORPOREAL LIFE SUPPORT}

With an understanding of the physiology of extracorporeal circulation in hand, and with an understanding of the pathophysiology of the patient's primary disease, it is obvious that the goal of ECLS is to maintain systemic oxygen delivery and carbon dioxide removal in the proper proportion to systemic metabolism. This is achieved at low ventilator or inotropic drug settings that could not otherwise be tolerated. This process should eliminate any further ventilator-induced lung injury and improve systemic perfusion, allowing time for the native lung or heart to recover from the acute illness.

\section{PLANNING AND PRIMING THE CIRCUIT}

Although total support may never be necessary, the circuit must be planned with total support in mind. The tubing, connectors, and pump must be capable of adequate blood flow (typically $100 \mathrm{cc} / \mathrm{kg} /$ min for newborn infants, $75 \mathrm{cc} / \mathrm{kg} / \mathrm{min}$ for children, and $50 \mathrm{cc} / \mathrm{kg} / \mathrm{min}$ for adultsi. If venovenous access is used for respiratory support, these estimates of blood flow should be increased by $20 \%$, because higher blood flow will be required for adequate oxygenation because of recirculation. The venous access catheter should be large enough 10 deliver this blood flow with the assistance of $100 \mathrm{~cm}$ of siphon, and the arterial or reinfusion catheter should be large enough to permit this blood flow at line pressures less than $300 \mathrm{~mm} \mathrm{Hg}$ proximal to the membrane lung.

\section{ARTIFICIAL LUNGS}

Membrane lungs are used for ECLS (rather than bubble or liquid oxygenators) to avoid the problems of direct gas exposure, and to build a circuit that is noncompliant. Most of the experience with ECLS has been with solid silicone rubber membrane lungs, although membranes made of microporous materials have the same blood 


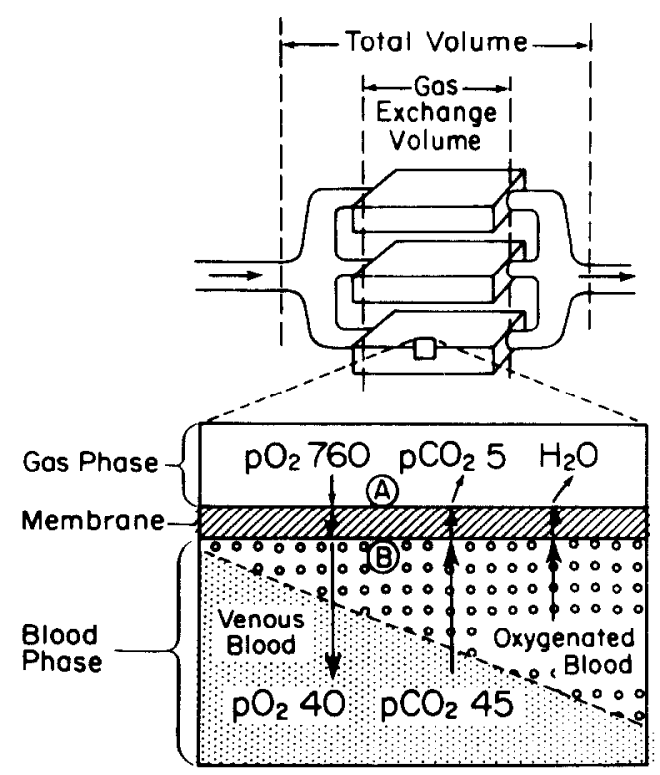

FIG 9.

Gas transfer in membrane lungs

surface characteristics and have been used successfully for prolonged support. All membrane lungs have in common the characteristics shown in Figure 9. Blood enters the device and is distributed through a header or manifold system to the gas exchange area. As blood flows past the membrane, oxygen diffuses into the blood because of the pressure gradient (or driving force) between $100 \%$ oxygen in the ventilating gas and the oxygen pressure in venous blood (a gradient of approximately $700 \mathrm{~mm} \mathrm{Hg}$ ). At the same time, carbon dioxide diffuses out, responding to the pressure gradient between the $\mathrm{PCO}_{2}$ of venous blood and the ventilating gas (a gradient of approximately $40 \mathrm{~mm} \mathrm{Hg}$. Although the pressure gradient for gas transfer is much greater for oxygen than carbon dioxide, the rate of diffusion through blood and the membrane per mm IIg gradient is much greater for carbon dioxide. Therefore, the diffusion of both oxygen and carbon dioxide through the membrane and through the flowing blood film must be taken into consideration when studying membrane oxygenator performance.

The rate of oxygen diffusion through a film of venous blood is the limiting factor in effectiveness of almost all membrane lungs. The rate of diffusion through silicone polymer membrane used in most devices is $1,210 \mathrm{~mL} \mathrm{O} \mathrm{O}_{2} / \mathrm{m}^{2}$ of membrane/min/mil membrane thick- 
ness (at a gradient of $760 \mathrm{~mm} \mathrm{Hg}$ ). Commercially used membranes are 3 to 6 mils* thick, so that most devices have a potential oxygen transfer of 200 to $400 \mathrm{~mL} / \mathrm{m}^{2} / \mathrm{min}$. However, the rate of diffusion through a film of venous blood is approximately $100 \mathrm{~mL} \mathrm{O} \mathrm{O}_{2} / \mathrm{m}^{2} / \mathrm{min}$ $100 \mu$ thickness (at $720 \mathrm{~mm} \mathrm{Hg}$ gradient). It is difficult to build a device with blood film thickness less than $200 \mu$ across; hence the full potential of oxygen transfer of the membrane is never reached.

These phenomena are shown in Figure 9. Oxygen diffuses readily through the membrane from point $A$ to point $B$, then slowly through the blood film to the center. As blood enters the gas exchange chamber, the red cells nearest the membrane become saturated with oxygen, the $\mathrm{PO}_{2}$ in the surrounding plasma goes up, and oxygen diffuses deeper into the blood film, saturating more red cells, with an advancing front of saturated blood that progresses further into the blood film with time. The longer the blood film is in the gas exchange area, the more complete the saturation of hemoglobin with oxygen. A definite period of time is required for full oxygenation. If the blood flows through faster than that time, incompletely saturated blood will leave the device. This situation is further complicated by the fact that the pattern of blood flow within the gas exchange film is laminar. Blood cells in the center of the film travel faster than those at the edges. This has the effect of making the exposure time for flowing blood relatively shorter than the exposure time of an equivalent amount of blood in a static film. Anything that can be done to interrupt the laminar flow pattern will improve the efficiency of oxygen transfer.

The actual oxygen delivery through the artificial lung (or the biologic lung, for that matteri is limited by the oxygen carrying capacity of the blood, discussed earlier. Oxygen transfer is related to the flow and oxygen content of venous blood as shown in Figure 4. As flow rate increases, oxygen transfer is proportionately increased until the oxygen transfer limitation imposed by blood film thickness is reached for that specific device. From that point on, increased flow results in desaturated blood leaving the outflow side of the membrane lung (Fig 10). The flow rate at which normal venous blood perfusate leaves the oxygenator at 95\% saturation has been referred to as the "rated flow" by Galletti. ${ }^{105}$ The rated flow for any artificial lung can be specifically measured. This is an extremely valuable concept for design and development of membrane lungs, for evaluating membrane lung function with changes due to time, coagulation, elc.. and in designing ECLS circuits for clinical use.

The complex interrelationship of the advancing front of saturated hemoglobin with laminar or turbulent flow patterns can be modeled and analyzed to assist in the design of devices with optimal charac-

${ }^{*} 1 \mathrm{mil}=.001 \mathrm{in} .=0.025 \mathrm{~mm}-25 \mu$. 


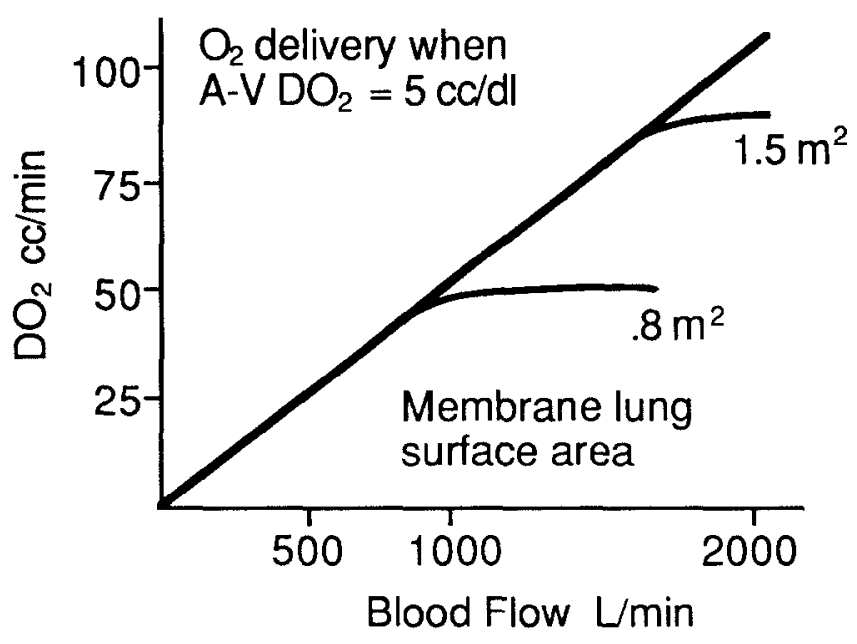

FIG 10.

The concept of "rated flow." The amount of oxygen delivery through a membrane lung is primarily limited by oxygen carrying capacity and blood flow (diagonal line for $\mathrm{AVDO}_{2}$ equals 5). The surface area and geometry of the membrane lung are secondary determinants of function. When normal venous blood leaves the membrane lung $95 \%$ saturated this limitation has been met. The blood flow at this limitation is referred to as the rated flow. Rated flow for membrane lungs of 8 and $1.5 \mathrm{~m}^{2}$ are illustrated.

teristics. There are design trade-offs between priming volume, residence time, blood film thickness, blood flow resistance, induced secondary flows for blood mixing, workability of materials, thrombogenecity of materials, and expense of manufacture. The ideal membrane lung would have the following properties in order of preference):

1. Low thrombogenecity.

2. Maximal oxygen transfer per unit surface area induced by secondary flows.

3. Relatively large and accessible gas space (to minimize water condensation and improve carbon dioxide clearance).

4. Low blood flow resistance.

5. Low cost.

6. Ease of priming.

7. Low priming volume.

These priorities are addressed in different ways by different manufacturers. The Sci-Med Kolobow lung is most widely used for ECLS. It is made from a long envelope of solid silicone rubber, spirally wound around a mandril. Gas passes through the envelope and 
blood passes lengthwise between the windings of the spiral coil. lixcellent gas exchange and low priming volume are achieved by high residence time at the cost of relatively high perfusion pressure. The Medtronic Maxima membrane lung is made of woven capillaries of microporous plastic. Gas passes through the capillaries and blood flows around the irregular capillary bundles creating secondary flows. This device achieves excellent gas exchange by using secondary flows with very low blood flow resistance. The microporous material is easy to prime, but has the risk of water condensation in the gas phase, wettability, and plasma leakage. The interested reader is referred to excellent reviews of engineering and oxygenator designs by Drinker, ${ }^{104}$ Colton, ${ }^{140}$ and Dorson. ${ }^{141}$

Carbon dioxide transfer is limited by the transfer rate through the membrane in most membrane lungs. The rate of carbon dioxide transfer through silicone polymer membrane is 6 times greater than that of oxygen for equivalent membrane thickness and pressure gradient. However, the pressure gradient for carbon dioxide transfer can never be greater than the difference between the $\mathrm{Pco}_{2}$ of the venous blood and zero (usually $45-50 \mathrm{~mm} \mathrm{Hg}$. With this pressure gradient and the usual membrane thickness of 3106 mils, cartom dioxide transfer limitation is approximately $200 \mathrm{~mL} / \mathrm{min} / \mathrm{m}^{2}$ for most devices. This is considerably more than oxygen transfer as outlined above, so carbon dioxide transfer will alwavs be more than oxvgen transfer for most solid membrane devices. In fact, it is usually necessary to use a carbon dioxide enriched mixture $2.5^{(\%)}-4 \%$ carbon dioxide) for ventilating the lung to prevent hypocapnia and respiratory acidosis when the ECLS sustem is being used for total gas exchange support.

Because carbon dioxide transfer is relatively independent of blood flow rate but very dependent on surface area, any malfunction that diminishes overall surface area will affect carbon dioxide transfer before other oxygenator functions. Therefore, carbon dioxide transfer is a very sensitive measure of loss of functioning membrane surface area in the device.

Water vapor at a temperature of $37^{\circ} \mathrm{C}$ passes through silicone polymer membranes at a rate corresponding to 5 to $10 \mathrm{~mL}$ liquid water: $\mathrm{m}^{2}$ of 4-mil membrane/hr. This water loss has two important consequences: 1) the patient on prolonged support may lose a significant amount of water each day through the membrane lung; and (2) the water vapor that leaves the blood at $37^{\circ} \mathrm{C}$ condenses and may fill compartments in the cooler gas phase, blocking ventilation and resulting in areas of decreased gas exchange. The gradient for water vapor transfer can be decreased by humidifying the ventilating gas, and the dew effect can be minimized by warming the ventilating gas. These steps are not necessary with solid silicone rubber membrane lungs, but are important when using microporous devices. 


\section{Pathophysiology of Membrane Lungs}

Like the biologic lung, the membrane lung is subject to pulmonary edema, ventilation/perfusion imbalance, pulmonary embolism, and several other abnormalities of function. Most of these potential malfunctions are illustrated in Figure 11 and can be diagnosed by measuring changes from the normal state in oxygen transfer, carbon dioxide transfer, and vascular resistance.

Abnormalities of perfusion in membrane lungs include thrombosis of inlet headers and major distribution ports, minor thromboses within the membrane cells, or blood leak into the gas phase. Thromboses causes a decrease in both oxygen and carbon dioxide transfer, and a major increase in blood flow resistance. Perfusion pressure

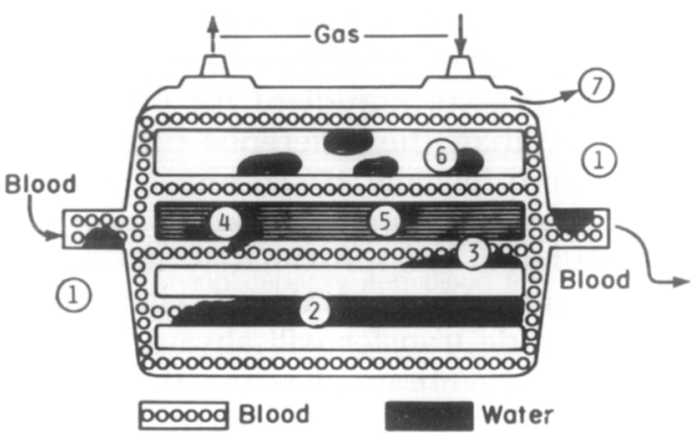

\begin{tabular}{|c|c|c|c|}
\hline BLOOd FlOM OBSTRUCTION & $\Delta 0_{2}$ & $\Delta P$ & $\triangle \mathrm{CO}_{2}$ \\
\hline (1) Major ImLet or OutLet Thrombosis & $\downarrow \downarrow \downarrow$ & $\uparrow \uparrow \uparrow$ & $\downarrow \downarrow \downarrow$ \\
\hline (2) Complete Thrombosis of Individual Cells & $\downarrow$ & $\uparrow$ & $\downarrow \downarrow$ \\
\hline (3) Partial thrombosis of Individual Cells & -- & $\cdots$ & -- \\
\hline \multicolumn{4}{|l|}{ (4) BloOd Leak (May CAUSE (5) or (6)) } \\
\hline \multicolumn{4}{|l|}{ GAS FLOW OBStruction } \\
\hline (5) COMPLETE OBSTRUCTION OF CELL (MATER OR BLOOD) & $\downarrow$ & - & $\downarrow \downarrow \downarrow$ \\
\hline (6) PARTIAL $\left\{\begin{array}{l}\text { VENTILATION } \\
\text { OBSTRUCTION OF CELL (WATER) }\end{array}\right.$ & -- & -- & $\downarrow \downarrow$ \\
\hline (1) Gas Leak (mar cause (6)) & & & \\
\hline \multicolumn{4}{|l|}{ Ventilation Perfusion Imbalance } \\
\hline $\begin{array}{l}\text { (8) Poor Ventilation ((6), (D) in area of High } \\
\text { Flow (due to (1), (2), (3), (4)) or design }\end{array}$ & $\downarrow$ & -. & $\sqrt{ }$ \\
\hline
\end{tabular}

FIG 11.

The mechanisms of membrane lung faiture. 
before and after the membrane lung should be measured during ECLS to detect occlusion in the arterial line or thromboses in the membrane lung. Major inlet header thrombosis is unusual. Minor thromboses occur in all membrane lungs wherever areas of slow flow are inherent in the design of the device. Blood leakage into the gas phase is unusual with modern manufacturing techniques. A pressure relief valve should be included in the ventilating gas line to avoid air embolism if a leak occurs in the membrane.

Abnormalities of ventilation of the membrane lung are caused by accumulation of water or blood in the gas phase. The pathophysiologic characteristic of water accumulation in the gas phase is carbon dioxide retention. Accumulated water becomes fully saturated with oxygen from the ventilating gas so that blood perfusing that cell is still oxygenated. However, the gradient for carbon dioxide clearance is lost as carbon dioxide accumulates in the water. When carbon dioxide clearance is selectively decreased, the sweep gas flow is increased with the intent of blowing out water droplets and avoiding gas phase pressure higher than the blood phase pressure. This technique clears the water and also improves carbon dioxide clearance in the normally functioning cells.

Ventilation/perfusion mismatch can occur if blood is diverted to poorly functioning units while ventilation continues to nonperfused units. It can be seen that the membrane lung functions and malfunctions very much like the biologic lung. However, when the membrane lung malfunctions it is fairly simple to discard and replace, which is the treatment for any of the abnormalities listed above.

\section{Pumps}

A roller pump is used for most circuits. Some measure must be taken to ensure that the pump does not apply suction to the venous catheter. Therefore, the pump should be a passive-filling pump, for two reasons: (1) even a small amount of negative pressure will cause major hemolysis; and (2) the right atrium and superior vena cava may become sucked into the catheter, causing endothelial damage. In cardiac surgery these problems are avoided by including a large blood reservoir into which the venous line drains. A large reservoir is unacceptable for ECLS because the stagnant blood may thrombose and because the extracorporeal circuit must maintain essentially constant volume. The occlusive roller pumps that are usually used for extracorporeal support could generate direct suction on the venous catheter. In practice this problem is avoided by the inclusion of a small collapsible bladder positioned at the lowest point of the venous line. The bladder (or a transducer directly in the venous line) is attached to an electrical switch that slows or stops the roller pump whenever the pressure drops and the bladder collapses, then restarts the pump instantly when the bladder fills again. This system 
has two important advantages: (1) whenever the bladder collapses or the pump stops, the suction effect of the siphon between the patient and the level of the bladder stops, avoiding any direct suction on the right atrium; and (2) because the pump motor is turned off whenever the bladder is collapsed, the pump cannot generate negative pressure in the blood between the pump and the bladder. Thus, the bladder and electrical switching mechanism provide servoregulation and a measure of safety for prolonged perfusion with a roller pump. The pump is adjusted to provide the desired level of gas exchange or cardiac support. As long as the venous drainage is adequate the bladder remains distended and the desired flow is delivered. If venous drainage is impeded for any reason (hypovolemia, pneumothorax, kinking of the venous catheterl the pump stops and an alarm sounds. Flow resumes as soon as venous drainage is reestablished. Early in the course of extracorporeal circulation, flow is increased to the point where the bladder collapses, thus identifying the physical limitation of venous drainage for the system. This flow rate is usually considerably greater than the flow actually required for extracorporeal support. However, if maximal flow through the system is inadequate after making optimal the volume status and the siphon, another venous catheter must be added to gain more flow.

A pumping system that has all the advantages of the servoregulated roller pump without the extra bladder and hardware is the passively filling Rhone Poulenc pump (Collin Cardio, Paris). It is used by Durandy and Chevalier for extracorporeal support, as well as for cardiac surgery. ${ }^{1+2}$ This unique pump uses a flaccid but distensible silicone rubber tube that is stretched over rollers without a raceway to push against. The pumping chamber fills passively, allowing the generation of flow and pressure. However, if the venous drainage is inadequate the pumping chamber simply collapses without generating negative pressure. As the pumping chamber becomes more round the amount of pressure generated reaches a plateau at about $400 \mathrm{~mm} \mathrm{Hg}$, so that flow decreases above this pressure and arterial line blowouts cannot occur.

Centrifugal pumps, in which a spinning rotor generates flow and pressure, should be ideal for prolonged extracorporeal circulation. ${ }^{143}$ At low flow, centrifugal pumps work very well, but these pumps can generate significant negative pressure whenever the venous drainage is impaired, causing extensive hemolysis. Although centrifugal pumps have been used for prolonged support the potential for hemolysis heating and thrombosis makes them less desirable than other pumps.

\section{Catheters and Tubing}

From the above discussion it can be seen that both building and monitoring the ECLS circuit requires a knowledge of the pressure, 
flow, and resistance characteristics of each of the blood conduit components. Although these relationships can be calculated for straight tubes of known diameters, most of the access catheters have irregular diameters and side holes that require individual characterization. Our group has recently described a standard system for describing pressure flow relationships in blood access devices that we have called the " $M$ number." ${ }^{\text {4.4 }}$ If the $M$ number for a specific catheter is known then the pressure and flow over the full range of use can be determined from the nomogram (Fig 12). If a given combination of pressure and flow is required, then reference to the nomogram will identify the corresponding $\mathbf{M}$ number. Any catheter or combination of catheters with a smaller $M$ number will be capable of meeting the conditions. $M$ numbers for some typical devices used for ECLS are listed in Table 2.

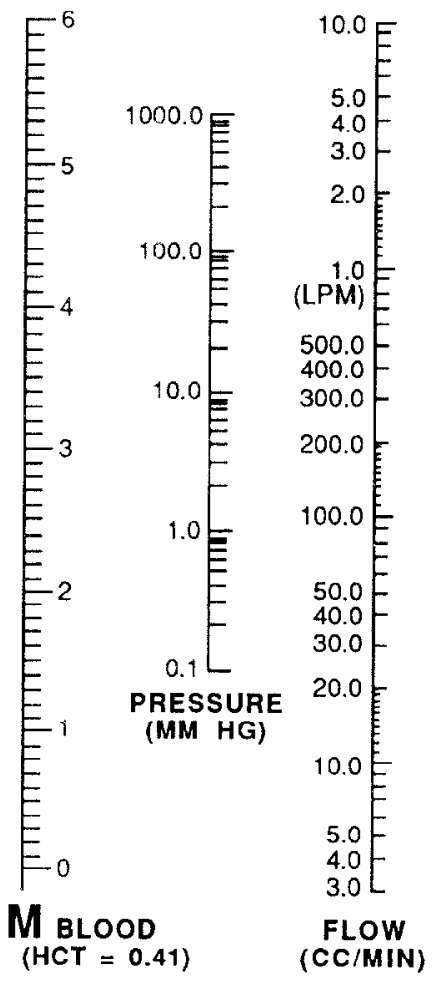

FIG 12.

Nomogram for determining pressure and flow relationships based on the $M$ number (from Montoya JP et al: A standardized system for describing flowipressure relatıonships in vascular access devices. ASAIO Trans 1990, in press). 
TABLE 2.

M Number for Different Tubing and Catheters in FCLS

\begin{tabular}{|c|c|c|}
\hline Catheter & Sizet & M Number \\
\hline 'lubing, $1 \mathrm{~m}$ & $3 / 16$ in., 4.5 mm ID & 4.2 \\
\hline Tubing, $1 \mathrm{~m}$ & $1 / 4 \mathrm{in} ., 6 \mathrm{mim} \mathrm{ID}$ & 3.1 \\
\hline Tubing, $1 \mathrm{~m}$ & $3 / 8$ in., $9 \mathrm{~mm}$ (1) & 2.0 \\
\hline Elecath arterial & $10 \mathrm{~F}$ & 4.1 \\
\hline Biomedicus arterial & $10 \mathrm{~F}$ & 4.0 \\
\hline Cook arterial & $20 \mathrm{~V}$ & 3.25 \\
\hline DLP arterial & $21 \mathrm{r}$ & 2.65 \\
\hline Elecath venous & $11 \mathrm{~F}$ & 3.7 \\
\hline Biomedicus venous & $12 \mathrm{~F}$ & 3.55 \\
\hline Cook venous & $28 \mathrm{I}$ & 2.65 \\
\hline DLP venous & $21 \mathrm{~F}$ & 3.05 \\
\hline
\end{tabular}

\section{Heat Exchangers}

Because heat is lost in evaporation of water through the membrane lung it is essential to take steps to warm the circuit for the patient. Usually this is done with an in-line blood heat exchanger. Under operating conditions for prolonged support this will always function as a blood warmer. The Sci-Med tubular stainless steel heat exchanger is usually used for ECLS. This is a long narrow device that is placed in the circuit after the membrane lung. When mounted vertically it serves as a macro-bubble trap and warms the blood to normal temperature just before perfusion into the patient. It should be noted that the heat exchanger in cardiac surgery extracorporeal circulation is usually placed before the artificial lung, so that gas bubbles do not "boil" out of solution during rapid blood warming. During ECLS in infants it is important to place the heat exchanger as the last component of the circuit before blood goes into the patient to maintain babies at normothermia. For larger children and adults the placement of heat exchanger (or even the presence of a heat exchanger) is less important.

\section{CANNULATION}

While the circuit is being primed, vascular access cannulas are placed. For the reasons outlined above we would always use the right internal jugular vein as the location of choice for venous access. The largest internal diameter, shortest catheter (i.e., lowest $\mathrm{M}$ number) that can be placed into the jugular vein will usually permit the desired blood flow. If venoarterial circulation is to be used, the right common carotid artery is the vessel of choice because it is 
large enough to accept a large arterial catheter and provide flow directly into the aortic route. Both the jugular vein and carolid artery are ligated distally. Both arterial and venous collateral circulations are adequate in almost all patients. The carotid artery provides excellent access in children and adults. The adequacy of brain collateral circulation is tested by observing left sided motor and sensory function during temporary occlusion. If venovenous access is used for respiratory support, the perfusate blood can be returned directly to the jugular vein catheter using the tidal flow system ${ }^{122,123}$ or it double-lumen catheter. ${ }^{145}$ Alternatively the perfusate can be returned to any large systemic vein. Usually the femoral vein is catheterized by way of the saphenous bulb. It is tempting to use the umbilical vein in neonates, but this usually results in portal hypertension and ascites in full-term newborn infants.

Because of the importance of introducing the largest possible access catheters, cannulation is usually done under direct vision using local anesthesia. Percutaneous access using the Seldinger technique is an acceptable alternative if very large catheters can be introduced. By using sequentially larger dilators placed over a spring wire, peelaway sheath introducers or the access catheters themselves can be introduced into large arteries and veins. The jugular vein is the preferred access site for the percutaneous approach because it is large and short, but the femoral vein can also be used. When the femoral vein is used the $M$ number of the access catheter will be higher and suction may be required to gain adequate venous return. Suction will result in hemolysis, so femoral access is limited to low flow extracorporeal circulation. If venovenous bypass is used the venous return line can be introduced by the percutaneous technique. ${ }^{146}$ Double-lumen catheters for simultaneous drainage and reinfusion into the venous system have been used by direct cutdown ${ }^{145.1 .4}$ and eventually may be placed by the percutaneous method. The diameter of the arterial catheter is less important than that of the venous catheter and percutaneous entry into the femoral artery is fairly easily accomplished. Percutaneous access into the carotid artery is not recommended because of the risk of distal embolization.

\section{MONITORING}

During ECLS several factors must be monitored in addition to patient vital signs, blood gases, and ventilator settings. Blood flow is monitored continuously, usually by counting rpm on the roller pump. Although routinely used, this method of measuring flow can be grossly in error if the rollers are not occlusive or if the tubing is not round. Pressure should be monitored on the arterial side of the circuit, preferably before and after the membrane lung. An increas- 
ing pressure gradient across the membrane lung suggests thrombosis. The expected postoxygenator pressure should be predicted for any given flow based on the $M$ number of the return catheter. If the pressures are higher than expected then the arterial line or catheter is kinked or occluded. The most important parameter is continuous monitoring of mixed venous saturation (see Fig 5). This is measured by placing an Oximetrix fiberoptic catheter through a valved adapter into the venous line. Since venous drainage blood represents a mixture of superior vena cava, inferior vena cava, and coronary sinus blood, the $\mathrm{Svo}_{2}$ is an accurate representation of the $\mathrm{Do}_{2} \mathrm{No}_{2}$ ratio during venoarterial bypass. With venoarterial bypass, when $\mathrm{Svo}_{2}$ is in the range of $75 \%$ and all aspects of perfusion are going well, it is not necessary to measure systemic or circuit blood gases more frequently than every 8 hours or so. If the system includes a transcutaneous oximeter and an on-line $\mathrm{PCO}_{2}$ monitor, sampling of blood for gas analysis is rarely necessary. During venovenous bypass the mixed venous saturation is elevated because of recirculation. With venovenous bypass the intent is to maintain the venous saturation as high as possible, usually between $85 \%$ and $90 \%$. If the cardiac output is normal this level of saturation will be sufficient to maintain normal systemic oxygen delivery. When $\mathrm{SvO}_{2}$ is combined with transcutaneous oximetry in the venovenous patient, the adequacy of extracorporeal support and the amount of lung function can be assessed simultaneously. Measurement of end tidal carbon dioxide at the airway is another helpful monitor of native lung function. During the early days of an ECLS run, end tidal carbon dioxide may be 5 $\mathrm{mm} \mathrm{Hg}$ or less. As functioning lung units resume ventilation, or as pulmonary blood flow to ventilated units increases, end tidal carbon dioxide will increase. When end tidal carbon dioxide is near normal (over $35 \mathrm{~mm} \mathrm{Hg}$ ) a trial of weaning should be considered. The status of anticoagulation is monitored by measuring whole blood ACT hourly. The platelet count is measured every 8 to 12 hours.

\section{MANAGING THE PATIENT ON EXTRACORPOREAL LIFE SUPPORT}

The blood flow is set at a level that will provide total oxygen and carbon dioxide exchange, and mechanical ventilation is reduced to minimal or lung rest settings. Patient arterial blood gases are checked and continuous monitors are calibrated. Thereafter, venous saturation is maintained at the desired level by increasing or decreasing extracorporeal blood flow. $\mathrm{PaCO}_{2}$ is maintained around 40 $\mathrm{mm} \mathrm{Hg}$ by adjusting the flow rate and composition of sweep gas. Systemic blood pressure is maintained at the desired level by adjusting blood volume. Hemoglobin is maintained between 14 and $15 \mathrm{~g} /$ dL. Platelet count is maintained greater than 75,000 and ACT is 
maintained at approximately 200 seconds. A major decrease in venous saturation without any change in the other settings is usually caused by an increase in metabolic rate, which may be transient (during crying or seizures) or sustained. A sustained increase in metabolic rate can be matched by an increase in blood flow, or treated with sedation, paralysis, and/or hypothermia. A major increase in venous saturation without a change in other settings is usually caused by a decrease in metabolic rate or the onset of native lung function. Sudden decrease in venous drainage may be caused by hypovolemia, catheter kinking or malposition, pneumothorax, or pericardial tamponade. Gradual decrease in systemic oxygenation or increase in $\mathrm{PaCO}_{2}$ may be a sign of deteriorating membrane lung func:tion. Membrane lung function is assessed by measuring oxygen and carbon dioxide transfer and comparing the results to the expected transfer at that level of blood flow and carbon dioxide gradient. If membrane lung is deteriorating a new lung should be inserted. "This is rarely necessary.

\section{PATIENT CARE ON EXTRACORPOREAL LIFE SUPPORT}

The patient is alert and awake with mild analgesia and sedation during ECLS. The attending nurse has an essential role in calmly and pleasantly reassuring the patient while constantly guarding against position or movements that might dislodge or kink the access lines. Keeping the patient clean, dry, and comfortable, keeping the room orderly, clean, and free of traffic, and helping distraught family members adjust to the unfamiliar and frightening scene are important considerations.

Despite the many vascular intrusions, systemic sepsis is successfully avoided by cleaning catheter access sites daily with antiseptic: solution and cleaning and replacing stopcocks and infusion tubing at regular intervals.

Because of heparinization no intramuscular injection should be given and traumatic procedures like tracheal suctioning must be done very carefully.

Nutrition is provided from the onset of ECLS through the parenteral route. Full caloric and protein support is given based on measured requirements. Although it is possible to use the stomach and intestine for feeding, we avoid relying on the gut for full nutrition because paralytic ileus for necrotizing enterocolitis in the newborn may occur, complicating enteral feeding. Small amounts of tube feeding into the stomach are desirable to avoid low gastric pH and to maintain intestinal muscosal integrity. The patient is weighed daily, and if the patient is more than $5 \%$ above baseline weight diuretics or hemofiltration are instituted until the extra cellular fluid 
volume is normal. Patients on ECLS are often quite edematous as a result of resuscitation prior to extracorporeal support. The lung recovers more quickly once edema has been eliminated.

Since the patient is no longer dependent on the ventilator, endotracheal tubes can be removed and changed at will, bronchoscopy can be done safely for indefinite periods of time, and endotracheal bronchial lavage can be done without limitation. ${ }^{148-150}$ Extensive air lcaks can be diminished by lowering ventilator pressure. A novel approach to this problem has been reported by Ratliff, ${ }^{151}$ who used a bronchoscope to selectively occlude the bronchus leading to the leaking segment. A radioopaque occlusive plug is introduced through the bronchoscope, allowing segmental collapse until the air leak seals. It is important to remember that perfusion and gas exchange are maintained by the extracorporeal circuit. The usual reflex to respond to blood gas abnormalities with changes in ventilator settings needs to be "unlearned" by members of the intensive care unit tearn.

Cardiac catheterization and angiography are facilitated by ECLS support, particularly in children. With contrast injected through the bypass catheters congenital anomalies can be identified and the size and patency of the ductus arteriosus can be seen. Cardiac imaging is best done by echocardiography, ${ }^{152}$ with catheterization and angiography reserved for the definitive diagnosis of total anomalous pulmonary venous drainage if echocardiography findings are equivocal.

Major surgical procedures can be done on ECLS patients, provided that the platelet count is increased, the ACT is decreased, and blood transfusion is available. During operations isuch as ligation of the ductus arteriosus, repair of congenital diaphragmatic hernia, or abdominal exploration for acute inflammation) careful attention is paid to hemostasis, including liberal use of electrocautery, avoidance of incisions into the muscle or periosteum wherever possible, and placement of suction drains to monitor postoperative bleeding. These precautions must be applied to simple operations such as tracheostomy or chest tube placement as well as to major procedures.

\section{WEANING AND DECANNULATION}

Indicators of lung recovery include increasing $\mathrm{V}_{\mathrm{sal}}, \mathrm{PaO}_{2}$, or decreasing $\mathrm{PaCO}_{2}$ without changing ventilator or ECIS settings; increased $\mathrm{VO}_{2}$ or $\mathrm{VCO}_{2}$ measured via the airway; increasing compliance; and clearing chest $x$-ray. Indicators of cardiac recovery include increasing $\mathrm{SvO}_{2}$ without a change in $\mathrm{VO}_{2}$ or other parameters; increasing pulse contour; and improving contractility detected by echocardiography.

When native lung or cardiac function improves, extracorporeal 
flow is gradually decreased, allowing the native lung to carry more of the load. When $70 \%$ to $80 \%$ of the gas exchange is occurring via the native lung (i.e., the extracorporeal flow rate is $20 \%$ to $30 \%$ of the initial flow rate) the patient should be tried off bypass at moderate ventilator settings. In venoarterial bypass the tubing leading to the patient is clamped, permitting continuing circulation through a bridge. If gas exchange and perfusion are adequate the catheters can be removed, usually after another period of low flow bypass to be sure that lung function will be maintained. In venovenous bypass a trial off bypass consists of capping off gas flow to the membrane lung but continuing extracorporeal flow. With this arrangement the venous saturation monitor becomes a useful guide to the adequacy of systemic oxygen delivery during the trial off bypass.

Using these simple physiologic principles of management, extracorporeal circulation can be maintained in the absence of pulmonary function for 1 to 6 weeks.

\section{EXTRACORPOREAL LIFE SUPPORT TEAM}

Extracorporeal life support should not be undertaken without extensive laboratory training and experience. Experts in operating room extracorporeal circulation, such as perfusionists and cardiac surgeons, are not trained or equipped to manage ECLS. Most of the active life support centers have found that a team consisting of a specially trained nurse, engineer, and perfusionist is necessary to manage this procedure. ${ }^{153}$ These ECMO technical specialists are specially trained individuals who come from a background in medicine, nursing, perfusion, or respiratory therapy. The usual training course includes 50 to 100 hours of training before the specialist is certified to manage ECLS patients. A trained ECLS specialist can manage all the details of patient care, including blood sampling, blood product and drug infusion, management of the extracorporeal perfusion, ventilator, inotropes, and heparin dose. The major job of the specialist is to control and regulate blood flow and anticoagulation, but the major responsibility of the specialist is to diagnose and manage patient and circuit emergencies that might arise. Because a circuit emergency (such as electrical failure, membrane lung failure, or circuit disruption) can be lethal within seconds, the ECLS specialist must have both the knowledge and the equipment to replace any component of the circuit quickly and accurately. Extracorporeal life support management is carried out under physician supervision, but it is not necessary for the physician to be in continuous attendance at the bedside or even in the hospital. 


\section{CLINICAL APPLICATION}

The basic principles of prolonged extracorporeal circulation have been defined in the preceding sections. In clinical application the technique and results vary considerably depending on the diseases and patient groups studied. We will discuss clinical application in three areas: respiratory failure in newborn infants, respiratory failure in older children and adults, and cardiac failure. Monitoring and technical management apply to all of these patient groups. These discussions will present representative examples, report on clinical experience, and focus on technical details unique to that particular patient group.

\section{NEWBORN RESPIRATORY FAILURE}

Over 4,000 infants have been treated with ECLS. There are more than 60 neonatal centers offering ECLS as standard treatment. Currently the treatment is used for moribund infants, with $83 \%$ survival overall and 90\% survival in most experienced centers. ${ }^{88}{ }^{154-156}$ The incidence of pulmonary or neurologic handicap (approximately $20 \%$ I is lower than that of other neonatal intensive care unit graduates. Two prospective randomized studies have demonstrated the effectiveness of ECLS in newborn infants. The study mentioned earlier by the Michigan group, ${ }^{82}$ and the more recent study by O'Rourke et al. ${ }^{86}$ from Boston Children's Hospital both used adaptive designs to make optimal the statistical significance while minimizing the ethical problems of a prospective randomized study in which death is the end point. Both of these studies prove that survival was better

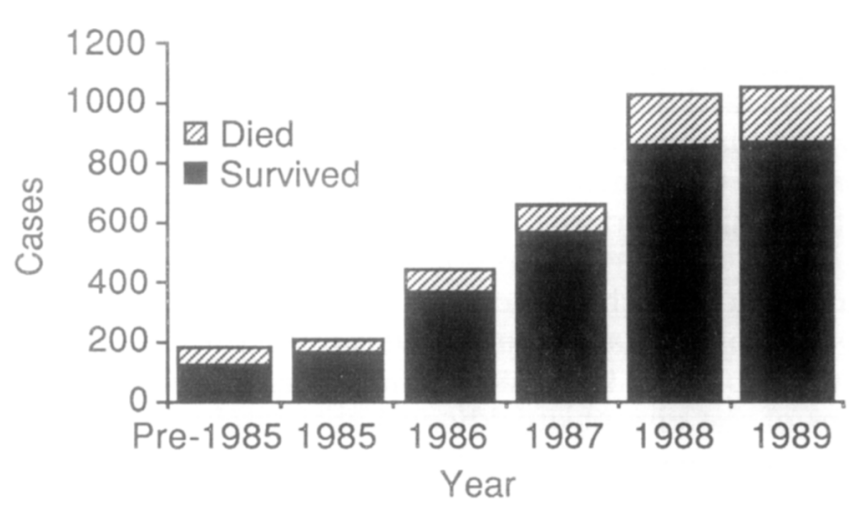

FIG 13.

Extracorporeal life support for newborn respiratory failure in the last decade. 
with ECLS than with conventional ventilation techniques in term and near term infants with respiratory failure. ${ }^{157,}{ }^{158}$ Two other studies have documented an overall decrease in hospitalization and expense when ECLS is used in neonatal respiratory failure. Thus, although ECLS is the ultimate example of high-tech labor and resource-intensive, expensive invasive procedures it routinely results in healthy children at less cost, resource utilization, and morbidity than the previous conventional treatment. As mentioned previously, the centers using ECLS have joined together to form the Extracorporeal Life Support Organization (ELSO). This organization maintains a registry of ECLS cases done in children that can be used to document growth of the technology and the current state-of-the-art. Extracorporeal life support centers are listed in the Appendix. The growth of neonatal cases is shown in Figure 13.

\section{Patient Selection: Mortality Criteria, Indications, and Contraindications}

Persistent pulmonary hypertension of the newborn (PPHN) is the major pathophysiologic mechanism of respiratory failure in the fullterm newborn regardless of the underlying disease process. ${ }^{159}$ The pulmonary vasculature of the neonate is prone to respond to such factors as hypoxia, hypercarbia, and acidosis with vasoconstriction. ${ }^{160}$ Increased pulmonary vascular resistance may result in a right-to-left shunt through the ductus arteriosus and foramen ovale. This serves to exacerbate the hypoxic and acidotic state, resulting in further elevation in the pulmonary vascular resistance. $A$ vicious cycle is established that can usually be broken through the use of paralysis, mechanical ventilation, induced respiratory alkalosis, and pharmacologic therapy. ${ }^{161}$ The results of ventilator treatment are generally excellent. However, $2 \%$ to $5 \%$ of neonates fail to respond. Wung et al. ${ }^{162}$ indicate that, paradoxically, this may be directly related to the use of high-pressure ventilation. Although high-pressure ventilation may result in a rise in $\mathrm{PaO}_{2}$, it may simultaneously lead to a decrease in venous return and cardiac output, resulting in a deterioration in overall oxygen delivery. In addition, several studies have demonstrated that bronchopulmonary dysplasia (BPD) is related to barotrauma from high airway pressures and to loxicity from high oxygen concentrations. ${ }^{16: 3-16: 5}$ in these newborns with PPHN, as well as those with diseases of the pulmonary parenchyma, ECLS can be lifesaving by allowing reversal of the cvele of increasing pulmonary hypertension, by minimizing the complications of high-pressure mechanical ventilation, and by "buving time" to allow the pulmonary pathology to resolve and the lung to heal, ${ }^{166^{6}}$

In the early neonatal ECLS trials, moribund infants were judged to be unresponsive to ventilator and pharmacologic therapy by the neonatologist. ${ }^{70,72}$ The desire for a more objective evaluation of neo- 
natal mortality in respiratory failure led to development of methods to define mortality risk. ${ }^{167}$ Krummel et al. explored the use of the postductal $(\mathrm{A}-\mathrm{a}) \mathrm{O}_{2}$ gradient $\left(\mathrm{AaDo}_{2}\right)$, demonstrating that an $\mathrm{AaDo}_{2}$ of $600 \mathrm{~mm} \mathrm{Hg}$ or above despite 12 hours of maximal medical management identified a mortality of $94 \%$ while excluding only $12 \%$ of subsequent deaths. ${ }^{168}$ Beck et al. found that an $\mathrm{AaDo}_{2}$ of 610 or more for 8 hours defined a $79 \%$ mortality risk. ${ }^{169}$

Some centers are currently utilizing the $90 \%$ mortality criteria determined in the prospective, randomized ECLS neonatal trial to determine indications for ECLS. ${ }^{82}$ These criteria were useful for that study in 1982, but are too cumbersome and outdated for general use. We are currently using the oxygenation index (OI), which is based on arterial oxygenation and mean airway pressure and is computed by the following formula ${ }^{170}$ :

$$
\mathrm{OI}=\text { mean airway pressure } \times \frac{\mathrm{FIO}_{2} \times 100}{\mathrm{PaO}_{2}}
$$

In our neonatal intensive care unit a value consistently greater than 25 defines $50 \%$ mortality and over 40 defines an $80 \%$ mortality. ${ }^{157}$

We currently consider ECLS in an infant with an OI consistently over 25, and we use ECLS if improvement does not occur or if the OI reaches 40 .

In addition to defining the mortality in high-risk neonates, one would also wish to identify and exclude those newborns with no reasonable chance of recovery with ECLS support. The initial trials in neonatal ECLS were plagued with episodes of intracranial bleeding. $^{72,73,89}$ Thirty-five percent of patients developed intracranial hemorrhage, with a resulting $94 \%$ mortality. ${ }^{171}$ In a retrospective study Cilley demonstrated that estimated gestational age (EGA) greater than 34 weeks was the single most important factor in avoiding intracranial hemorrhage and poor uutcone on ECMO. ${ }^{17}$ Extracorporeal membrane oxygenation does not appear to alter the incidence of intracranial hemorrhage, but it may influence the severity and location of the bleeding secondary to heparinization. ${ }^{172.173}$ We currently consider EGA below 35 weeks or any intracranial hemorrhage detected by cranial ultrasound to be a relative contraindication to ECMO ${ }^{171}$ It should be noted, however, that some centers are having success in treating neonates with a grade I hemorrhage by using high flow, low anticoagulation ECMO. In a pilot program, we have returned to the evaluation of ECLS in premature ( $<35$ weeks') infants, with good preliminary results. Other contraindications to ECMO support include profound neurologic impairment, congenital anomalies or conditions not compatible with a meaningful life, and irreversible lung disease such as severe BPD. Mechanical ventilation 
for more than 7 days is a relative contraindication while over 10 days is an absolute contraindication because of the high incidence of BPD and irreversible lung disease. The exception to this rule is the occasional patient who has reversion to persistent fetal circulation (PFC) a number of days or weeks after an initial episode of PFC. In patients with congenital diaphragmatic hernia, the absence of a "honeymoon period," which would be defined by a postductal $\mathrm{Pao}_{2}$ greater than 70, is considered evidence of irreversible pulmonary hypoplasia and therefore a relative contraindication to ECLS. ${ }^{174}$ However, some patients with no "honeymoon" have recovered normal lung function, so the contraindications to ECLS in patients with diaphragmatic hernia are controversial. Finally, patients with major cardiac anomalies should be treated operatively, although they may be supported with ECMO until surgical intervention can be accomplished. A cardiac echocardiogram and a cranial ultrasound are performed on each child before consideration for ECLS.

\section{Technique in the Newborn}

The total circuit volume for newborn extracorporeal circulation ranges from 300 to $400 \mathrm{~mL}$ according to the size of the membrane lung selected. The circuit volume may be 1 to 2 times that of the baby so it is important that the prime be adjusted as close to normal as possible. Hypocalcemia, acidosis, and hyperglycemia may result if the prime is not carefully prepared. The blood prime mixture includes 1 unit of packed red cells, 1 unit of fresh frozen plasma, 50 $\mathrm{mL}$ of platelet concentrate, tromethamine, heparin, and calcium gluconate.

The umbilical vessels would seem to be the ideal access site since the infants have been sustained by arteriovenous perfusion of the placenta for the past several months. Unfortunately, the umbilical vessels cannot supply adequate blood flow for complete cardiopulmonary support. The initial ECMO trials by Dorson ${ }^{44}$ and White ${ }^{4.5}$ used this approach, and showed that respiratory support would be adequate for premature infants. The extracorporeal circuit must be capable of providing complete respiratory and hemodynamic support. Bypass is instituted by cannulation of the right internal jugular vein for venovenous access and right common carotid artery for venoarterial access. The right internal jugular vein is a large vessel in the newborn and can be ligated with impunity. Care must be taken to avoid occluding the opposite jugular, which could lead to increased intracranial venous pressure. The carotid arteries are the only vessels close to the aortic arch that can accommodate large catheters. Both vessels are left ligated after ECLS because the risk of thrombus formation and embolization from debrided intima outweighs any theoretical benefit of repair. For the past 2 years we have 
used a double-lumen catheter for venovenous access, eliminating problems related to carotid artery ligation. ${ }^{147}$

Cannulation is done under local anesthesia in the intensive care unit. After exposure of the internal jugular vein and common carotid artery, the infant is loaded with heparin $(100-150 \mathrm{units} / \mathrm{kg})$. The vessels are ligated distally and controlled proximally by vascular clamps. Prolene stay sutures are placed in the carotid artery to pre-
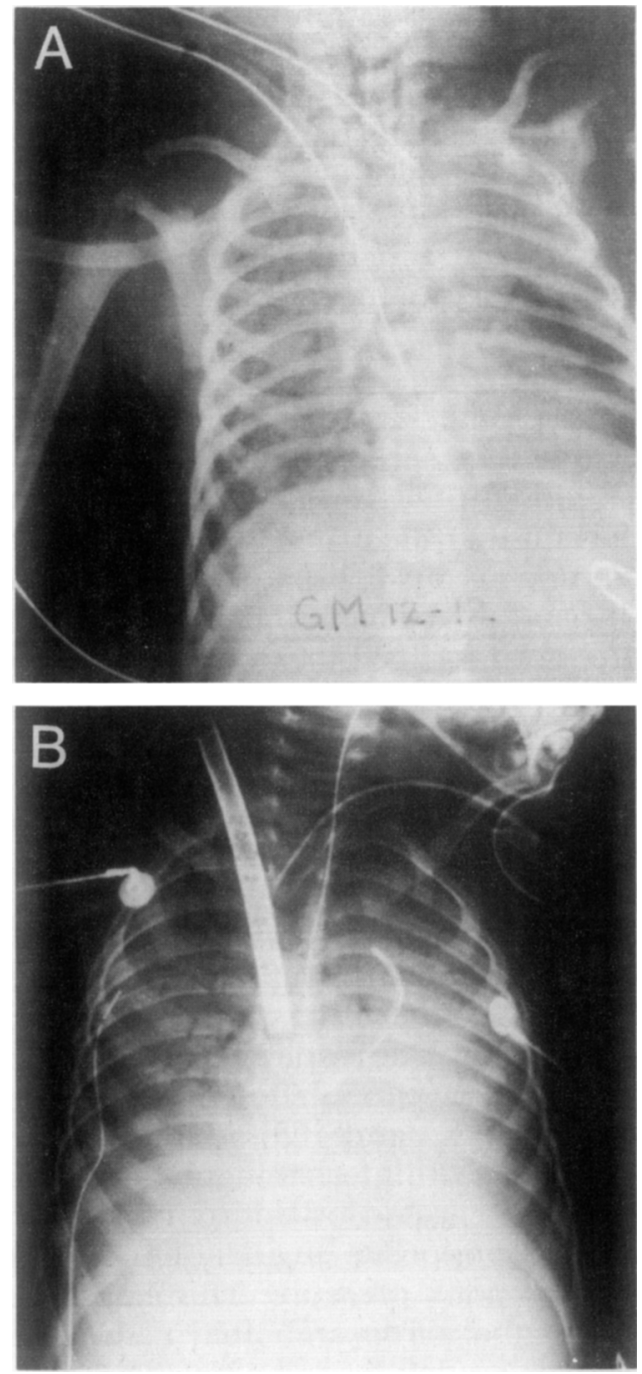

FIG 14.

Chest $x$-rays during ECLS in newborn infants showing typical placement of catheters for (A) venoarterial bypass, and (B) single catheter double-lumen venovenous bypass. 
vent intimal dissection. The catheters are double tied and proper position is verified by chest $x$-ray (Fig 14). A typical case is described in Figure 15.

When beginning bypass, it is important to slowly mix the blood prime into the patient by gradually increasing the extracorporeal flow rate over 5 to 10 minutes. Reaching maximum blood flow over this time reduces hemodynamic instability and provides a steady Iransition to extracorporeal support. Flow is increased to maximum level to determine the capability of the system, then decreased to approximately 100 to $120 \mathrm{cc} / \mathrm{kg} / \mathrm{min}$. Supportive drugs can be weaned. At the same time, the ventilator can be reduced to nontraumatic settings, typically $\mathrm{F}_{1} \mathrm{O}_{2} .21$ to 4 , peak inspiratory pressure (PIP] positive end-expiratory pressure (PEEP) 20/4 and a rate of 10. During

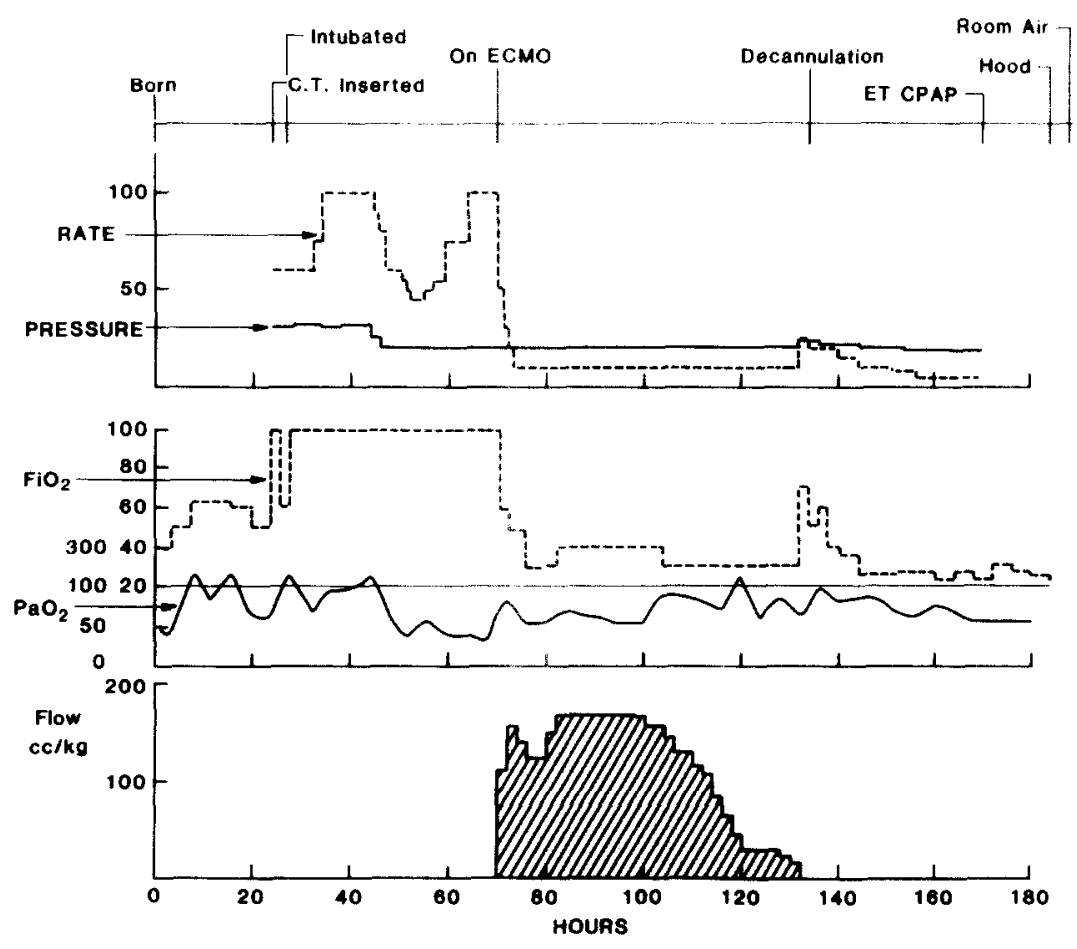

FIG 15.

Physiologic characteristics during a typica! neonatal ECMO case of persistent fetal circuIation. Initially there is a good response to conventional management but at 65 hours profound hypoxia persists despite maximal treatment. When the baby is started on ECMO ventilator settings are decreased to lung rest levels. After 2 days it is possible to wean the flow as lung blood flow improves. Shortly atter ECMO the patient is extubated, and discharged. $\mathrm{CT}=$ chest tube; $\mathrm{ET}=$ endotracheal tube. 
venoarterial bypass flow is regulated to maintain the $\mathrm{PaO}_{2}$. The best indicator of adequate perfusion is a mixed venous saturation greater than $70 \%$, which can be measured in the venous drainage blood. With venovenous bypass the venous saturation is typically $85 \%$ to $90 \%$ and the $\mathrm{PaO}_{2}$ is 45 to $55 \mathrm{~mm} \mathrm{Hg}$.

The patient's hemodynamic and fluid balance remains stable, even though the extracorporeal blood volume is usually much larger than that of the patient. Large membrane oxygenators increase platelet consumption, so it is ideal to select an artificial lung that will provide adequate gas transfer with the least amount of surface area to minimize the blood surface interaction. This is particularly true in newborn infants where the bone marrow platelet producing abilities are overshadowed by the relatively large surface area of the extracorporeal circuit. Arterial pressure is monitored continuously from a peripheral artery, usually the umbilical, left radial, or tibial artery. Blood volume is adjusted to maintain normal blood pressure.

Initially, the neonate may have a consumption coagulopathy from preexisting hypoxia, acidosis, sepsis, or poor perfusion. The heparin requirements to maintain $A C T$ at $200 \pm 2$ seconds range from 30 to 80 units $/ \mathrm{kg}$. Platelets are transfused when the count drops below $100,000 \mathrm{~mm}^{3}$. In neonates, usually 1 or 2 units of platelets per day are required to maintain adequate platelet levels. Platelet consumption varies and is usually a function of oxygenator size and the presence or absence of sepsis, bleeding, or multiple exchange transfusion. ${ }^{134}$ Packed red blood cells are given to maintain the hematocrit between $40 \%$ and $50 \%$. Fresh frozen plasma or albumin is transfused when the patient's hematocrit exceeds $50 \%$ and blood volume expansion is indicated.

\section{Patient Care}

Since the patient is no longer dependent on the mechanical ventilator for support, pcrcussion, postural drainage, suctioning, or lavage can be used without limit. The patient can be placed on continuous positive airway pressure (CPAP) or even extubated. The endotracheal tube can be changed without urgency. The chest $x$-ray at 24 hours often shows no aeration, and the patient is totally supported by the circuit. Keszler has presented a convincing study showing that alveolar inflation is maintained and recovery is facilitated by using 10 to $15 \mathrm{~cm} \mathrm{H}_{2} \mathrm{O}$ PEEP. ${ }^{175}$ Lung recovery usually occurs over the next few days and the chest $x$-ray gradually improves, normal aeration occurs, compliance improves, and gas exchange begins. The pump flow can be weaned gradually, based on pulse oximetry and mixed venous saturation. Prior to decannulation the pump is usually set at an "idle" flow of $50 \mathrm{cc} / \mathrm{min}$ (10\% cardiac outpul) for 6 hour's in order to ensure the patient is ready for decannulation. An infant can be tried off the extracorporeal system by clamping the arterial 
and venous lines above the bridge and allowing the blood to recirculate. When the patient is taken off bypass, the ventilator is adjusted to moderate settings to allow for adequate lung expansion and gas exchange. Test periods off bypass are used to study the improvement of the lung during ECLS. On venovenous bypass, a trial off bypass is accomplished by turning off gas flow to the membrane lung.

Surgical procedures can be conducted as long as principles outlined earlier are followed. During thoracotomy or ligation of a patent ductus arteriosus, platelets are transfused prior to operation and the ACTs are lowered to 180 seconds. Excessive bleeding may require reexploration at incision sites, but usually this is minimized if electrocautery and fibrin glue are used. Acute renal insufficiency can be treated with dialysis, but hemofiltration is preferred to augment renal output and to manage fluid overload. ${ }^{176}$ Infants who present for ECLS are usually edematous from the initial treatment. Diuretics (typically furosemide and mannitol) are given until the patient has returned to birth weight. Daily patient weight is the best measure of fluid status. Total parenteral nutrition is begun within 24 hours. No feedings are given into the gastrointestinal tract for the first 2 weeks of life in order to minimize the likelihond of necrotizing enterocolitis.

\section{Complications}

The complications of ECLS fall into three major categories: (1) bleeding associated with heparinization; (2) mechanical problems; and (3) sequelae of the hypoxia and hemodynamic instability that occurred before the onset of bypass.

Because of systemic heparinization, bleeding complications are the most common. Intracranial bleeding is the most feared of all ECLS complications. The overall incidence of intracranial hemorrhage in our first 100 newborns was $29 \%{ }^{89}$ Intracranial hemorrhage has occurred in only 4 of the last 100 ECLS patients in our series. Some abnormal bleeding, such as oozing from the cannulation site. occurs in almost all patients on ECLS. However, major bleeding complications other than intracranial hemorrhage occur in about $10 \%$ of cases. This includes pericardial tamponade, postoperative intrathoracic bleeding, gastrointestinal bleeding, and retroperitoneal hemorrhage. Bleeding is managed by lowering the ACT to approximately 180 seconds and by ensuring that the platelet count is greater than 100,000 . If tolerated by the patient, ECLS support may be temporarily discontinued with reinstitution of full ventilator support. The ACT is allowed to normalize for 1 to 2 hours before return to bypass. If the bleeding persists at a significant rate in spite of these manipulations, aggressive surgical intervention or discontinuation of ECLS support is indicated. ${ }^{1}$

Technical complications occur in one third of all patients. ${ }^{74,88} \mathrm{OX}-$ ygenator failure occurred in $20 \%$ of our early cases ${ }^{89}$ but is rare 
now. Other technical complications included malfunction of the heat exchanger, electrical or mechanical pump failure, and tubing leak or rupture. In our own experience, 3 patients had complications related to cannula placement or removal, resulting in 2 deaths. Otherwise, there was no resulting mortality from a technical complication, although temporary physiologic instability was often observed until the problem could be corrected.

Neonatal venoarterial ECMO is routinely performed via right internal jugular vein and carotid artery access. The common carotid artery is ligated during cannulation and no attempt is made to repair it after decannulation. Collateral flow is established after carotid ligation in neonates and the symptoms of right hemispheric dysfunction have been minimal. ${ }^{89.179}$ However, Schumacher and associates have noted a predominance of mild left-sided tone abnormalities on physical exam in some of our post-ECMO infants. ${ }^{180}$ The incidence of such abnormalities is low, but any steps to improve neurologic outcome are justified. Successful use of venovenous ECLS would make carotid artery ligation unnecessary.

Kolobow has used venovenous ECLS in newborn lambs. ${ }^{122}$ Tidal flow is established by intermittently draining and reinfusing through a single large catheter placed in the right atrium. Chevalier has reported a similar system, using the Rhone-Poulenc self-regulating roller pump. This group reported successful venovenous neonatal perfusion in animals and patients. ${ }^{181}$ Our group has experimented with a double-lumen catheter for continuous flow venovenous ECLS, ${ }^{145,147}$ and recent clinical trials look very promising. If the adequacy of life support is equivalent, the advantage of carotid ligation makes venovenous access the method of choice for most newborn patients

Seizures were noled during ECLS in 24 of our first 100 neonates. ${ }^{89}$ It is sometimes difficult to distinguish between seizure activity and the twitching and involuntary movements that are often seen in newborns on ECLS. Documentation of seizures by EEG is often necessary. Other less frequent complications include cardiac arrest prior to and while on ECLS support, hypertension requiring vasoactive drug therapy, global myocardial dysfunction, and renal failure.

\section{Current Results}

The neonatal ECMO registry has recorded 3,876 cases from 65 centers as of July $1990 .{ }^{88}$ There have been 3,197 survivors, a survival rate of $82.5 \%$. Meconium aspiration was the most common diagnosis and also was associated with the best survival rate, while patients with congenital diaphragmatic hernia had the poorest outcome with a survival rate of $62 \%$. However, the overall results of congenital diaphragmatic hernia management have improved ${ }^{182-187}$ (Table 3). Technical and physiologic complications in the neonatal series are listed in Table 4. Two detailed Registry reports have been published. ${ }^{74,88}$ 
TABLE 3.

Neonatal Respiraıory Survival Rates*

\begin{tabular}{|c|c|c|}
\hline Diagnosis & $\begin{array}{l}\text { Number of } \\
\text { Cases }\end{array}$ & $\begin{array}{l}\text { Percent } \\
\text { Survived }\end{array}$ \\
\hline $\begin{array}{l}\text { Meconium } \\
\text { aspiration } \\
\text { syndrome }\end{array}$ & 1478 & 92.7 \\
\hline $\begin{array}{l}\text { Respiratoly } \\
\text { distress } \\
\text { syndrome }\end{array}$ & 589 & 83.5 \\
\hline $\begin{array}{l}\text { Congenital } \\
\text { diaphragmatis: } \\
\text { hernia }\end{array}$ & 6.51 & 616 \\
\hline Sepsis & 462 & 76.0 \\
\hline $\begin{array}{l}\text { Persistent } \\
\text { pulmonary } \\
\text { hypertension of } \\
\text { the ncwhorn }\end{array}$ & 515 & 86.8 \\
\hline Cardiar & 56 & 62.5 \\
\hline Airleak & 14 & 71.4 \\
\hline Other & 99 & 828 \\
\hline Overall & 3876 & 82.5 \\
\hline \multicolumn{3}{|c|}{$\begin{array}{l}\text { "Data as of July } 1990 \text { from LLSO Neonatal ECM() } \\
\text { Registry Extracorporeal Life Support Organization } \\
\text { Ann Abor. Michigan. }\end{array}$} \\
\hline
\end{tabular}

\section{TABLE 4.}

Complications and Outcome During EC.S for Neonatal Respiratory Failure*

\begin{tabular}{|c|c|c|}
\hline & $\begin{array}{c}\text { Incidence } \\
(0, j)\end{array}$ & $\begin{array}{c}\text { Survival } \\
\left.\qquad y_{0}\right)\end{array}$ \\
\hline \multicolumn{3}{|c|}{ Physiologic complications } \\
\hline \multicolumn{3}{|c|}{ Bleeding } \\
\hline [CH LS! & 13.0 & 50.8 \\
\hline Operative sits: & 13.0 & 62.0 \\
\hline Gastrointestinal & 4.0 & 60.1 \\
\hline Hemolysis & 8.0 & 72.8 \\
\hline Seizures & 15.0 & 6.5 \\
\hline Positive culture & 5.0 & 68.0 \\
\hline Hemofilter & 11.0 & 57.1 \\
\hline \multicolumn{3}{|c|}{ Mechanical complications } \\
\hline Oxygenator failures & 5.2 & 67 \\
\hline Tubing rupture & 2.3 & 85 \\
\hline Pump failure & 1.4 & 81 \\
\hline Cannula problem & 6.7 & 77 \\
\hline
\end{tabular}


Long-term follow-up of patients treated with ECMO is important in evaluating the usefulness of this treatment. Because these patients are selected from a population with a very high mortality risk, there is no readily available control group with which to compare follow-up data. There are reports of neonates with severe respiratory failure treated with mechanical ventilation and tolazoline. In one of these reports, $77 \%$ of 3-year survivors were normal, but the remainder sustained some developmental or neurologic impairment. ${ }^{188}$ Several of the more experienced ECMO centers have published their initial follow-up studies, and all of these have documented that the majority of their ECMO patients are normal at 1 year of age. ${ }^{179,190-195}$ Some of the neonatal ECMO follow-up series are listed in Table 5.

These results are all comparable to those reported for conventionally treated patients who did not require ECMO, ${ }^{189}$ suggesting that pre-ECMO events are at least partly responsible for suboptimal outcomes. The experience to date demonstrates that newborns with a high mortality risk can be effectively and safely treated with ECMO and that the majority of children who survive will have normal growth and development.

\section{RESPIRATORY FAILURE IN ADULTS AND OLDER CHILDREN}

Well over 300 trials of ECMO for respiratory failure were carried out in adults and children between 1970 and 1979. Although ECMO was technically successful in providing life support, and many patients recovered who were considered moribund, close to $90 \%$ of the patients in all clinical series died, usually after several agonizing days or weeks characterized by bleeding and progressive multiple organ failure stemming from the original illness. These cases often resulted in the most difficult of ethical problems when the lung was totally fibrotic with no blood flow; however, the patient was still

TABLE 5.

Neonatal ECLS Neurologic Follow-up Studies

\begin{tabular}{|c|c|c|c|c|c|}
\hline \multirow[b]{2}{*}{ Author } & \multirow[b]{2}{*}{$\mathbf{n}$} & \multirow[b]{2}{*}{ Age } & \multirow[b]{2}{*}{ Normal $(\%)$} & \multicolumn{2}{|c|}{ Handicap $(\%)$} \\
\hline & & & & Minor & Major \\
\hline Towne $^{190}$ & 24 & $4-13 \mathrm{yr}$ & 72 & - & 28 \\
\hline Andrews ${ }^{191}$ & 14 & $1-3 \mathrm{yT}$ & 50 & 15 & 35 \\
\hline Glass* & 59 & $2 \mathrm{yr}$ & 58 & 24 & 19 \\
\hline Glass $^{179}$ & 42 & $1 \mathrm{Vr}$ & 75 & 19 & 5 \\
\hline Schumacher ${ }^{195}$ & 80 & $1-7 y \mathrm{r}$ & 75 & 5 & 20 \\
\hline Wilkerson ${ }^{*}$ & 114 & $6 \mathrm{mo}-4 \mathrm{yr}$ & 8.5 & 5 & 10 \\
\hline Bauer* & 37 & $8 \mathrm{mo}$ & 80 & 10 & 10 \\
\hline
\end{tabular}


awake as long as ECMO was continued. Now, in the last decade, using the same patient selection criteria but different ECLS techniques. Gattinoni, Pesenti, and Kolobow demonstrated 50\% recovery in adult patients. ${ }^{63,91}$ This experience has been corroborated in many centers, ${ }^{64-66}$ and FCLS is now becoming a reasonable approach to severe respiratory failure in children and adults when other treatment modalities are not successful. The Gattinoni technique includes venovenous bypass, emphasizing carbon dioxide removal and minimal ventilation. Two hundred patients have been treated in this fashion during the last decade with $\mathbf{5 0} \%$ survival. Pulmonary fibrosis is still the major cause of death.

\section{Patient Selection: Mortality Criteria, Indications, and Contraindications}

Extracorporeal life support is indicated when the patient has acute severe potentially lethal respiratory failure, unresponsive to conventional management, with a primary condition that is reversible. The criteria used to select patients for the NIH adult ECMO trial are still generally used for children and adults because the mortality risk of severe respiratory failure has not changed in the last 15 years. ${ }^{61,196,197}$ The selection criteria detected $90 \%$ mortality risk in the original study and all indications are that the mortality risk is essentially unchanged. Using the selection criteria identifies a patient group that has been standardized for the last 15 years. The criterion used in the NIH adult trial (scientifically paraphrased) is transpulmonary shunt greater than $30 \%$ despite optimal ventilator settings and pharmacologic management. We would add an additional selection criterion of static compliance less than $0.5 \mathrm{cc} / \mathrm{cm} \mathrm{H}_{2} \mathrm{O} / \mathrm{kg}$. The severity of acute respiratory failure and the associated mortality risk are best measured by these objective criteria, rather than by minor variations in blood oxygenation that can be dependent on the extent of ventilator treatment.

Identifying reversible pulmonary disease is a larger challenge. In the neonatal group, essentially all respiratory failure is reversible. However, in older children and adults the diseases that cause respiratory failure lead to interstitial inflammation that in turn causes fibrosis, bacterial infection, and necrosis. The extent of fibrosis appears to relate to the severity and duration of interstitial inflammation, as well as to the duration of high airway pressure from mechanical ventilators. ${ }^{198}$ The patients in the NIH ECMO study, for example, were on high pressure and $100 \%$ oxygen for an average of 5 days before they entered the study, and many of the patients continued on high pressure and high oxygen despite the fact that ECMO affords total lung "rest." ${ }^{12}$ Patients in this study and other studies of adult respiratory failure died with multiple organ failure, very low compliance, and high pulmonary vascular resistance secondary to 
fibrosis of the lung capillary bed. This condition, at least at the stage of meeting the entry criteria for the ECMO study, was irreversible in most of the NIH study patients. ${ }^{59}$ Consequently, as trials of ECMO in adults resume, the patient selection should include a short period of acute illness ( 5 days or less), the avoidance of high airway pressures using extracorporeal support, and perhaps pharmacologic means to prevent or minimize pulmonary fibrosis. It should be noted that the $50 \%$ survival reported by the Milan group is based on patients selected without regard to duration of illness or extent of pulmonary fibrosis or infection. ${ }^{63}$

\section{Technique in Adults and Older Children}

The techniques for extracorporeal respiratory support in adults and children are usually different from those described for neonates. To be sure, conventional venoarterial bypass can totally support both respiratory and cardiac function in adult patients and is a satisfactory method of life support. Venoarterial bypass, as described for neonates, is preferred when circulatory shock or cardiac failure are superimposed on respiratory failure. However, if the problem is purely respiratory failure, venovenous perfusion has significant advantages for lung perfusion. It allows relief from mechanical ventilation and achieves oxygenation by relatively low $\left(10-20 \mathrm{~cm} \mathrm{H}_{2} \mathrm{O}\right)$ CPAP, with whatever concentration of $\mathrm{F}_{1} \mathrm{O}_{2}$ is needed to maintain adequate arterial blood saturation (usually 40\%-70\% oxygen).

If the goal is primarily carbon dioxide removal the extracorporeal blood flow rate can be as low as $1 \mathrm{~L} / \mathrm{m}^{2} / \mathrm{min}$. If oxygenation is required, blood flow must be 2 to $4 \mathrm{~L} / \mathrm{m}^{2} / \mathrm{min}$. Although the patient may be hypoxic, normal hemoglobin and increased cardiac output assure adequate oxygen delivery. ${ }^{199}$ Vascular access is gained through jugular or femoral veins, with one catheter placed in the right atrium for venous drainage and a return catheter in the femoral vein. The airway is managed with CPAP with occasional inflation, but never exceeding $40 \mathrm{~cm} \mathrm{H}_{2} \mathrm{O}$. With this type of management it is almost always possible to achieve blood oxygenation without mechanical ventilation, and as noted, recovery of the lung and the patient are reasonable expectations.

Low-flow venovenous bypass is not successful in the newborn. The problem is that infants go through a period of absent lung function, so that total extracorporeal oxygenation is an essential part of the procedure. This relates to the primary difference in pathophysiology between these groups of patients, since the problem in infants is primarily one of pulmonary arteriolar vasospasm with right-to-left shunting through the ductus and foramen ovale. In older children and adults blood continues to flow through the lung, despite extensive transpulmonary shunts. Hence, any alveolar inflation with oxy- 


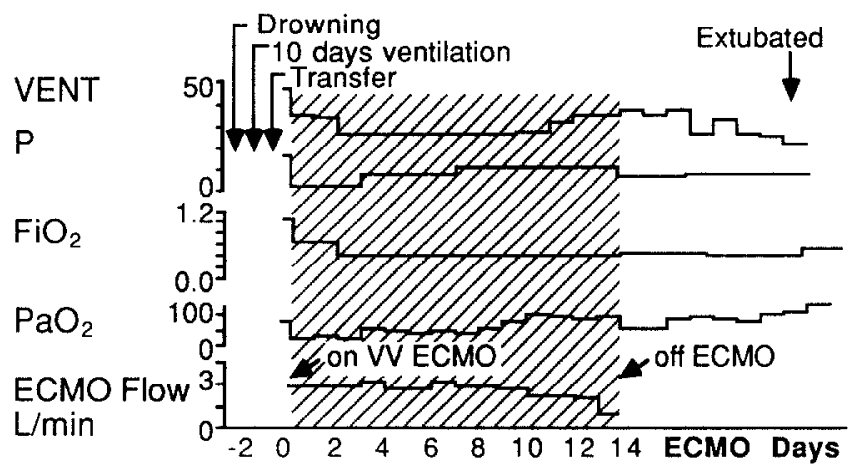

FIG 16.

Venovenous ECLS used for pulmonary insufficiency because of a near drowning episode. High flow and total gas exchange support is required for 2 weeks before lung function returns. $W=$ venovenous; $V$ ent $P=$ vertilator pressure.

gen will result in some gas exchange. If the lung deteriorates to the point of no oxygen exchange, venovenous flow can be increased until both carbon dioxide and oxygen exchange are totally supported (as in the neonate).

The principles of nutrition, infection control, pulmonary management, and anticoagulation described for neonates are all appropriate for children and adults. Typical cases are shown in Figures 16 and 17 .

TABLE 6.

Results of F(MO) in Pediatric: Respiratorv I'ailure*

\begin{tabular}{|c|c|c|c|}
\hline Diagnosis & $\underset{\substack{\text { Suminal } \\
\text { Sain }}}{ }$ & $\underset{\mid 0,0}{\text { Mortality }}$ & $\begin{array}{l}\text { No. of } \\
\text { Patients }\end{array}$ \\
\hline $\begin{array}{l}\text { Respiratory } \\
\text { distress } \\
\text { syndrome }\end{array}$ & $41+$ & 58.6 & 29 \\
\hline $\begin{array}{l}\text { Viral } \\
\text { pneumonia }\end{array}$ & 458 & 54.2 & 24 \\
\hline Aspiration & (6) 0 & 40.0 & 10 \\
\hline $\begin{array}{l}\text { Bacterial } \\
\text { pneumonia }\end{array}$ & $n$ & 100 & 3 \\
\hline Other & 46.7 & 53.3 & 15 \\
\hline Total & 444 & 55.6 & 81 \\
\hline \multicolumn{4}{|c|}{$\begin{array}{l}\text { *Data from Pediatric: Pulmonary hegistry of Extra- } \\
\text { corporeal Life Support Organization as of January } \\
1990 \text {. }\end{array}$} \\
\hline
\end{tabular}




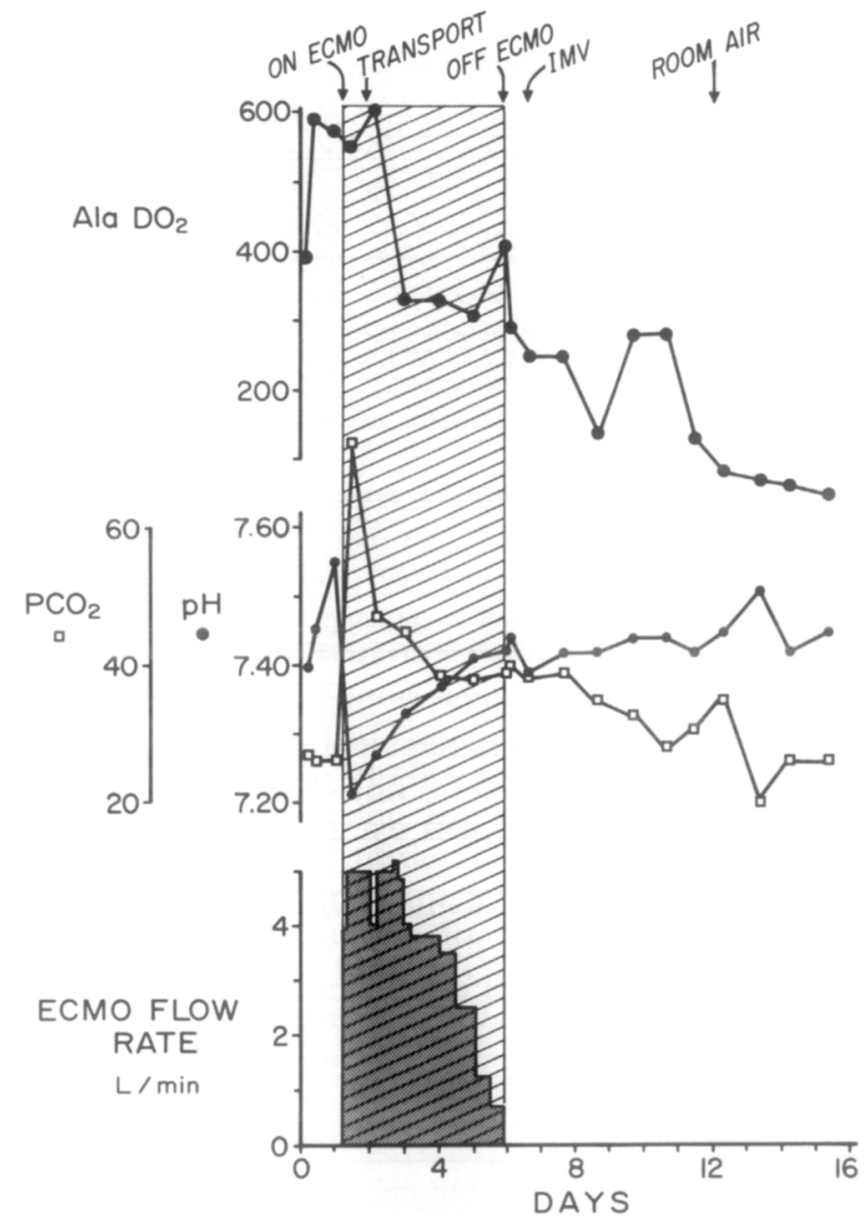

FIG 17.

Extracorporeal life support for acute respiratory failure in a 17-year-old woman. Venoarterial bypass was used because of the need for both cardiac and pulmonary support. A-a gradient was measured during test periods off bypass. Lung function began to improve on the fourth day and the patient was removed from bypass on the fifth day.

\section{Current Results}

The results of ECMO for respiratory support in adults and older children are listed in Tables 6 and 7 . The early results were summarized in publications by Gille, ${ }^{202}$ and in our monograph of $1978 .{ }^{5}$ At that time there were 190 reported cases with 29 survivors. Since that time approximately 200 adult cases and 80 pediatric cases have been treated with the newer techniques. After a decade of dormancy, 
TABLE 7.

\begin{tabular}{|c|c|c|c|}
\hline Site & $\begin{array}{l}\text { No. of } \\
\text { Patients }\end{array}$ & $\begin{array}{c}\text { No. of } \\
\text { Survivors }\end{array}$ & $\begin{array}{l}\text { Survival } \\
\text { Rate }\{\%)\end{array}$ \\
\hline Marburg & 86 & +6 & 53 \\
\hline Berlin & 8 & 6 & 75 \\
\hline Dusseldorf & +1 & 1 & 25 \\
\hline Milan/Monza & $\pi 3$ & 35 & 48 \\
\hline Stockholm & 1,6 & 5 & 38 \\
\hline liund & : & 2 & 100 \\
\hline Paris & 1.1 & 6 & 43 \\
\hline Total & 200 & 101 & 51 \\
\hline
\end{tabular}

ECMO for adult respiratory failure appears to be at a state similar to that of ECMO for newborn respiratory failure in 1982. We can expect several centers to undertake major clinical trials again in the next decade.

\section{EXTRACORPOREAL SUPPORT FOR CARDIAC FAILURE}

Extracorporeal life support has been used for approximately 150 patients with cardiac failure. Most of the cases were postoperative pediatric cardiac patients and the survival rate was $42 \%$.

\section{Case Selection}

The characterization of severe cardiac failure is not difficult. Indeed, the major problem is to identify patients before multiple organ failure has begun. Statistically, most cases of cardiac failure are caused by coronary atherosclerosis and myocardial infarction, leading predominantly to left ventricular failure. Counter pulsation with an intra-aortic balloon pump or a left ventricular assist device provides isolated left ventricular support, and is adequate to treat most adult patients with cardiac failure. However, when both the right and left ventricles are damaged, or when the problem is primarily right ventricular failure (as is the case with massive pulmonary embolism, congenital heart disease, myocarditis, and heart transplants undergoing immunologic rejection) left ventricular support is inadequate and biventricular support is required. This can be accomplished by a totally implanted artificial heart, or by the utilization of separate right and left sided pumping systems using the lungs as the gas exchange system. Both of these approaches require thoracotomy for insertion and removal of the support device. This is a significant disadvantage, particularly if transplantation is contem- 
plated, since the thoracic cavity has become contaminated in the process of establishing prosthetic support. However, such approaches do not require an extracorporeal oxygenator and are usually carried out with minimal anticoagulation.

Extracorporeal circulation for cardiac support is indicated for patients who are not suitable for other means of support. Consequently most of these applications have been in children or in emergency situations when thoracotomy is not feasible. There are several case reports in the literature, including sizeable series from groups headed by Pennington, ${ }^{96}$ Klein ${ }^{95}$ and Bartlett. ${ }^{92}$ In our center specific indications are cardiac index less than $2 \mathrm{~L} / \mathrm{m}^{2} / \mathrm{min}$ and/or mixed venous saturation less than $50 \%$ for 2 hours or more despite optimal pharmacologic and mechanical cardiac support. Contraindications are brain damage, metabolic acidosis with base deficit less than $10 \mathrm{mEq} / \mathrm{L}$ and/or venous saturation greater than $50 \%$ for 6 hours or more, and the patient is not a suitable candidate for myocardial recovery or transplantation.

\section{Technique for Cardiac Support}

venoarterial bypass is required for cardiac support. The techniques of vascular access have been described above. Since pulmonary function is usually adequate, and left ventricular blood is adequalely uxygenaled, arterial and venuus access through femoral vessels is feasible, as long as the venous catheters are of sufficient diameter and length to reach into the right atrium. Systems for percutaneous vascular access are now available and are being used in the cardiac catheterization laboratory. However, direct cutdown placement of catheters is generally preferred because the success of the procedure depends on the size of the venous catheter, and the largest catheter generally requires jugular venous cutdown. If the left ventricle does not contract at all, high pressure may occur in the left atrium and left-sided venting may be required. This condition is diagnosed by measurement of pulmonary capillary wedge pressure and by watching the pulse contour. If the wedge pressure is greater than $25 \mathrm{mmHg}$ on high-flow venoarterial bypass and if the pulse contour is lost, then the left ventricle or atrium should be vented into the venous return. This can be accomplished by transvenous transseptal catheterization of the left atrium, ${ }^{87}$ by transaortic cannulation of the left ventricle, ${ }^{203}$ by catheter drainage of the pulmonary artery, ${ }^{139}$ by creation of an atrial septal defect ${ }^{204}$ or by direct placement of a left atrial catheter at thoracotomy. A typical case is presented in Figure 18.

The methods used for extracorporeal cardiac support are currently limited by the requirement for systemic heparinization. For example, the technique is not advised for patients who fail to come off the conventional heart-lung machine in the operating room, pa- 


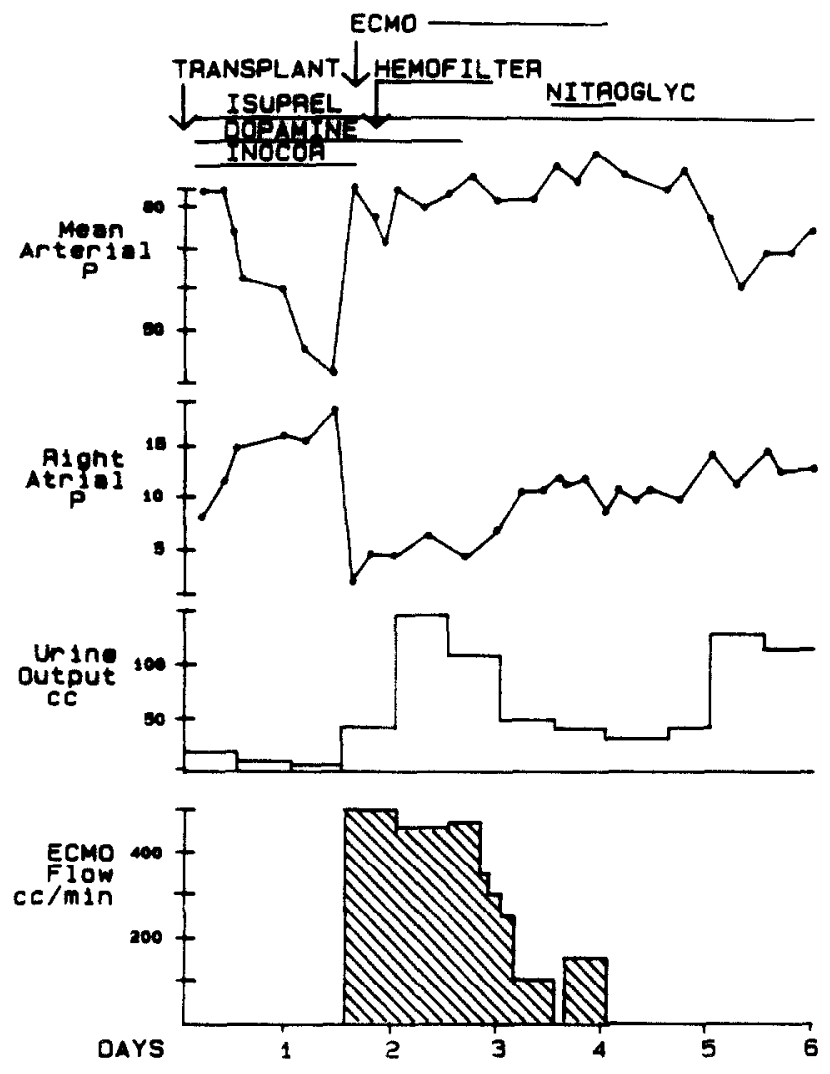

FIG 18.

Venoarterial ECLS used for postoperative cardiac support of a child following cardiac transplantation. $P=$ pressure; $/$ suprel $=$ isoproterenol; inocor $=$ anspinovie; nitroglyc $=$ nitroglycerin. (From Bartlett RH: Esperanza [ASAIO Presidential Address]. ASAlO Trans 1985: 31:723-725. Used by permission).

tients with extensive trauma, or patients with other sites of bleeding. In addition, once the patient is heparinized, changing access sites by puncture or cutdown is contraindicated because of the possibility of bleeding. With the new nonthrombogenic surfaces, the techniques of extracorporeal circulation for cardiac support will change considerably. Placement of catheters and initiation of bypass in the operating room will be much easier, and simple partial bypass through percutaneous femoral puncture may be initiated, followed by revision of vascular access without fear of bleeding.

Maintaining and monitoring extracorporeal support for cardiac failure is straightforward. Venous saturation is a direct measure of the adequacy of perfusion, and bypass flow is simply regulated to 
maintain the venous saturation at $70 \%$ to $75 \%$. The pulmonary artery pressure must be monitored for reasons outlined above. Determining the status of the heart and the reversibility of the cardiac lesion is possible through ultrasound examination, ${ }^{152}$ or by simply interrupting bypass flow to assess the adequary of perfusion. In the past there was no alternative for the patient with irreversible heart damage and the procedure was terminated if heart function did not improve. In the modern era transplantation has become a potential alternative, and if the patient is a transplant candidate a search for a potential donor should begin as soon as irreversible cardiac damage is identified. ${ }^{204}$ Because of the risk of bleeding and the complexity of the system compared to the relative simplicity of implantable left ventricular assist devices, prolonged extracorporeal circulation is not generally recommended as a bridge to transplantation. However, if ECMO is carried out in a nonheparinized patient without continuous technician attendance, extracorporeal support may be the preferred method.

\section{Current Results}

Results of extracorporeal support for patients with cardiac failure are listed in Table 8 . The recording of these cases is complicated by definitions. Every cardiac surgery center can cite examples of patients maintained on venoarterial bypass for hours or even days following cardiac operations with occasional successful outcomes. With the introduction of percutaneous systems, many more trials of extracorporeal support will be instituted, often by personnel who are not experienced in prolonged extracorporeal support. Cases listed in Table 8 are those in which prolonged extracorporeal circulation was undertaken with the intent of maintaining this procedure

\section{TABLE 8.}

\begin{tabular}{|c|c|c|c|}
\hline Diagnosis & $\begin{array}{c}\text { Survival } \\
(\%)\end{array}$ & $\begin{array}{c}\text { Mortality } \\
|\%|\end{array}$ & $\begin{array}{c}\text { No. of } \\
\text { Patients }\end{array}$ \\
\hline $\begin{array}{l}\text { Cardiac } \\
\text { surgery }\end{array}$ & 43.1 & 56.7 & 123 \\
\hline $\begin{array}{l}\text { Cardiac } \\
\text { transplant }\end{array}$ & 33.3 & 66.7 & 9 \\
\hline $\begin{array}{l}\text { Myocardi- } \\
\text { opathy }\end{array}$ & 250 & 75.0 & 4 \\
\hline Other & 50.0 & 50.0 & 2 \\
\hline T'otal & 42.0 & 58.0 & 138 \\
\hline
\end{tabular}


until cardiac function recovered, irreversibility was documented, and/or transplantation was undertaken.

One of the most interesting series of cases is the recent report by Pennington's group of extracorporeal circulation undertaken as a resuscitative measure for cardiac arrest. ${ }^{205}$ Venoarterial bypass provides the ultimate in resuscitative technique. The problem is establishment of adequate perfusion before brain injury or other major organ failure has occurred. In the inilial experience of this group, perfusion support could be established very quickly, but the risk of major brain injury proved to be prohibitively high.

\section{HEMORRHAGIC SHOCK}

Appropriate treatment of hemorrhagic shock is blood replacement by transfusion. However, extracorporeal circulation offers several theoretical advantages as an adjunctive treatment for the exsanguinating patient in the operating room. Autotransfusion systems in which blood shed from the operative field is aspirated, anticoagulated, filtered, and reinfused into the patient constitute a mini-extracorporeal circulation. Blood flow in this procedure may be as high as $500 \mathrm{~mL} / \mathrm{min}$, the rate limited by the size of the intravenous return catheter in most situations. The use of a very large venous catheter can turn the autotransfusion system into a type of venovenous bypass, and permits maintenance of normal blood volume even in massively bleeding patients. If cardiac arrest occurs in the course of hemorrhagic shock, autotransfusion (with venous return) may be inadequate to return blood fast enough to resuscitate the patient. In addition, if bank blood or large amounts of room-temperature solutions have been used, the patient's body temperature may be decreased to the point where acidosis and cardiac cooling interfere with resuscitation. In this circumstance, rapidly established venoarterial bypass with oxygenation and a heat exchanger may provide the required mechanical assistance while the vascular damage is repaired. We have utilized cardiopulmonary bypass several times in trauma patients in this dire situation, with occasional success. One patient sustained hypovolemia and severe hypothermia $\left(20^{\circ} \mathrm{C}\right)$ following an automobile accident in the snow. Blood was warmed and transfused with venoarterial bypass during 2 hours of direct cardiac massage. The heart was eventually resuscitated, and the patient recovered with normal brain function. Pulmonary function is usually normal during hemorrhagic shock, so that arch perfusion is not necessary. Femoral catheters provide the necessary access to institute venoarterial bypass. Investigation of hemorrhagic shock treatment with extracorporeal circulation in the laboratory has been reported by Bergentz. 206 
The use of extracorporeal circulation in septic shock has been investigated by Lefemine et al $^{207}$ Since endotoxemia is characterized by systemic vasodilation and abnormally high cardiac output, it is not surprising that venoarterial bypass adds little to this hyperdynamic state. Our clinical experience corroborates these findings. We have used ECMO for pulmonary failure in three patients who were also in endotoxic shock. Although excellent extracorporeal flow could be achieved, systemic perfusion, blood pressure, and oxygen delivery never improved sufficiently to clear metabolic acidosis and reverse the moribund condition.

\section{OTHER CLINICAL CONDITIONS}

Extracorporeal circulation has been applied to several other clinical problems that are outside the scope of this monograph, but should be mentioned. Total body washout, an extreme of exchange transfusion, has been used with some success to remove toxins, particularly in patients with liver failure. ${ }^{208}$ This technique is facilitated by extracorporeal circulation, which sustains perfusion and permits controlled cooling. ${ }^{209}$ Isolated limb and organ perfusion with oxygenated blood has been used in cancer chemotherapy for many years. $^{210}$ A similar apparatus has been used to perfuse amputated limbs prior to reimplantation, and to perfuse isolated organs for physiologic study or transplantation. ${ }^{211}$ Cadaver perfusion (after brain death and cardiac arrest) has been investigated as a method to preserve several organs for subsequent transplantation, allowing time for tissue typing. ${ }^{212}$

Multiple organ failure, including heart, lung, and kidney, may be treated with extracorporeal support before failure of any one organ system becomes predominant. The mortality in multiple organ failure is very high, and such a radical step may prove to be the safest course. The possibility of inducing bleeding complications makes such an approach impractical at present, but if noncoagulable circuits become available, early use of ECMO in patients with multiple organ failure could be evaluated. Finally, extracorporeal circulation has been reported in the successful trealnent of patients with priapism, ${ }^{213}$ a rare but devastating disorder.

\section{FUTURE DEVELOPMENTS}

\section{ARTIFICIAL ORGANS}

In the future, variations of microporous membrane lungs will replace the solid silicone rubber membrane because of improved effi- 
ciency of gas transfer, lower perfusion pressures, workability of materials, and lower cost of manufacture. The only problem that precludes the use of microporous membranes currently is the plasma leakage that occurs when the micropores have become wet. This is usually related to condensation of water in the gas phase (in a process very similar to causing a tent to leak in the rain by touching it with a damp finger). The problem of plasma leakage will be eliminated through a combination of surface coating and minimizing water condensation. ${ }^{214}$ It may be that the process of heparin bonding to microporous materials will be sufficient to eliminate the wettability and plasma leakage problem without the need for further modification to sweep gas temperature or humidification. ${ }^{215}$

As the systemic heparin dose decreases, manufacturers will pay increasing attention to flow design, minimizing stagnant and eddy current zones while maintaining low resistance to blood flow. With these modifications only two sizes of membrane lung will be necessary: a neonatal/pediatric size with a rated flow of approximalely 1 $\mathrm{L} / \mathrm{min}$ and a child/adult size with a rated flow of approximately $5 \mathrm{~L}$ $\min$.

The IVOX, a long thin capillary membrane oxygenator designed to be placed inside the vena cava and right atrium, is just entering clinical trials. ${ }^{216}$ The gas exchange capacity of this device is not adequate for total support, but it may find application in partial carbon dioxide removal, an extracorporeal membrane lung that fills the conduit tubing, or, with modifications, as the first implantable orthotopic artificial lung.

The servoregulated roller pump is certainly the workhorse of extracorрогеal circulation but it is inherently potentially dangerous. The centrifugal pump is equally dangerous because high negative pressure and hemolysis can easily occur. The ECLS pumps of the future will be passive filling, mechanically servoregulated, inexpensive, portable, compact, unable to aspirate or pump air, and durable. As outlined earlier, the Rhone-Poulenc (Collin Cardio, Paris) pump currently used in Paris has most of these characteristics. ${ }^{142,}$, 81 It is nol hard to imagine valved, ventricle pumps activated pneumatically, hydraulically, or mechanically that would have the same characteristics. Any of these pumps will require accurate on-line flow meters. Pump speed will be automatically adjusted to maintain adequate systemic oxygen delivery under a wide range of conditions, probably based on mixed venous saturation.

In the future almost all ECLS for respiratory support will be carried out in the venovenous mode using a single catheter with two lumens ${ }^{147}$ or tidal flow systems. ${ }^{122-124}$ Venoarterial bypass will be used when cardiac support is required. Percutaneous access will become more common, using dilators to introduce peel-away sheaths through which the access catheters will be placed. The most impor- 
tant advance in the next decade will be in the development of nonthrombogenic prosthetic surfaces. These advances are important only when companies are able to routinely and reliably produce devices with specific coatings. Both Medtronic/Carmeda ${ }^{214}$ and Bentley Laboratories $^{215}$ have developed methods of surface bonding that permit ECLS without systemic anticoagulation in the laboratory. These systems will make it possible to conduct extracorporeal support with minimal or no systemic heparin. This will totally change indications, applications, and complications of extracorporeal support. Various aspects of the technique will have to be changed to allow continuous high flow, without bridges or Luer Locks, while maintaining flow around catheters in access vessels, etc. Although permanent surface bonding of heparin may minimize the platelet adherence, adhesion, and aggregation, heparin alone will not be the final answer to nonthrombogenic surface. Some combination of heparin, plasminogen activator, and prostacyclin analogue all bound to the prosthetic surface will come closer to the normal endothelium, and may permit longer perfusion with lower flow rates.

\section{CLINICAL PRACTICE OF EXTRACORPOREAL LIFE SUPPORT}

It will be interesting to see how the clinical supervision of ECLS is managed in the future. By the turn of the century it is likely that there will be a dozen patients on ECLS simultaneously in any major medical center, including premature infants, adult ventilator patients, and patients in cardiogenic and hemorrhagic shock. Common sense would dictate that one professional team should manage this system in conjunction with intensive care nursing. This team may be composed of a distinct new paramedical profession of ECLS specialists (as is currently the practice) or the responsibility might ultimately be assumed by subspecialties in perfusion, respiratory therapy, or nursing. The manpower requirements will be similar to current needs in major centers (three or four deep on-call schedules) but a typical work shift will involve priming circuits, emergency cannulations, elective decannulations, managing emergencies, and making rounds on the 10 or 20 ECLS patients for general supervision and preventive maintenance.

Extracorporeal life support has grown to routine practice in the last several years because of the standardized system and approach, and because of the development of a new health care professional: the ECLS clinical specialist. The need for ECLS specialists arose because the current systems require continuous attendance for monitoring and management, coagulation control, and management of emergencies. Specialists may be trained in medicine, nursing, respiratory therapy, or perfusion. Extensive didactic, laboratory, and bed- 
side experience is required, because even individuals from these various professions do not have the background necessary for ECLS management. The ECLS specialist team is essential for making the technique work, but it is also the most expensive component of ECLS. During the next decade the role of the ECLS specialist will change from continuous bedside supervision to simultaneous supervision of several ECLS patients, generally on an on-call basis. Minute-to-minute and hour-to-hour supervision of the ECLS system will be managed by the bedside nurse, much in the way that mechanical ventilators are managed now. Of course, this will not be possible until the safety features outlined above are incorporated into the circuits, and until intensive care nurses are educated in the details of prolonged extracorporeal circulation.

With improved circuit safety, single vein access, and minimal anticoagulation, indications for ECLS will change from patients in a moribund status to those with moderate respiratory failure. Extracorporeal life support will become an adjunct to conventional ventilation and pharmacologic management, rather than something to try when standard ventilation and pharmacology are failing. Extracorporeal life support will have a significant role for patients who are difficult to wean from mechanical ventilation. Low flow venovenous bypass (or intracaval gas exchange) will be used to facilitate extubation and allow ambulation, eating, and other activities that are often precluded by intubation and mechanical ventilation.

\section{INFLUENCE OF EXTRACORPOREAL LIFE SUPPORT}

Many of the lessons learned in ECLS have already been applied to bypass for cardiac surgery (servoregulation, mixed venous saturation monitoring, membrane lungs, standardized descriptors of vascular access catheters). Heparin bonded nonthrombogenic circuits will provide a major advance for cardiac operation and other procedures in which extracorporeal circulation with circulatory arrest or control of local blood flow is desirable. The techniques of cardiac operations without systemic heparin need to be worked out in the laboratory. How should blood in the lungs and cardiac chambers be anticoagulated? Will thrombosis occur below an aortic cross clamp? With heparin-bonded circuits, heparin can be discontinued once the heart is closed, eliminating the dilemma of continued oozing while weaning off bypass as opposed to coming off prematurely to facilitate clotting. Nonthrombogenic surfaces will find major application for other types of blood-contact artificial organs, including dialysis, hemofiltration, and plasmapheresis. The technology of ECLS will be applied to normothermic organ perfusion.

Extracorporeal life support has already led to better understand- 
ing of pulmonary pathophysiology. The identification of pulmonary hypertension in the newborn as the underlying pathophysiology in virtually all cases of full-term respiratory failure is one example. Extracorporeal membrane oxygenation studies led to the identification of progressive irreversible fibrosis as the final common pathway in patients with acute adult interstitial lung disease ${ }^{60}$ Earlier and more extensive use of ECLS will lead to the study of pharmacologic agents to reverse fibrosis and growth factors to cnhance lung generation or regeneration. The study of ECLS has brought proper emphasis to the separation of oxygenation from carbon dioxide removal, and the realization that high peak airway pressure during attempted hyperventilation for carbon dioxide clearance is the major culprit in ventilator-induced lung injury. ${ }^{198}$ With this realization a return to pressure limited mechanical ventilators will occur, with ECLS being used as an adjunct when low pressure mechanical ventilation has not achieved carbon dioxide clearance. The study of oxygen kinetics and the role of mixed venuus saluration during ECLS has already found its way into the routine management of intensive care patients. In the intensive care unit it is currently common practice to manipulate $\mathrm{Do}_{2}$ to optimize the $\mathrm{Do}_{2} \mathrm{No}_{2}$ ratio. During ECLS it is easy to regulate $\mathrm{VO}_{2}$ by regulating temperature, and this technique will find its way to routine intensive care management.

The two prospective randomized trials of ECLS in newborns with respiratory failure ${ }^{82,86}$ used adaptive statistical designs, ${ }^{83}$ bringing randomized clinical trial design to the forefront of discussion. ${ }^{217}$ This was particularly important because of the evaluation of ECLS as a life support technique, so that ethical as well as statistical considerations guided the planning of these studies. Although initially criticized ${ }^{85}$ both the conclusions and the methodology in these studies have stood the test of time and the use of adaptive designs will simplify prospective randomized studies in a variety of areas in the future.

Finally, the general success of ECLS in newborn infants has brought the economics and ethics of high-tech intensive care to center stage. One prominent author questioned whether the cost of ECMO was justified to save a newborn life ${ }^{218}$ (He reckoned the cost at $\$ 25,000$; it is actually about $\$ \mathbf{1 5 , 0 0 0}$.) The question is certainly valid, although we commonly spend much more than that in the treatment of a single patient with acquired immunodeficiency syndrome, pancreatic cancer, newborn asphyxia, prematurity, and other conditions with less favorable outcomes. A recent study demonstrated that length of hospitalization and hospital costs were actually decreased in ECLS patients compared to patients on conventional ventilation. ${ }^{157}$ Nonetheless, because ECLS is such a highly visible complex technology, we will be, and should be, constantly asked, "Is it worth it?" 


\section{CLINICAL APPLICATIONS}

With the improvements in the system outlined above, ECLS will be applied earlier in respiratory and cardiac failure. It will be routinely used for premature infants, older children, and adults with respiratory failure from a variety of causes. Extracorporeal life support will be used in conjunction with lung transplantation in two ways: to support the lung transplant patient through acute edema or a later rejection crisis, and as a bridge to lung transplant for children and adults with acute irreversible disease.

Extracorporeal life support will gain wider application as temporary mechanical support of the circulation in children with cardiac failure. Intra-aortic balloon pumps and left ventricular assist devices will be preferable for adults with cardiac failure, but children, because of the nature of cardiac disease and the variety of sizes, will do better with venoarterial cardiopulmonary bypass supporting both right and left ventricular function. This application will be primarily for postoperative cardiac patients. Although ECLS can be used as a bridge to cardiac transplantation the likelihood is small of getting a donor heart of appropriate size and blood type within 2 or 3 weeks of time permitted by uncomplicated ECLS. Consequently, ECLS as a bridge to cardiac transplantation will not be used until the donor supply is greatly increased (perhaps by ECLS as an organ perfusion system).

New applications of ECLS will include emergency room and cathctcrization laboratory resuscitation in cardiac failure, resuscitation in trauma and hemorrhagic shock, and use as an adjunct to perfusion and temperature control in other types of critical illness. Emergency bypass systems are already being used in many cardiac catheterization labs. There are occasional success stories, but often sequential complications lead to emergency cardiac operations with unfavorable outcomes. In the experience of the author, this relates to the use of ECLS technology by physicians and assistants who have no training, background, or experience in perfusion technology. Even in expert hands the use of venuarterial bypass for cardiac: resuscitation is fraught with problems. The use of the technique should be limited to experienced professionals.

The application of ECLS in the management of trauma and resuscitation from hemorrhagic shock will come with the nonthrombogenic system. Exsanguinating hemorrhage, from a ruptured liver or a duodenal ulcer, for example, may be managed by simultaneous transfusion and volume replacement associated with quick cannulation for ECLS. Rapid cooling with perfusion will allow total circulatory arrest or continuous cold perfusion at very low flow rates to permit identification and repair of the bleeding vessels or organs followed by rewarming on bypass. 
This prospectus for the future of ECLS seems at best presumptive and at worst preposterous. Ilowever, in 1970 there had been no successful cases and it was widely held that prolonged extracorporeal support was impossible. By 1980 it had been demonstrated that successful ECLS was possible, but it was widely held that acute lung disease was irreversible in any patient sick enough to need it, and the technique, although possible, was impractical or unnecessary. In 1990 ECLS is standard trealment for some groups of patients. By now, experience has taught us to predict not the limitations but rather the possibilities.

\section{APPENDIX}

ADULT U.S. ECLS CENTERS*

\begin{tabular}{|c|c|c|}
\hline Center & Location & Director \\
\hline Sharp Hospital & San Diego, CA & Walter Dembitsky, M.D. \\
\hline Pacific Medical Center & San Francisco, $C A$ & J. Donnald Hill, M.D. \\
\hline $\begin{array}{l}\text { Univ. of Michigan Medical } \\
\text { Center }\end{array}$ & Ann Arbor, MI & Robert Bartlett, M.D. \\
\hline $\begin{array}{l}\text { Univ. of Minnesota } \\
\text { Medical Center }\end{array}$ & Minneapolis, MN & Jerome Abrams, M.D. \\
\hline $\begin{array}{l}\text { St. Louis Univ. Medical } \\
\text { Center }\end{array}$ & S1. Louis, MO & Glenn Pennington, M.D. \\
\hline $\begin{array}{l}\text { Hershey Medical Center } \\
\text { L.Js. Hospital }\end{array}$ & Hershey, PA & $\begin{array}{l}\text { Michael Snyder, M.D. } \\
\text { Alan Morris, MD. }\end{array}$ \\
\hline
\end{tabular}

*This summary was composed in May 1990, and mav not be inclusive of all centers performing adult ECLS. Centers listed have had major experience with adult ECLS.

PEDIATRIC U.S. ECLS CENTERS*

\begin{tabular}{|c|c|c|}
\hline Center & Location & Director \\
\hline $\begin{array}{l}\text { Ochsner Foundation } \\
\text { Hospital }\end{array}$ & New Orleans, $\mathbf{I} \mathbf{I}$ & Kenneth Falterman, M.D. \\
\hline $\begin{array}{l}\text { Boston Children's } \\
\text { Hospital }\end{array}$ & Boston, MA & James Fackler, M.D. \\
\hline $\begin{array}{l}\text { Children's Hospital of } \\
\text { Michigan }\end{array}$ & Detroit, MI & Michael Klein, M.D. \\
\hline $\begin{array}{l}\text { Univ. of Michigan Medical } \\
\text { Center }\end{array}$ & Ann Arbor, MI & Robert Bartlett, M.D. \\
\hline $\begin{array}{l}\text { Minnesota Registry ECMO } \\
\text { Program }\end{array}$ & Minneapolis, MN & Thomas Green, M.D. \\
\hline $\begin{array}{l}\text { Cardinal Glennon } \\
\text { Children's Hospital }\end{array}$ & St. Louis, MO & Tom Weber, M.D. \\
\hline $\begin{array}{l}\text { St. Loi is Children's } \\
\text { Hospi }\end{array}$ & St. Louis, MO & Thomas Spray, M.D. \\
\hline
\end{tabular}




\begin{tabular}{|c|c|c|}
\hline Center & Location & Director \\
\hline Babies Hospital & New York, NY & Charles Stolar, M.J. \\
\hline $\begin{array}{l}\text { Children's Hospital of } \\
\text { Pittsburgh }\end{array}$ & Pillshurgh, PA & Ralph Siewers, M.D. \\
\hline John Sealy Hospital $(\mathbf{C}-90)$ & Galveston, TX & Jay Zwischenberger, M.D. \\
\hline
\end{tabular}

NEONATAL ECLS CENTERS (MEMBERS OF THE ELSO REGISTRY, MAY 1990)

Childrens Hospital of Alabama, Birmingham, AL

St. Vincent's Hospilal, Bimingham, AL

Phoenix Childrens Hospital, Phoenix, AZ

St. Joseph's Hospital and Medical Center, Phoenix, AZ

Arkansas Childrens Hospital, Little Rock, AR

Childrens Hospital of Los Angeles, Los Angeles, CA

Childrens Hospital of Oakland, Oakland, CA

Childrens Hospital of Orange County, Orange, CA

Huntington Memorial Hospital, Pasadena, CA

San Diego Regional ECMO Program, San Diego, CA

Sutter Memorial Hospital, Sacramento, CA

Stanford University Hospital, Stanford, CA

UCLA Medical Center, Los Angeles, CA

University of California, San Francisco, CA

Childrens Hospital, Denver, $\mathrm{CO}$

Childrens National Medical Center, Washington, DC

Georgetown University Hospital, Washington, DC

Miami Childrens Hospital, Miami, FL,

University of Florida, Gainsville, FL

Arnold Palmer Hospital, Orlando, Fl.

Medical College of Georgia, Augusta, GA

St. Luke's Hospital, Boise, ID

Childrens Memorial Hospital, Chicago, IL

Cook County Hospital, Chicago, IL

Lutheran General Hospital, Park Ridge, II,

St. Francis Medical Center, Peoria, IL

James Whitcomb Riley Hospital, Indianapolis, IN

Kosair Childrens Hospital, Louisville, KY

Oschner Foundation Hospital, New Orleans, LA

Boston Childrens Hospital, Boston, MA

Massachusetts General Hospital, Boston, MA

Johns Hopkins University, Baltimore, MD

Childrens Hospital of Michigan, Detroit, MI

University of Michigan Medical Center, Ann Arbor, MI 
Minnesota Regional ECMO Program, Minneapolis, MN Cardinal Glennon Childrens Hospital, St. Louis, MO The Childrens Mercy Hospital, Kansas City, MO

St. Louis Childrens Hospital, St. Louis, MO University of Nebraska Medical Center, Omaha, NE The Babies Hospital, New York, New York Charlotte Memorial Hospital, Charlotte, NC Childrens Hospital Medical Center, Cincinnati, $\mathrm{OH}$ Miami Valley Hospital, Dayton, $\mathrm{OH}$

Rainbow Babies and Childrens Hospital, Cleveland, $\mathrm{OH}$ Childrens Hospital, Columbus, $\mathrm{OH}$

Eastern Oklahoma Perinatal Center, Tulsa, OK

Emanuel Hospital and Health Center, Portland, OR

Childrens Hospital of Pittsburgh, Pittsburgh, PA

Thomas Jefferson University Hospital, Philadelphia, PA

Medical University of South Carolina, Charleston, SC

University of South Carolina, Columbia, SC

John Sealy Hospital, Galveston, TX

Texas Tech University, Lubbock, TX

Wilford Hall Medical Center, Lackland Air Force Base, TX

Presbyterian Hospital of Dallas, Dallas, TX

Primary Childrens Medical Center, Salt Lake City, UT

Medical College of Virginia, Richmond, VA

Childrens Hospital and Medical Center, Seattle, WA

Childrens Hospital of Wisconsin, Milwaukee, WI

Assistance Publique Hopitauz de Paris, Paris, France

Hopital Trousseau, Paris, France

Kumamoto University Medical School, Kumamoto, Japan

Central Hospital, Kasugai-Aichi, Japan

Karolinska Institutet, Stockholm, Sweden

Universitäts-Kinderklinik, Mannheim, West Germany

Royal Alexandra Childrens Pavillion, Edmonton, Alberta, Canada

\section{REFERENCES}

1. Hirschl RB, Bartlett RH: Extracorporeal membrane oxygenation (ECMO) support in cardiorespiratory failure, in Tompkins $\mathrm{R}$, et al (eds): Advances in Surgery, Chicago, Year Book Medical Publishers, 1987, pp 189-211.

2. Sinard JM, Bartlett RH: Extracorporeal life support in critical care medicine. $J$ Crit Care Med 1990; in press.

3. Ionescu MI, Wooler C: Current Techniques in Extracorporeal Circulation, ed 2. London, Butterworth's, 1980.

4. Sinard JM, Bartlett RH: Extracorporeal membrane oxygenation (ECMO): Prolonged bedside cardiopulmonary bypass. Perfusion 1990; in press.

5. Bartlett RH, Gazzaniga AB: Extracorporeal circulation for cardiopulmonary failure. Curr Probl Surg 1978; Vol. 15.

6. Gibbon $\mathrm{JH} \mathrm{Jr}_{\mathrm{r}}$ : Artificial maintenance circulation during experimental occlusion of pulmonary artery. Arch Surg 1937; 34:1105. 
7. Dennis C: A heart lung machine for open-heart operation: How it came about. ASAIO Trans 1989; 35:767-777.

8. Dennis C: Certain methods for artificial support of the circulation during intracardiac surgery. Surg Clin North Am 1956; 36:423.

9. Morrow AG, Gilbert JW, Sharp E, et al: Experimental use of the Melrose pump-oxygenator. ASAIO Trans 1957: 3:46-49.

10. Cross FS, Kay FB: Direct vision repair of intracardiac defects utilizing a rotating disc reservoir oxygenator. Surg Gynecol Obstet 1957; 104:711-716.

11. DeWall R, Rentley D.J, Hirose M, et al: A temperature controlling (omnithermic) disposable bubble oxygenator for total body perfusion. Dis Chest 1966; 49:207.

12. Rygg IH, Hengell HC, Kyvsgaard E: A heart lung with a disposable polvethylene oxygenator. Dan Med Bull 1956; 3:200-202.

13. Lillehei $\mathrm{CW}$, Cohen $\mathrm{M}$, Warden HC, et al: The result of direct vision closure of ventricular septal defects in 8 patients by means of controlled cross circulation. Surg Gynccol Obstet 1955; 101:447.

14. Gibbon JH: Application of a mechanical heart and lung apparatus to cardiac surgery. Minn Med 1954:37:171.

15. Lee WH Jr, Krumhar D, Fonkalsrud EW, et al: Denaturation of plasma proteins as a cause of morbidity and death after intracardiac operations. Surgery 1961; 50:29-39.

16. Dobell ARC, Mitri M, Galva R, et al: Biological evaluation of blood after prolonged recirculation through film and membrane oxygenators. Ann Surg $1965 ; 161: 617-622$.

17. Kolff WJ, Effler DB: Disposable membrane oxygenator theart lung machine and its use in experimental and clinical surgery while the heart is arrested with potassium citrate according to the Melrose technique. ASAIO Trans $1956 ; 2: 13-21$

18. Clowes GHA Jr, Hopkins $A \mathrm{~L}$, veville $W \mathrm{E}$ : An artificial lung dependent upon diffusion of oxygen and carbon dioxide through plastic membranes. 1 Thorac Surg 1956; 32:630-637

19. Clowes GHA Jr, Neville Wl: further development of a blood oxygenator dependent upon the diffusion of gases through plastic membranes. ASAIO Trans $1957 ; 3.52-58$

20. Kammermever K: Silicone rubber as a solective barrier. Ind Eng chem 1957; $49: 1685$.

21. Kolobow T', Bowman Rl: Construction and evaluation of an alveolar membrane artificial heart lung. ASH/O Trans 1963; 9:238.

22. I andé AJ, Dos SJ, Carlson KG, et al: A new membrane oxygenator-dialyzer. Surg Clin North Am 1967; 47:1461

23. Pierce EC II: Modification of the Clowes membrane lung $J$ Thorac Cardiovasc Surg 1960; 39:438.

24. Dorson WJ, Baker $\mathbf{E}$, Cohen MIL, et al: A pertusion system for infants. ASAIO Trans 15:155, 1969.

25. Day SW, Crystal DK, Wagner CI, et al: Properties of synthetic membranes in extracorporeal circuits. Am I Surg 1967; 114214.

26. Kolobow T, Zapol $W$, Pierce It, et al: Partial extracorporeal gas exchange in alert newborn lambs with a membrane artificial lung perfused via an AV shunt for periods up to 96 hours. ASAIO Trans $1968 ; 14328$.

27. Galletti PM, IIopf MA, Brecher GA: Problems associated with long-lasting heart-lung bypass. ASAIO Trans 1960; 6:180.

28. Bramson ML, Osborn JJ, Main FB, et al: A new disposable membrane oxy- 
genator with integral heat exchanger. $J$ Thorac Cardiovasc Surg 1965; 50:391.

29. Landé AJ, Fillmore SJ, Subramanian $V$, et al: 24 hour venoarterial perfusions of awake dogs with a simple membrane oxygenator. ASAIO Trans 1969; 15:181.

30. Bartlett RH, Drinker PA, Burns NE, et al: The toroidal membrane oxygenator: Design, performance and bypass testing of a clinical model. ASAIO Trans 1972; 18:369-373.

31. Weissman MH, Mockros LF: Oxygen transfer to blood flowing in round tubes. I Eng Mech Div ASCE 93: no. EM6, Proc paper 5696, Dec 1967, pp $225-244$.

32. Bartlett RH, Kittredge D, Noyes BS Jr, et al: Development of a membrane oxygenator: Overcoming blood diffusion limitation. $J$ Thorac Cardiovasc Surg $1969 ; 58: 795$.

33. Bellhouse BJ, Bellhouse FH, Curl CM, et al: A high efficiency membrane oxygenator and pulsatile pumping system, and its application to animal trials. ASAIO Trans $1973 ; 19: 72$.

34. Kolobow T, Zapol W, Pierce J: High survival and minimal blood damage in lambs exposed to long term (1 week) veno-venous pumping with a polyurethane chamber roller pump with and without a membrane blood oxygenator. ASAIO Trans $1969 ; 15: 172-177$.

35. Bartlett RH, Isherwood J, Moss RA, et al: A toroidal flow membrane oxygenator; Four day partial bypass in dogs. Surg forum 1969; 20:152-153.

36. Kolobow T, Zapol WM, Sigman RL, et al: Partial cardiopulmonary bypass lasting up to seven days in alert lambs with membrane lung blood oxygenation. $J$ Thorac Cardiovase Surg 1970; 60:781-788.

37. Zapol WM, Kolobow T, Pierce JE, et al: Artificial placenta: Two days of total extrauterine support of the isolated premature lamb fetus. Science 1969; 166:617-618.

38. Gemer M, Dunegan LJ, Lehr JL, et al: Pulmonary insufficiency induced by oleic acid in the sheep: A model for investigation of extracorporeal oxygenation. $J$ Thorac Cardiovasc Surg 1975; 69:793-799.

39. Callaghan JC, Maynes EA, Hug HR: Studies in lambs of the development of an artificial placenta: Review of nine long-term survivors of extracorporeal circulation maintained in a fluid medium. Can J Surg 1965; 8:208-213.

40. Hill JD, Bramson ML, Rapaport E, et al: Experimental and clinical experiences with prolonged oxygenation and assisted circulation. Ann Surg 1969; 170:448.

41. Bartlett RH, Fong SW, Bruns NE, et al: Prolonged partial venoarterial bypass: Physiologic, biochemical and hematologic responses. Ann Surg 1974; 180:850-856.

42. Fong SW, Burns NE, Williams G, et al: Changes in coagulation and platelet function during prolonged extracorporeal circulation (ECC) in sheep and man. ASAIO Trans $1974 ; 20: 239-246$.

43. Rashkind WJ, Freeman A, Klein D, et al: Evaluation of a disposable plastic, low volume, pumpless oxygenator as a lung substitute. $J$ Pediatr 1965; 66:94-102.

44. Dorson W Jr, Meyer B, Baker E, et al: Response of distressed infants to partial bypass lung assist. ASAIO Trans $1970 ; 16: 345$.

45. White JJ, Andrews HG, Risemberg $\mathrm{H}$, et al: Prolonged respiratory support in newborn infants with a membrane oxygenator. Surgery 1971; 70:288-296.

46. Leenders E, Andrews HG, Griggs EA, et al: Prolonged respiratory support in 
animals using veno-venous bypass and a spiral coil membrane respirator. Am Surg 1972; 38:17-25.

47. Hill JD, O'Brien TG, Murray JJ, et al: Extracorporeal oxygenation for acute post-traumatic respiratory failure (shock-lung syndrome): Use of the Bramson Membrane Lung. $N$ Engl $J$ Med 1972; 286:629-634.

48. Hicks RE, Kenney TR, Raphaely RC, et al: Successful treatment of varicella pneumonia with prolonged extracorporeal membrane oxygenation in a child with leukemia. J Thorac Cardiovasc Surg 1977; 73:297-302.

49. Kolobow 'T, Stool EW, Sacks KL, et al: Acute respiratory failure: Survival following 10 days's support with a membrane lung. $J$ Thorac Cardiovasc Surg $1975 ; 69: 947-953$.

50. Nelems JM, Duffin J, Glynn FX, et al: Extracorporeal membrane oxygenator support for human lung transplantation. J Thorac Cardiovasc Surg 1978; $76: 28-32$.

51. Soeter JR, Mamiya RT, Sprague AY, et al: Prolonged extracorporeal oxygenation for cardiorespiratory failure after tetralogy correction. $J$ Thorac Cardiovasc Surg 1973; $66: 214$.

52. Hieden D, Mielke CH Jr, Rodvien R, et al: Platelets, hemostasis, and thromboembolism during treatment of acute respiratory insufficiency with extracorporeal membrane oxygenation: Experience with 28 clinical perfusions. $J$ Thorac Cardiovasc Surg 1975; 70:644-655.

53. Hanson EL, Drinker PA, Don HF, et al: Venoarterial bypass with a membrane oxygenator: Successful respiratory support in a woman following pulmonary hemorrhage secondary to renal failure. Surgery 1974; $75: 557-565$.

54. Geelhoed GW Corso P. Joseph WL: The role of membrane lung support in transient acute respiratory insufficiency of Pneumocystis carinii pneumonia. $J$ Thorac Cardiovasc Surg 1974; 68:802-809.

55. Cooper JD. 'Teasdale S, Nelems JM, et al: Cardiorespiratory failure secondary to peripheral pulmonary emboli survival following a combination of prolonged extracorporeal membrane oxygenator support and pulmonary embolectomy. $J$ Thorac Cardiovasc Surg 1976; 71:872-877.

56. Bartlett $\mathrm{RH}$, Gazzaniga $\mathrm{AB}$, Fong $\mathrm{SW}$, et al: Lxtracorporeal membrane oxvgenator support for cardiopulmonary failure: Experience in 28 cases. 1 Thorac Cardiovase Surg 1977; 73:375-386.

55. Zapol WM, Qvist J (eds): Artificial Lungs for Acute Respiratory Failure. New York, Academic Press, 1976

58. Blake LH: Goals and progress of the NHLI collaborative ECMO study, in Zapol W, Qvist $\mathrm{J}$ leds): Artificial lungs for Acute Respiratory Failure. New York, Academic Press, 1976, pp 513-524.

59. Zapol WM, Snider MT, Hill JD, et al: Extracorporeal membrane oxygenation in severe respiratory failure. JAMA 1979; 242:2193-2196.

60. Pratt PC, Vollmer RT, Shelburn JD, et al: Pulmonary morphology in a multihospital collaborative extracorporeal membrane oxvgenation project. $\mathrm{Am}$ $J$ Pathol 1979; 95:191-212.

61. Bartlett RH, Morris AH. Fairley HB, et al: A prospective study of acute hypoxic respiratory failure. Chest $1986 ; 5: 684-689$.

62. NHLBI-NIH: Extracorporeal Support for Respiratory Insufficiency. DHEW Publication, 1980 Bethesda, MD.

63. Gattinoni $L$, Pesenti $A$, Mascheroni D, et al: Low frequency positive pressure ventilation with extracorporeal $\mathrm{CO}_{2}$ removal in severe acute respiratory failure. JAMA 1986; $256: 881-885$. 
64. Knoch M: Treatment of severe ARDS with extracorporeal $\mathrm{CO}_{2}$ removal, in Gille JP (ed): Neonatal and Adult Respiratory Failure: Mechanisms and Treatment. Paris, Elsevier, 1989, pp 123-136.

65. Falke K, Schulte HD: Extracorporale $\mathrm{CO}_{2}$ elimination mit niedrigfrequenter beatmung zur behandlung des schwern akuten wengenversagens. Dtsch Med Wochenschr 1985; 110:663-664.

66. Bindslev L: Extracorporeal circulation using surface heparinized equipment in Gille JP (ed): Neonatal and Adult Respiratory Failure: Mechanisms and Treatment. Paris, Elsevier, 1989, pp 97-100.

67. Todd T: Personal communication, 1988.

68. Morioka T, Terasaki H: Present status of extracorporeal lung assist (ECLA as ECMO or extracorporeal $\mathrm{CO}_{2}$ removal) in Japan, in Gille JP (ed): Neonatal and Adult Respiratory Failure: Mechanisms and Treatment. Paris, Elsevier, 1989, pp 147-157.

69. Gille JP (ed): Neonatal and Adult Respiratory Failure: Mechanisms and Treatment. Paris, Elsevier, 1989.

70. Bartlett RH, Gazzaniga AB, Jefferies R, et al: Extracorporeal membrane oxygenation (ECMO) cardiopulmonary support in infancy. ASAIO Trans 1976; $22: 80-88$.

71. Bartlett RH: Esperanza (ASAIO Presidential Address). ASAIO Trans 1985; 31:723-725.

72. Bartlett $\mathrm{RH}$, Gazzaniga $\mathrm{AB}$, Huxtable $\mathrm{RF}$, et al: Extracorporeal circulation (ECMO in neonatal respiratory failure. $J$ 'Thorac Cardiovasc Surg 1977; 74:826-833.

73. Bartlett RH, Andrews AF, Toomasian JM, et al: Extracorporeal membrane oxygenation $(\mathrm{ECMO})$ for newborn respiratory failure: 45 cases. Surgery 1982; $92: 425-433$.

74. Toomasian JM, Snedecor SM, Comell R, et al: National experience with extracorporeal membrane oxygenation (ECMO) for newborn respiratory failure: Data from 715 cases. ASAIO Trans 1988; 34:140-147.

75. Hardesty RL, Griffith BP, Debski RF, et al: Extracorporeal membrane oxygenation: Successful treatment of persistent fetal circulation following repair of congenilal diaphragmatic hernia. I Thorac Cardiovase Surg 1981; $81: 556-563$

76. Kirkpatrick BV, Krummel TM, Mueller DG, et al: Use of extracorporeal membrane oxygenation for respiratory failure in term infants. Pediatrics $1983 ; 72: 872-876$.

77. Short BL, Miller MK, Anderson KD: Extracorporeal membrane oxygenation in the management of respiratory failure in the newborn (review). Clin Perinatol $1987 ; 14: 737-748$.

78. Loe W, Graves E, Ochsner J, et al: Extracorporeal membrane oxygenation for newborn respiratory failure. $J$ Pediatr Surg 1985; 20:684-688.

79. Weber TR, Pennington DG, Connors R, et al: Extracorporeal membrane oxygenation for newborn respiratory failure. Ann Thorac Surg 1986; 42:529-535.

80. Moront MG, Katz NM, Keszler M, et al: Extracorporeal membrane oxygenator for neonatal respiratory failure: A report of $\mathbf{5 0}$ cases. $J$ Thorac Cardiovasc Surg 1989; 97:706-714

81. Lillehei CW, O'Rourke PP, Vacanti JP, et al: hole of extracorporeal membrane oxygenation in selected pediatric respiratory problens. $J$ Thorac: Cardiovasc Surg 1989; 98:968-971. 
82. Bartlett RH, Roloff DW, Cornell RG, et al: Extracorporeal circulation in neonatal respiratory failure: A prospective randomized study. Pediatrics 1985: 4:479-487.

83. Cornell RG, Landenberger $\mathrm{BD}$, Bartlett $\mathrm{RH}$ : Randomized play-the-winner clinical trials. Commmications in Statistics: Theory and Methods 1986; $1: 159-178$.

84. Wei LلJ, Durham S: The randomized play-the-winner rule in medical trials. $J$ Am Stat Assoc 1978; $73: 840-843$.

85. Ware JII, Epstein MF: lixtracorporeal circulation in respiratory failure (commentaries). Pediatrics 1985; 76:849-851.

86. O'Rourke PP, Krone R, Vacanti $J$, et al: Extracorporeal membrane oxygenation and conventional medical therapy in neonates with persistent pulmonary hypertension of the newborn: A prospective randomized study. Pe. diatrics 1989; 84:957-963.

87. Dennis C, Hall DP, Moreno JK, et al: Reduction of the oxygen utilization of the heart by left heart bypass. Circ Res 1962; 10:298.

88. Stolar CJ, Snedecor SS, Bartlett RH: Extracorporeal membrane oxygenation and neonatal respiratory failure: Experience from the extracorporeal life support organization. J Pediatr surg 1990; in press.

89. Bartlett RH, Gazzaniga AB, Toomasian JM, et al: Extracorporeal membrane oxygenation (ECMO) in neonatal respiratory failure: 100 cases. Ann Surg $1986 ; 204: 236-245$.

90. Cornish D: ECLS for neonatal respiratory failure. Presented at American Society of Artificial Internal Organs, 1990.

91. Gattinoni L: ECLS for adult respiratory failure. Presented at American Society of Artificial Internal Organs, May 1990, Washington, D.C.

92. Anderson HL, Attorri RJ, Custer JR, et al: Extsacorporeal membrane oxygenation (ECMO) for pediatric cardiopulmonary failure. $J$ Thorac Cardiovasc Surg 99:1011-1019, 1990.

93. Ortiz RM, Cilley RE, Bartlett RH: Extracorporeal membrane oxygenation in pediatric respiratory failure. Pediatr Clin North Am 1987; 34:39-46.

94. Redmond CR, Graves ED. Falterman KW, et al: Extracorporeal membrane oxygenation for respiratory and cardiac failure in infants and children. I Thorac Cardiovasc Surg 1987; 93:199-204.

95. Klein MD, Whittlesey GG, Penske WW, et al: Extracorporeal membrane oxygenation (ECMO) for the circulatory support of children after repair of congenital heart disease. J Thorac Cardiovasc Surg 1990; in press.

96. Kanter KR, Pennington DG, Weber TG, et al: Extracorporeal membrane oxygenation for postoperative cardiac failure in children. $J$ Thorac Cardiovase Surg 1987; 93:27-35.

97. Griffith BP, Borovetz HS, Hardesty RL, et al: Arteriovenous ECMO for neonatal respiratory support: A study in perigestational lambs. $J$ Thorac Cardiovasc Surg 1979; 77.595-601.

98. Schmidt S, Dudenhausen JW. Langner $K$, et al: A new perfusion circuit for the newborn with lung immaturity: Extracorporeal $\mathrm{CO}_{2}$, removal via an umbilical arterio-venous shunt during apneic $0_{2}$ diffusion. Artif Organs 1984: 8:478-480.

99. Gille JP, Bauer $P$, Bollaert $P_{i}$, et al: $\mathrm{CO}_{2}$ removal with hemodialysis and control of plasma oncotic pressure. ASAIO Trans 1989; 35:654-658.

100. Bartlett RH, Dechert RE, Mault J, et al: Measurement of metabolism in multiple organ failure. Surgerv 1982: 92:771-778. 
101. Cilley RE, Wesley JR, Zwischenberger JB, et al: Method of pulmonary and membrane lung gas exchange measurement during extracorporeal membrane oxygenation. ASAIO Trans $1986 ; 32: 525-529$.

102. Fick A: On the measurement of the blood quantity in the ventricles of the heart. Proceedings of the Physiological Medical Society of Wurzburg, July 9, 1870.

103. Cilley RE, Polley TZ, Zwischenberger JB, et al: Independent measurement of oxygen consumption and oxygen delivery. $J$ Surg Res 1989; $47: 242-247$.

104. Drinker PA, Lehr JL: Engineering aspects of ECMO technology (review). Artif Organs 2(1):6-11, 1978.

105. Galletti PM, Richardson PD, Snider MT: A standardized method for defining the overall gas transfer performance of artificial lungs. ASAIO Trans 1972; 18:359.

106. Kolobow T: Gas exchange with membrane lungs, in Gille JP (ed): Neonatal and Adult Respiratory Failure: Mechanisms and Treatment. Paris, EIsevier, 1989, pp 89-96.

107. Bernstein EF, Cosentino LC, Reich S, et al: A compact low hemolysis nonthrombogenic system for nonthoracotomy prolonged left ventricular by pass. ASAIO 'Trans 1974; 20:643.

108. Jacobs LA, Klopp EH, Seamone $W$, et al: Improved organ function during cardiac bypass with a roller pump modified to delivery pulsatile flow. $J$ Thorac Cardiovasc Surg 1969; 58:703.

109. Kohlstaedt KG, Page IH: The liberation of renin by perfusion of kidneys following reduction of pulse pressure. $J$ Exp Med 1940; 72:201.

110. Many $M$, Giron F, Birtwell $W C$, et al: Effects of depulsation of renal bluod flow upon renal function and renin secretion. Surgery 1969; 66:242.

111. Mukherjee ND, Berran AV, Hirai J, et al: In vivo determination of renal tissue oxygenation during pulsatile and nonpulsatile left heart hypass. Ann Thorac Surg 1973; 15:345.

112. Boucher JK, Rudy LW, Edmunds LH: Organ blood flow during pulsatile cardiopulmonary bypass. $J$ Appl Physiol 1974; 36:86

113. Harken $\mathrm{AH}$ : The influence of pulsatile perfusion on oxygen uptake by the isolated canine hind limb. $J$ Thorac Cardiovasc Surg 1975; 70:1237.

114. Rudy LW, Heyman MA, Edmunds LH: Distribution of systemic blood flow during cardiopulmonary bypass. J Appl Physiol 1973; 34:194.

115. Dunn J, Kirsch M, Harness $J$, et al: Hemodynamic, metabolic and hematologic effects of pulsatile cardiopulmonary bypass. $J$ Thorac Cardiovasc Surg $1974 ; 68: 138$.

116. Replogle $R$, Levy $M$, DeWall $R A$, et al: Catecholamine and serotonin response to cardiopulmonary bypass. $J$ Thorac Cardiovasc Surg 1962; 44:638.

117. Sanderson JM, Wright G, Simms FW: Brain damage in dogs immediately following pulsatile and nonpulsatile blood flows in extracorporeal circulation. Thorax 1972; $27: 275$.

118. Harrison TS, Chawla RC, Seton JF, et al: Carotid sinus origin of adrenergic response comprising the effectiveness of artificial circulatory support. Surgery 1970; 68:20.

119. Harrison TS, Seton JF: An analysis of pulse frequency as an adrenergic excitant in pulsative circulatory support. Surgery 1973; 73:868.

120. Shepard RB, Kirklin JW: Relation of pulsatile flow to oxygen consumption and other variables during cardiopulmonary bypass. J Thorac Cardiovasc Surg 1969; 58:694.

121. Trinkle JK, Helton NE, Wood PE, et al: Metabolic comparison of a new pul- 
satile pump and a roller pump for cardiopulmonary bypass. $J$ Thorac Cardiovasc Surg 1969; 58:562.

122. Kolobow T, Borell $M$, Spatola $R$, et al: Single catheter venovenous membrane lung bypass in the treatment of experimental ARDS. ASAIO Trans $1988 ; 34: 35-38$.

123. Ladowski JS, Borovetz $\mathrm{H}$, Brant AM, et al: Flow characteristics of Kolobow system for extracorporeal $\mathrm{CO}_{2}$ removal $\left(\mathrm{ECCO}_{2} \mathrm{R}\right)$. ASAIO Trans $1984 ; 30: 635-638$.

124. Durandy Y, Chevalier JY, Lecompte $Y$ : Veno-venous extracorporeal lung support: Initial experience in paediatric patients, in Gille JP (ed): Neonatal and Adult Respiratory Failure: Mechanisms and Treatment. Paris, Elsevier, 1989, pp 159-172.

125. Roohk HV, Pick J, Hill R, et al: Kinetics of fibrinogen and platelet adherence to biomaterials. ASAIO Trans 1976; $22: 1$.

126. Bartlett RH, Andersen JC: Blood-surface interactions: An overview, in Stanley JC (ed): Biologic and Synthetic Vascular Prostheses. New York, Grune and Stratton, 1982, pp 63-81.

127. Hicks RE, Dutton $\mathrm{RC}$, Ries $\mathrm{CA}$, et al: Production and fate of platelet aggregate emboli during venovenous perfusion. Surg Forum 1973; 24:250.

128. Dutton RC, Edmunds LH Jr, Hutchinson JC, et al: Platelet aggregate emboli in patients during cardiopulmonary bypass with membrane and bubble oxygenators and blood filters. J Thorac Cardiovasc Surg 1973; 67:258.

129. Kolobow T, Stoll EW, Weathersby PK, et al: Superior blood compatibility of silicone rubber free of silica filler in the membrane lung. ASAIO Trans 1974; $20: 269$.

130. Ross JN, Brown CH, Harness MK, et al: Role of platelet aggregation in prolonged extracorporeal respiratory support. Circulation 1974; 49(suppl 11):219.

131. Whittlesey GC, Kundu SY, Salley SO, et al: Is heparin necessary for extracorporeal circulation? ASAIO Trans 1988; 34:823-826.

132. Wakabayashi A, Chen CC, Mullin PJ, et al: Successful prolonged heparinless venoarterial bypass in sheep. $J$ Thorac Cardiovasc Surg 1976; 71:648-658.

133. Fletcher JR, McKee AE, Herman CM: Membrane oxygenation in baboons without anticoagulants. $J$ Surg hes 1977; $22: 273$.

134. Anderson HL, Cilley RE, Zwischenberger JB, et al: Thrombocytopenia in neonates after extracorporeal membrane oxygenation. ASAIO Trans 1986; 32:534-537.

135. Zach TL, Steinhorn RH, Georgieff MK, et al: Leukopenia associated with extracorporeal membrane oxygenation in the newborn. $J$ Pediatr 1990; 116:440-443.

136. Bartlett $\mathrm{KH}$ : Hemodynamics and extracorporeal circulation, in Hagl $\mathbf{S}$, Klovekorn WP, Mayr N, et al (eds): Proceedings of the Symposium: Thirty Years of Extracorporeal Circulation. Deutsches Hergzentrum Munchen. Munich 1984, pp 99-109.

137. Reynolds M: Personal communication, 1989.

138. Shneider B, Maller E, vanMarter $L$, et al: Cholestasis in infants supported with extracorporeal membrane oxygenation. $J$ Pediatr 1989; 115:462-465.

139. Kolobow T, Rossi F, Borellim M, et al: Long term closed chest partial and total cardiopulmonary bypass by peripheral cannulation for severe right and/or left ventricular failure including ventricular fibrillation. ASAIO Trans 1988; 34:485-489.

140. Colton CK: Fundamentals of gas transport in blood, in Zapol WM, Qvist J (eds): Artificial Lungs for Acute Respiratory Failure. New York, Academic Press, 1976, p 1. 
141. Dorson WJ, Voorhees ME: Analysis of oxygen and carbon dioxide transfer in membrane lungs, in Zapol WM, Ovist J (eds): Artificial Lungs for Acute Respiratory Failure. New York, Academic Press, 1976, p 43.

142. Durandy Y, Chevalier JY, Lecompte Y: Single cannula venovenous bypass for respiratory membrane lung support. $J$ Thorac Cardiovasc Surgery 1990; 99:404-409.

143. Palder SB, Shaheen KW, Whittlesey GC, et al: Prolonged extracorporeal membrane oxygenation in sheep with a hollow-fiber oxygenator and a centrifugal pump. ASAIO Trans 1988; 34:820-822.

144. Montoya JP, Merz SI, Bartlett RH: A standardized system for describing flow/pressure relationships in vascular access devices. ASAIO Trans 1990; in press.

145. Otsu T, Merz SI, Hultquist KA, et al: Laboratory evaluation of a double lumen catheter for venovenous neonatal ECMO. ASAIO Trans 1989; $35: 647-650$.

146. Pesenti A, Gattinoni L, Kolobow T, et al: Extracorporeal circulation in adult respiratory failure. ASAIO Trans $1988 ; 34: 43-47$.

147. Anderson HL, Otsu T, Chapman RA, et al: Venovenous extracorporeal life support in neonates using a double lumen catheter. ASAIO Trans 1989; 35:650-653.

148. Cooper JD: Symposium on intensive care. 4. Respiratory failure. Can J Surg $1978 ; 21: 84-87$.

149. Altose MD, Hicks RE, Edwards MW Jr: Extracorporeal membrane oxygenation during bronchopulmonary lavage. Arch Surg 1976:111:1149-1153.

150. Hiratzka LF, Swan DM, Rose EF, et al: Bilateral simultaneous lung lavage utilizing membrane oxygenator for pulmonary alveolar proteinosis in an 8month-old infant. Ann Thorac Surg 1983; 35:313-317.

151. Ratliff JL: Extracorporeal biologic oxygenation for prolonged total respiratory support. $J$ Thorac Cardiovasc Surg 1968; 55:686-690.

152. Martin GR, Short BL: Doppler echocardiographic evaluation of cardiac performance in infants on prolonged extracorporeal membrane oxygenation. Am J Cardiol 1988; 62:929-934.

153. Wetmore NE, Bartlett $\mathrm{PH}$, Gazzaniga AB, et al: Extracorporeal membrane oxygenation (ECMO): A team approach in critical care and life-support research. Heart Lung 1979; 8:288-295.

154. Arnold D, Kachel W, Rettwitz W, et al: Clinical application of extracorporeal membrane oxygenation (ECMO) in neonatal respiratory failure. Thorac Cardiovasc Surg 1987; 35:321-325.

155. Cornish JD, Gerstmann DR, Clark RH, et al: Extracorporeal membrane oxygenation and high-frequency oscillatory ventilation: Potential therapeutic relationships. Crit Care Med 1987; 15:831-834.

156. Trento A, Griffith BP, Hardesty RL: Extracorporeal membrane oxygenation experience at the Iniversity of Pittsburgh. Ann Thorac Surg 1986; 42:56-59.

157. Schumacher R, Roloff DW, Chapman RA, et al: Neonatal ECMO: A prospective randomized study of cost effectiveness. 1990; submitted for publication.

158. Pearson GD, Short BL: An economic analysis of extracorporeal membrane oxygenation. $J$ Intensive Care Med 1986; 1:47-54.

159. Lyrenne RK, Phillips JB: Control of pulmonary vascular resistance in the fetus and newborn. Clin Perinatol 1984; 11:561-584.

160. Fox $W W$, Duara $S$ : Clinical management of persistent pulmonary hypertension of the newborn. $J$ Pediatr 1983; 103:505-511.

161. Andrews AF. Roloff DW, Bartlett RH: Use of extracorporeal membrane oxy- 
genators in persistent pulmonary hypertension of the newborn. Clin Perinatol 1984; 11:729-735.

162. Wung JT, James LS, Kilchevsky E, et al: Management of infants with severe respiratory failure and persistence of the fetal circulation without hyperventilation. Pediatrics 1985; 76:488-494.

163. Kolobow T, Moretti MP, Mascheroni D, et al: Experimental meconium aspiration syndrome in the preterm fetal lamb: Successful treatment using the extracorporeal artificial lung. ASAIO Trans 1983; 29:221-226.

164. Kolobow T, Fumagalli R, Arosio $P$, et al: The use of the extracorporeal membrane lung in the successful resuscitation of severely hypoxic and hypercapnic fetal lambs. ASAIO Trans 1982; 28:365-368.

165. Dreyfuss D, Soler P, Basset $G$, et al: High inflation pressure pulmonary edema. Am Rev Respir Dis 1988; 137:1159-1164.

166. Graves ED, Redmond CR, Arensman RM: Persistent pulmonary hypertension in neonate. Chest $1988 ; 93: 638-641$.

167. Wetmore NE, McEwen D, O'Connor MJ, et al: Defining indications for artificial organ support in respiratory failure. ASAIO Trans 1979; 25:459-461.

168. Krummel TM, Greenfield Lal, Kirkpatrick BV, et al: Alveolar-arterial oxygen gradients versus the neonatal pulmonary insufficiency index for prediction of mortality in ECMO candidates. $J$ Pediatr Surg 1984; 19:380-384.

169. Beck R, Anderson KD, Pearson GD et al: Criteria for extracorporeal membrane oxygenation in a population of infants with persistent pulmonary hypertension of the newborn. J Pediatr Surg 1986;21:297-302.

170. Hallman M, Merritt A, Jarvenpaa AL: Exogenous human surfactant for treatment of severe respiratory diuretics syndrome: A Randomized prospective trial. $J$ Pediatr 1985; 106:963-969

171. Cilley RE, Zwischenberger JB, Andrews AF, et al: Intracranial hemormage: during extracorporeal membrane oxygenation in neonates. Pediatrics 1986; $78: 699-704$.

172. Tavlor GA, Fitz CR, Miller MK, et al: Intracranial abnomalities in infants treated with extracorporeal membrane oxygenation: Imaging with is and CT. Radiology 1987; $165: 675-678$.

173. Bowerman RA, Zwischenberger JB. Andrews AF, et al: Cranial sonography of the infant treated with extracorporeal membrane oxygenation. AJR 1985; $145: 161-166$.

174. Stolar CJ, Dillon PW, stalcup SA: Extracorporeal membrane oxvgenation and congenital diaphragmatic hernia: Modification of the pulmonary vaso active profile. J Pediatr Surg 1985; 20:681-683.

175. Keszler M, Subramanian KNS Smith YA, et al: Pulmonary management during extracorporeal membathe uxygenation crit Care Med 1989; 174495500

176. Heiss KF, Pettit B, Hirschl RB, et al: Renal insufficiency and volume overload in neonatal ECMO managed by continuous ulladiltation. ASAO) Trans 1987; $33: 557-560$.

177. Zwischenberger JB, Cilley RL:, Hirsehl BB, et al: Life-threatening intrathoracic complications during treatment with extracorporeal membrane oxygenation. J Pediatr Surg 1988; 23:599-604.

178. Sell LL, Cullen ML, Whittlesev $G C$, et al: Hemorrhagic complications during extracorporeal membrane oxygenation: Prevention and treatment .J Pediatr Surg $1986 ; 21: 1087 \cdots 1091$.

179. Glass P. Miller M Short B: Morbidity for suvvivors of extracorporeal membrane oxygenation: Neurodevelopmental outcome at 1 vear of age Pediatrics $1989 ; 83: 72-78$. 
180. Schumacher RE, Barks JDE, Johnston MV, et al: Right-sided brain lesions following ECMO. Pediatrics 1988; 82:155- 161.

181. Chevalier JX, Durandy Y, Batisse A, et al: Preliminary report: Extracorporeal lung support for neonatal respiratory failure. Lancet 1990; 335:1364-1366.

182. Heiss $\mathrm{K}$, Manning $\mathrm{PB}$, Oldham $\mathrm{KP}$, et al: Reversal of mortality rate for $\mathrm{CDH}$ with ECMO. Ann Surg 1989; 209:225 230.

183. German JC, Gazzaniga AB, Amlie R, et al: Management of pulmonary insufficiency in diaphragmatic hernia using extracorporeal circulation with a membrane oxygenator (ECMO). $J$ Pediatr Surg 1977; 12:905-912.

184. Heaton JFG, Redmond CR, Falterman KF, et al: Congenital diaphragmatic hernia: Improving survival with extracorporeal membrane oxygenation. $P e$ diatr Surg Int 1988; 3:6-10.

185. Langham MR Jr, Krummel TM, Greenfield LJ, et al: Extracorporeal membrane oxygenation following repair of congenital diaphragmatic hernias. Ann Thorac Surg 1987; 44:247-252.

186. Redmond CR, Heaton J, Calix J, et al: Correlation of pulmonary hypoplasia, mean airway pressure, and survival in congenital diaphragmatic hernia treated with extracorporeal membrane oxygenation. J Pediatr Surg 1987; 22:1143-1149.

187. Weber TR, Connors RH, Pennington DG, et al: Neonatal diaphragmatic hernia: An improving outlook with extracorporeal membrane oxygenation. Arch Surg 1987; 122:615-618.

188. Brett C, Dekl M, Leonard PD, et al: Developmental follow-up of hyperventilated neonates: Preliminary observations. Pediatrics 1981; 68:588-591.

189. Cohen RS, Stevenson DK, Malachowski N, et al: Late morbidity among survivors of respiratory failure treated with tolazoline. $J$ Pediatr 1980; 97:644.

190. Towne BH, Lott IT, Hicks DA, et al: Long-term follow-up of infants and children treated with extracorporeal membrane oxygenation (ECMO): A preliminary report. $J$ Pediatr Surg 1985; 20:410-414.

191. Andrews AF, Nixon CA, Roloff DW, et al: One-to-three year outcome of fourteen neonatal ECMO survivors. Pediatrics 1986; 78:692-698.

192. Krummel TM, Greenfield LJ, Kirkpatrick BV, et al: The early evaluation of survivors after extracorporeal membrane oxygenation for neonatal pulmonary failure. $J$ Pediatr Surg 1984; 19:585-590.

193. Taylor GA, Glass P, Fitz CR, et al: Neurologic status in infants treated with extracorporeal membrane oxygenation: Correlation of imaging findings with developmental outcome. Radiology 1987; 165:679-682.

194. Adolph V, Ekelund $C$, Smith $C$, et al: Developmental outcome of neonates treated with extracorporeal membrane oxygenation. J Pediatr Surg 1990; 25:43-46.

195. Schumacher RE, Palmer TW, Roloff DW, et al: Follow-up of infants treated with extracorporeal membrane oxygenation for newborn respiratory failure. Pediatrics 1990; in press.

196. Montgomery AB, Stager MA, Cainco CJ, et al: Causes of mortality in patients with adult respiratory distress syndrome. Am Rev Respir Dis 1985; 132:485-489.

197. Simmons RS, Bordine GG, Siedenfeld JJ, et al: Fluid balance and the adult respiratory distress syndrome. Am Rev Respir Dis 1987; 35:924.

198. Kolobow T: On how to injure healthy lungs (and prevent sick lungs from recovering). ASAIO Trans 1988; 34:31-34.

199. Dudell G, Cornish JD, Bartlett RH: What constitutes adequate oxygenation? Pediatrics 1990; 85:39-41. 
200. Zwischenberger JB, Toomasian JM, Drake K, et al: Total respiratory support with single cannula venovenous ECMO: Double lumen continuous flow vs. single lumen tidal flow. ASAIO Trans 1985; 31:610-615.

201. Andrews AF, Toomasian JM, Oram A, et al: Total respiratory support with venovenous (W) ECMO. ASAIO Trans 1982; 28:350-353.

202. Gille JP, Bagniewski AM: Ten years of use of extracorporeal membrane oxygenation (ECMO) in the treatment of acute respiratory insufficiency (ARI). ASAIO Trans 1976; 22:102.

203. Zwart HHJ, Kralios AC, Kwan-Gett CS, et al: Transarterial closed chest left ventricular bypass for desperate heart failure. $J$ Assoc Advancement Med Instrum 1971; 5:44.

204. Delius RE, Zwischenberger JB, Cilley RE, et al: Prolonged extracorporeal life support of pediatric and adolescent cardiac transplant patients. Ann Thorac Surg 1990; in press.

205. Pennington GD, Merjavy JP, Codd JE, et al: Extracorporeal membrane oxygenation for patients with cardiogenic shock. Circulation (Suppl) 1984; I:130-137.

206. Bergentz SE, Brief DF: Assisted circulation in hemorrhagic shock: Effects of pulsatile partial venoarterial bypass with an oxygenator. J Surg Res 1964; 4:322.

207. Lefemine AA, Harken DE: Extracorporeal support of the circulation by means of venoarterial bypass with an oxygenator. $J$ Thorac Cardiovasc Surg $1971 ; 62: 769$.

208. Cline RE, Klebanoff G, Armstrong RG, et al: Extracorporeal circulation in hypothermia as used for total body wash-out in stage 4 hepatic coma. Ann Thorac Surg 1973; 16:44.

209. Ryan JF, Donlon JV, Molt RA, et al: Cardiopulmonary bypass in the treatment of malignant hyperthermia. $N$ Engl J Med 1974; 290:1121.

210. McBride CM, Sugarbaker EV, Hicky RC: Prophylactic isolation-perfusion as the primary therapy for invasive malignant melanoma of the limbs. Ann Surg 1975; 182:316.

211. Toledo-Pereyra LH, Simmons RL, Najarian JS: Two to three day intestinal preservation utilizing hypothermia pulsatile perfusion. Ann Surg 1974; 179:454.

212. Belzer FO, Kountz SL: Preservation and transplantation of human cadaver kidneys: A two-year experience. Ann Surg 1970; 172:394.

213. Douglas LL: Extracorporeal circulatory management of priapism. Urology 1976; 7:198.

214. Mottaghy K, Oedekoven B, Poppel K, et al: Heparin free long-term extracorporeal circulation using bioactive surfaces. ASAIO Trans 1989; 35:635-635.

215. Toomasian JM, Hsu L-C, Hirschl RB, et al: Evaluation of Duraflo II heparin coating in prolonged extracorporeal membrane oxygenation. ASAIO Trans 1988; 34:410-414.

216. Mortensen JD: An intravenacaval blood gas exchange device: A preliminary report. ASAIO Trans 1987; 33:570-573.

217. Meinert CL: Extracorporeal membrane oxygenation trials (commentaries). Pediatrics 1990; 85:365-366.

218. Philips JB: Treatment of PPHNS in long WA led): Fetal and Neonatal Cardiology. Philadelphia, WB Saunders, 1990, pp 691-701 